O problema de corte de estoque multiperíodo

Kelly Cristina Poldi 

SERVIÇO DE PÓS-GRADUAÇÃO DO ICMC-USP

Data de Depósito:

Assinatura:

\title{
O problema de corte de estoque multiperíodo
}

\author{
Kelly Cristina Poldi
}

Orientador: Prof. Dr. Marcos Nereu Arenales

Tese apresentada ao Instituto de Ciências Matemáticas e de Computação - ICMC-USP, como parte dos requisitos para obtenção do título de Doutor em Ciências - Ciências de Computação e Matemática Computacional.

\author{
USP - São Carlos \\ março/2007
}



"Aos meus pais ..." 



\section{Agradecimentos}

A Deus, pelo Dom da Vida.

Ao Prof. Marcos Nereu Arenales, pela orientação, compreensão e amizade. Toda minha admiração e carinho, pelo profissional e ser humano que é.

Aos meus pais, Arnaldo e Neiva, pelo amor, compreensão, apoio e dedicação incondicional que sempre tiveram por mim.

Aos meus irmãos Debbye e Junior, e a todos meus familiares, pelos bons momentos vivenciados. À Profa. Andrea Carla Gonçalves Vianna (UNESP-Bauru), por toda a sua ajuda e, principalmente, pelo carinho com que o fez.

Aos Professores Horacio Hideki Yanasse (INPE), Reinaldo Morabito (DEP/UFSCar) e Gerhard Wäscher (OTTO-von-Guericke-Universität), pelas sugestões e dicas que foram fundamentais para o desenvolvimento dessa tese.

À Profa. Franklina Maria Bragion de Toledo, pelo incentivo e pela colaboração que foram constantes durante todo o período em que estivemos no ICMC. Inclusive, pelo apoio na organização das festas do LOT!

À Profa. Vitória Pureza (DEP/USCar), Profa. Maristela dos Santos (ICMC/USP) e Prof. Aurelio Ribeiro Leite de Oliveira (UNICAMP), por terem contribuído em minha formação.

Aos professores e funcionários do ICMC-USP, pela cordialidade, atenção e colaboração.

Ao amigo Adriano Thomaz, pelo carinho de sempre e pelas boas conversas, mesmo que ultimamente, muitas delas, por e-mail.

Aos amigos Sônia, Lilian (e também ao Mô), Sílvio, Robinson, Araxá, Ricardo, Jelder, Gláucia, Cecília, Adriana, Carla (e também ao Edson), João Paulo, Mariá, Douglas, Lana e às "irmãzinhas" Aline e Daniela. Também meus sinceros agradecimentos a todos os colegas do Laboratório de Otimização, ICMC/USP.

Às amigas Lilian, Gisele e Aninha, do DEP/UFSCar pela companhia, amizade e carinho.

Ao Prof. Jakob Karup (DIKU-University of Copenhagen), pelo enorme carinho e companhia agradável na maioria dos congressos.

Aos amigos Yvonne, Stefan, Fernando, Piotr, Fadimé, Burcu e todos os outros participantes do EURO Summer Institute que ficaram para sempre em meu coração.

À FAPESP, pelo apoio financeiro.

Finalmente, agradeço a Deus pelas duas coisinhas maravilhosas que Ele me deu, Cherie e Marie, as cachorras mais lindas e mais queridas do mundo ... 



\section{Resumo}

Problemas de corte de estoque consistem em arranjar peças menores, em tamanhos e quantidades especificados, dentro de peças maiores. Tais problemas têm sido investigados intensamente nas últimas décadas, acrescidos de novas características e novos métodos de solução. Nesta tese abordamos o problema de corte de estoque multiperíodo que surge imerso no planejamento e programação da produção em empresas que têm um estágio de produção caracterizado pelo corte de peças. As demandas dos itens ocorrem em períodos diversos de um horizonte de planejamento finito, sendo possível antecipar ou não a produção de itens. Os objetos disponíveis em estoque não utilizados em um período ficam disponíveis no próximo período, juntamente com novos objetos adquiridos ou produzidos pela própria empresa. Um modelo de otimização linear inteira de grande porte é proposto, cujo objetivo pondera o custo das perdas nos cortes, os custos de estocagem de objetos e itens. O método simplex com geração de colunas foi especializado para resolver a relaxação linear do modelo proposto. Foram realizados experimentos computacionais com problemas de corte de estoque unidimensional e bidimensional. Tais experimentos mostram que ganhos efetivos podem ser obtidos usando-se o modelo de corte de estoque multiperíodo, quando comparado com a solução lote-por-lote, tipicamente utilizada na prática. Porém, na prática, a solução relaxada é de pouca, ou nenhuma, utilidade. Assim, nesta tese, desenvolvemos dois procedimentos de arredondamento da solução do problema multiperíodo, baseado em horizonte rolante, ou seja, determinamos uma solução inteira factível apenas para o primeiro período, a qual será, de fato, implementada. Enfim, concluímos que o modelo para o problema de corte de estoque multiperíodo permite flexibilidade na análise de uma solução a ser implementada e, portanto, é uma ferramenta que permite ao gerente de produção uma visão global do problema para auxiliá-lo na tomada de decisões.

Palavras-chave: problema de corte de estoque, otimização linear e inteira, geração de colunas. 



\section{Abstract}

Cutting stock problems consist of cutting a set of available stock objects in order to produce smaller ordered items. Such problems have been intensively researched over the last decades, together with additional characteristics and new methods for solving them. In this thesis, we address the multiperiod cutting stock problem, which arises in the production planning and programming in many industries that have a cutting process as an important stage. Ordered items have different due date over a finite planning horizon. An integer linear optimization model of large scale is proposed. The model makes possible to anticipate or not the production of items. Unused objects in inventory in a period become available to the next period, added to new inventory, which are acquired or produced by the own company. The mathematical model's objective is to minimize the cost of waste in the cutting process and costs for holding objects and final items. The simplex method with column generation was specialized to solve its linear relaxation. Computational experiments were carried out to solve one-dimensional and two-dimensional cutting stock problems. Such experiments showed that the multiperiod model could obtain effective gains when compared with the lot-for-lot solution, which is typically used in practice. However, in practical problems, the fractional solution is useless. So, in this thesis, two rounding procedures are developed to determine integer solutions for multiperiod cutting stock problems. Such procedures are based on a rolling horizon scheme, which roughly means, find an integer solution only for the first period, since this is the solution to be, in fact, carried out. Finally, we conclude that the proposed model for multiperiod cutting stock problems allows flexibility on analyzing a solution to be put in practice. The multiperiod cutting problem can be a tool that provides the decision maker a wide view of the problem and it may help him/her on making decisions.

Keywords: cutting stock problem, linear and integer optimization, column generation. 



\section{Índice}

Lista de Figuras $\quad$ xi

Lista de Tabelas $\quad$ xiii

1 Introdução 1

2 Problemas de corte de estoque acoplados ao planejamento da produção 5

2.1 O problema de corte de estoque . . . . . . . . . . . . . . 5

2.2 O problema de dimensionamento de lotes . . . . . . . . . . . . . 10

2.3 Problemas acoplados . . . . . . . . . . . . . . . . 12

2.3.1 Problema acoplado na indústria de papel . . . . . . . . . . . . 13

2.3.2 Problema acoplado na indústria de móveis . . . . . . . . . . . . 19

3 Problemas de corte de estoque multiperíodo 25

3.1 Problemas de corte de estoque multiperíodo irrestrito . . . . . . . . 25

3.1.1 Unidimensional . . . . . . . . . . . . . . 25

3.1 .2 Bidimensional . . . . . . . . . . . . . . . . 31

3.2 Problema de corte de estoque multiperíodo restrito $\ldots \ldots \ldots$

4 Método de solução para o problema multiperíodo $\quad 37$

4.1 Matriz básica inicial . . . . . . . . . . . . . . . . . . 37

4.2 Cálculo do vetor multiplicador simplex: $\pi \ldots \ldots \ldots$. . . . . . . . . . . . . . . . . . . .

4.3 Cálculo dos custos relativos . . . . . . . . . . . . . . . . 40

4.4 Exemplo ............................... 40

5 Abordagens de Arredondamento $\quad 45$

5.1 Abordagem A . . . . . . . . . . . . . . . 47

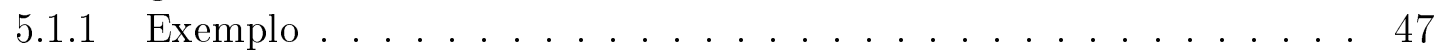

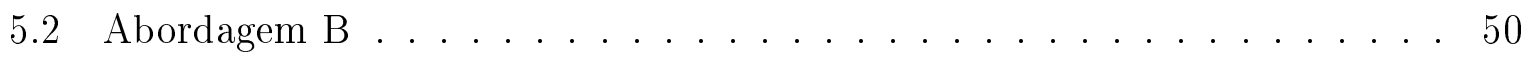

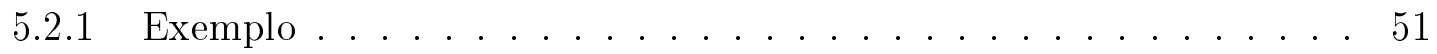

6 Experimentos computacionais $\quad \mathbf{5 5}$

6.1 Problema de corte de estoque multiperíodo unidimensional . . . . . . . . 55

6.1.1 Gerador aleatório . . . . . . . . . . . . . . . . 56 
6.1.2 Resultados computacionais - problema unidimensional irrestrito . . 56

6.1.3 Resultados computacionais - problema unidimensional restrito . . . 59

6.2 Problema de corte de estoque multiperíodo bidimensional . . . . . . . 60

6.2.1 Gerador aleatório . . . . . . . . . . . . . . 60

6.2.2 Resultados computacionais - problema bidimensional . . . . . . . 60

6.3 Abordagens de arredondamento . . . . . . . . . . . . . 62

7 Conclusões e Propostas $\quad 65$

$\begin{array}{ll}\text { A Métodos de solução } & \mathbf{6 7}\end{array}$

A.1 Método simplex com geração de colunas . . . . . . . . . . . . 67

A.2 O problema da mochila . . . . . . . . . . . . . . . . 70

A.2.1 Programação dinâmica . . . . . . . . . . . . . . . 71

A.2.2 Enumeração implícita . . . . . . . . . . . . . . 73

A.3 Abordagem grafo E/OU . . . . . . . . . . . . . . . 76

A.4 Métodos desenvolvidos para determinar soluções inteiras . . . . . . . . 79

A.4.1 Procedimento construtivo guloso . . . . . . . . . . . . 79

A.4.2 Procedimentos residuais ................. 80

B Um estudo de caso do problema de corte de estoque bidimensional 83

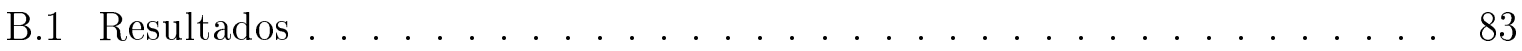

$\begin{array}{lr}\text { Referências Bibliográficas } & 87\end{array}$ 


\section{Lista de Figuras}

2.1 Problema de corte undimensional: (a) objetos disponíveis para corte, (b) itens demandados e (c) dois padrões de corte. . . . . . . . . . . 7

2.2 Tipos de padrões de corte bidimensionais: (a) guilhotinado vertical, (b) guilhotinado horizontal, (c) não-guilhotinado. . . . . . . . . . 7

2.3 Problema de corte bidimensional: (a) placas disponíveis para corte, (b) itens demandados e (c) dois padrões de corte. . . . . . . . . . . 8

2.4 Dimensionamento de lotes e corte. . . . . . . . . . . . . . . . 12

2.5 Produção na indústria de móveis. . . . . . . . . . . . . . . 12

2.6 Processo simplificado de produção de uma indústria de papel. . . . . . . . 13

2.7 Bobina-jumbo com gramatura $i$, perda de papel e gramatura $j \ldots \ldots$. . . 13

A.1 (a) parte do grafo E/OU representando padrões de corte; (b) padrão de corte representado em destaque em (a) . . . . . . . . . . . . . 77

A.2 Corte de um problema restrito. . . . . . . . . . . . . . 77

B.1 Tela do programa em Delphi com um exemplo de padrão de corte bidimensional. . . . . . . . . . . . . . . . . 85

B.2 Tela do programa em Delphi com outro exemplo de padrão de corte bidimensional. . . . . . . . . . . . . . . . 86 



\section{Lista de Tabelas}

3.1 Dados dos objetos disponíveis em estoque. . . . . . . . . . . . . . 28

3.2 Dados dos itens a serem produzidos. . . . . . . . . . . . . 28

3.3 Solução lote-por-lote: primeiro período $(t=1) \ldots \ldots \ldots \ldots$. . . . . 28

3.4 Solução lote-por-lote: segundo período $(t=2) \ldots \ldots \ldots$. . . . . 29

3.5 Solução lote-por-lote: terceiro período $(t=3) \ldots \ldots \ldots$. . . . . . 29

3.6 Solução multiperíodo: primeiro período $(t=1) \ldots \ldots \ldots \ldots$

3.7 Solução multiperíodo: segundo período $(t=2) \ldots \ldots \ldots \ldots$

3.8 Solução multiperíodo: terceiro período $(t=3) \ldots \ldots \ldots \ldots$

3.9 Dados dos objetos disponíveis em estoque. . . . . . . . . . . . . . 31

3.10 Dados dos itens a serem produzidos. . . . . . . . . . . . . 31

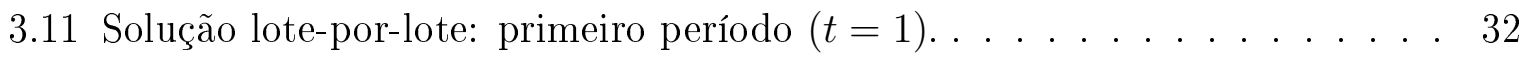

3.12 Solução lote-por-lote: segundo período $(t=2) \ldots \ldots \ldots$. . . . . . 32

3.13 Solução lote-por-lote: terceiro período $(t=3) \ldots \ldots \ldots$. . . . . . . . . . . . . . . . 32

3.14 Solução multiperíodo: primeiro período $(t=1) \ldots \ldots \ldots$. . . . . 33

3.15 Solução multiperíodo: segundo período $(t=2) . \ldots \ldots \ldots 33$

3.16 Solução multiperíodo: terceiro período $(t=3) \ldots \ldots \ldots$. . . . . 34

4.1 Estrutura geral da matriz básica inicial para o problema de corte de estoque multiperíodo. . . . . . . . . . . . . . 38

4.2 Dados dos objetos disponíveis em estoque. . . . . . . . . . . . . . . . . . . . . 41

4.3 Dados dos itens a serem produzidos. . . . . . . . . . . . . 41

5.1 Dados dos objetos disponíveis em estoque. . . . . . . . . . . . . . . 47

5.2 Dados dos itens a serem produzidos. . . . . . . . . . . . . . . . . . 47

5.3 Solução multiperíodo: primeiro período $(t=1) \ldots \ldots \ldots \ldots$

5.4 Primeira aproximação para a solução inteira - Abordagem A. . . . . . . . . 48

5.5 Segunda aproximação para a solução inteira - Abordagem A. . . . . . . . . 49

5.6 Terceira aproximação para a solução inteira (que é a solução final) - Abordagem A. . . . . . . . . . . . . . . . 50

5.7 Primeira aproximação para a solução inteira - Abordagem B. . . . . . . . . 52

5.8 Segunda aproximação para a solução inteira (que é a solução final) - Abordagem B. . . . . . . . . . . . . . . . 53 
6.1 Caracterização das 8 classes para o problema de corte multiperíodo unidimensional. . . . . . . . . . . . . . . . 57

6.2 Valor da função objetivo para o problema de corte de estoque unidimensional multiperíodo (média dos 20 exemplos em cada classe) $\alpha=\beta=0 . ~ . ~ . ~ 57$

6.3 Perda média e comprimento médio estocado nos 160 exemplos do problema de corte de estoque unidimensional multiperíodo, variando-se $\alpha$ e $\beta$. . . . 58

6.4 Valor da função objetivo para o problema de corte de estoque unidimensional multiperíodo (média dos 160 exemplos) $\alpha=\beta=0 \ldots \ldots$. . . . . . 59

6.5 Caracterização das 8 classes para o problema de corte multiperíodo bidimensional. . . . . . . . . . . . . . . . 6 6 61

6.6 Valor da função objetivo (área total perdida) para o problema de corte de estoque bidimensional multiperíodo (média dos 20 exemplos em cada classe). 61

6.7 Valor da função objetivo (perda) com arredondamento no primeiro período. 62

6.8 Valor da função objetivo (perda) com arredondamento no primeiro período e solução relaxada dos demais períodos. . . . . . . . . . . . . 63

6.9 Valor da função objetivo (perda) com arredondamento no primeiro período + arredondamento nos demais períodos. . . . . . . . . . . . 64

B.1 Porcentagem de perda de material. . . . . . . . . . . . 84 


\section{Capítulo 1}

\section{Introdução}

Problemas de corte de estoque consistem em cortar peças maiores (objetos) disponíveis em estoque com a finalidade de produzir peças menores (itens) para atender uma dada demanda, otimizando uma determinada função objetivo que pode ser, por exemplo, minimizar a perda de material, ou o custo dos objetos cortados. Estes problemas são essenciais no planejamento da produção em muitas indústrias, tais como indústrias de papel, vidro, móveis, metalúrgica, plástica, têxtil etc.

Com os avanços computacionais e também por motivos econômicos, as empresas têm se estimulado a tornar seus processos produtivos mais eficientes, o que induz, por sua vez, pesquisas acadêmicas de modelos de otimização para o controle e planejamento de sistemas produtivos. Surge, então, uma tendência em analisar o processo produtivo industrial de forma integrada (Farley [12], Hendry et al. [20], Nonas e Thorstenson [45], Menon e Schrage [37], Correia et al. [6]).

Neste contexto, o problema de corte de estoque, que em geral é NP-difícil, é considerado interdependente a outros problemas de otimização no ambiente industrial, por exemplo, o problema de dimensionamento de lotes com restrição de capacidade que, por sua vez, também é em geral NP-difícil. Tipicamente na prática, lotes são definidos e um problema de corte é resolvido para cada lote, sem que as perdas no estágio de corte interfiram na formação dos lotes. Modelos que acoplam os problemas de dimensionamento de lotes e de corte foram estudados por Gramani [18, 19], Respício e Captivo [55], Poltronieri $[53,54]$, entre outros. Nesses trabalhos, identificamos um subproblema que consiste no problema de corte de estoque multiperíodo, o qual é objeto de estudo deste trabalho.

O problema de corte de estoque multiperíodo consiste basicamente em resolver, a cada período em um horizonte de planejamento finito, um problema de corte de estoque, para atender a uma demanda de itens nos diversos períodos do horizonte de planejamento, porém podendo antecipar ou não a produção de itens. Isto permite que novas combinações sejam consideradas, pois um item de comprimento $\ell_{i}$ que não é demandado em um período, pode ser antecipado se sua combinação com os demais itens faz diminuir a perda de 
material. O estoque de objetos (peças a serem cortadas) não utilizados em um período fica disponível no próximo, juntamente com os novos objetos adquiridos (ou fabricados, como no caso da indústria de papel, Poltroniere [53, 54]) por um planejamento global que envolve outras decisões. As quantidades dos novos objetos adquiridos ou produzidos são consideradas neste artigo como dados do problema, as quais são incógnitas na otimização global. A função objetivo a ser minimizada, combina a perda de material, custos de estocar itens produzidos antecipadamente e, também, custos de estocar objetos. Em essência, trata-se de um problema com multi-objetivos, os quais podem ser convertidos numa mesma unidade monetária.

Farley [12] foi, talvez, o primeiro autor a publicar um estudo sobre o problema de corte de estoque em indústrias de roupa, acoplado ao problema de planejamento e programação da produção. Apesar desse problema ser, essencialmente, um problema de corte bidimensional irregular, esta dificuldade foi contornada por definir vários padrões de corte em retângulos da largura do rolo de tecido, de diferentes comprimentos, os quais foram usados para cortar os itens ao longo do comprimento do rolo (um problema de corte unidimensional). O autor evitou trabalhar com o problema de corte embutido no processo produtivo e o problema foi formulado como um de programação da produção em um único período.

Em 1996, Hendry et al. [20] estudaram o problema de corte acoplado ao problema de planejamento da produção em indústrias de cobre. A operação de fundição básica consiste em derreter pedaços de cobre numa fornalha, produzindo barras com diâmetros específicos, que são cortadas em itens menores de diâmetros e quantidades específicas. Os autores apresentam métodos de solução em dois estágios, baseados no desacoplamento dos problemas. No primeiro estágio, supõe-se conhecido o número máximo de barras de qualquer diâmetro que pode ser produzido por período, levando em conta a capacidade do forno e um problema de corte unidimensional é resolvido. Esta fornece o número de barras de cada diâmetro que deve ser produzida por período. No segundo estágio, é feito um planejamento da produção para cada período.

Nonas e Thorstenson [45], em 2000, propuseram uma formulação para o problema combinado de corte de estoque e dimensionamento de lotes para uma companhia da Noruega que produz um tipo especial de caminhões. A empresa produz a maioria das partes de aço dos caminhões e, assim, grandes placas de aço têm de ser cortadas em diferentes formas e tamanhos. Surge então um problema acoplado de dimensionamento de lotes e corte de estoque, cujo objetivo principal é minimizar o custo total do processo de corte de aço.

Gramani [18], em 2001, estudou a integração dos problemas de dimensionamento de lotes e de corte de estoque em indústrias de móveis. Esse problema integrado consiste em decidir a quantidade de produtos finais (móveis) a serem produzidos em cada período do horizonte de planejamento, tal que minimize não somente os custos de produção, preparação e estoque (problema de dimensionamento de lotes), mas também o custo das 
placas cortadas em itens que compõem os produtos finais demandados (problema de corte de estoque). O problema de corte estudado por Gramani [18] é bidimensional, ou seja, duas dimensões são relevantes no processo de corte. Para modelar e resolver o problema, a autora formulou um modelo matemático inteiro-misto o qual analisa o balanço entre antecipar a produção de certos lotes de produtos finais a fim de minimizar os custos no processo de corte e preparação e o aumento dos custos de estoque e, desenvolveu métodos heurísticos. Uma solução ótima para o problema integrado provavelmente contém soluções não-ótimas para os problemas de corte de estoque e dimensionamento de lotes quando considerados separadamente. Esta abordagem é explorada com mais detalhes no capítulo seguinte.

Em 2002, Respício e Captivo [55] abordam o problema de corte integrado com o planejamento da produção em uma indústria papeleira. A empresa produz diferentes tipos de papel, agrupados em famílias. Bobinas mestre de diferentes famílias são produzidas e depois cortadas em bobinas menores. A capacidade produtiva é menor que a demanda média, o que leva a atrasos na entrega dos produtos. O objetivo é encontrar um plano de produção que determine as quantidades que devem ser produzidas para cada família e evite longos atrasos na entrega. As autoras propõem um modelo de programação inteira, acoplando o problema de corte de estoque unidimensional ao problema de planejamento. O modelo é uma extensão da formulação de Gilmore e Gomory e considera demanda acumulada, restrições de conservação de estoque e restrições de capacidade.

Ainda, considerando os problemas de dimensionamento de lotes e corte de estoque de forma acoplada, Poltroniere $[53,54]$ propõe um estudo com aplicação prática em indústrias de papel. A indústria produz bobinas-mestre de vários tamanhos que, posteriormente, serão cortadas em bobinas intermediárias. Parte dessas bobinas intermediárias é embalada para atender uma demanda específica e o restante é cortado, produzindo diferentes tipos de itens finais, tais como modelo carta, A4, resmas etc. Pode haver estoque de bobinas intermediárias. A disponibilidade de bobinas-mestre no problema de corte é uma variável de decisão. Portanto, as decisões de planejamento consistem em escolher quais bobinas-mestre (definidas pelo seu comprimento e sua gramatura) e em que quantidades (tamanhos dos lotes) devem ser produzidas em cada período, de forma a atender a carteira de pedidos, evitar atrasos e estoque, minimizando a perda de material durante o processo de corte. Para isso, Poltroniere [53, 54] formulou um modelo de otimização inteira mista e desenvolveram métodos heurísticos de solução. Esta abordagem é explorada com mais detalhes no capítulo seguinte.

Recentemente, em 2006, Gramani e França [19] estudaram o problema de corte de lotes de peças demandadas. O objetivo é minimizar a perda e o tempo de setup. Os autores consideraram apenas um tipo de objeto disponível em estoque para ser cortado, em quantidade ilimitada e consideram a limitação na capacidade da máquina de corte. O problema é resolvido heuristicamente, usando a representação de um problema de caminho mínimo em redes, inspirado no método de Wagner-Whitin [63]. Cada período do horizonte de planejamento é representado por um nó. A cada arco da rede $(t, t+\tau)$ 
está associado um problema de corte de estoque, com as demandas integrais de todos os itens nos períodos $t+1, \ldots, t+\tau-1$ antecipadas para o período t. Após resolver todos os problemas de corte associados a cada arco $\left(\left(T^{2}+T\right) / 2\right.$, em que $T$ é o número de períodos), a rede é construída e então resta resolver um clássico problema de caminho mínimo. Esta abordagem de resolução limita consideravelmente o espaço de soluções. No modelo proposto neste artigo, permitimos a antecipação parcial das demandas, consideramos vários tipos de objeto disponíveis em estoque e a limitação na quantidade disponível de cada tipo de objeto em cada período do horizonte de planejamento.

As modelagens e métodos de solução de maior repercussão na literatura foram os publicados por Gilmore e Gomory [15, 16, 17] (para uma revisão veja Chvátal [5], Lasdon [31]). O modelo matemático para o problema de corte de estoque com vários tipos de objetos em estoque (diferentes comprimentos) guarda certa similaridade com o problema de corte em múltiplos períodos, já que permite melhores combinações dos itens a serem cortados nos objetos em estoque, o que faz reduzir a perda. Em caso de múltiplos períodos, a combinação de itens também pode ser melhorada por permitir que itens possam ser cortados antes do período no qual são demandados. Embora o problema com vários tipos de objetos em estoque seja bem conhecido, relativamente poucos trabalhos são encontrados na literatura (Belov e Scheithauer [3] e Holthaus [27]). O problema de corte com múltiplos períodos também foi pouco explorado na literatura, apenas por Gramani e França [19].

No Capítulo 2 são detalhados os dois trabalhos que motivam o estudo do problema de corte de estoque multiperíodo. No Capítulo 3 propomos um modelo matemático, baseado no modelo proposto por Gilmore e Gomory [15], e no Capítulo 4 descrevemos o método de solução utilizado: uma extensão da técnica clássica de geração de colunas. Para obtenção da solução inteira para o problema de corte de estoque multiperíodo foram propostas duas abordagens que são descritas no Capítulo 5. Experimentos computacionais são apresentados e comentados no Capítulo 6. No Capítulo 7, apresentamos as conclusões e propostas de continuidade do trabalho. No Apêndice A, são detalhados métodos da literatura que foram utilizados na resolução dos problemas de corte de estoque multiperíodo unidimensional e bidimensional. No Apêndice B, apresentamos um estudo de caso do problema de corte de estoque bidimensional em uma indústria de esquadrias metálicas. 


\section{Capítulo 2}

\section{Problemas de corte de estoque acoplados ao planejamento da produção}

O problema de corte multiperíodo foi motivado pelo estudo de problemas acoplados encontrados na prática. Temos como base dois problemas práticos de diferentes setores produtivos. O primeiro vem da indústria de papel (problema de corte de estoque unidimensional), em que se deve determinar a quantidade de bobinas de tamanhos padronizados a ser fabricada e depois cortada em tamanhos menores a fim de atender uma certa demanda. O segundo, da indústria de móveis (problema de corte de estoque bidimensional), em que se deve decidir a quantidade de produtos finais a ser produzida a partir do corte de placas retangulares com tamanhos específicos em peças menores, as quais irão compor os produtos finais demandados.

Para entendermos os modelos acoplados, definimos primeiramente, os problemas de corte de estoque e de dimensionamento de lotes e, a seguir, detalharemos os modelos acoplados. No próximo capítulo, focalizamos o problema de corte de estoque multiperíodo, que é objeto de estudo desta tese.

\section{$2.1 \quad$ O problema de corte de estoque}

O problema de corte de estoque (PCE) pode ser definido da seguinte forma.

Suponha que temos disponível $K$ tipos diferentes de objetos em estoque e cada um deles está disponível em uma quantidade $e_{k}, k=1, \ldots, K$. Além disso, temos um conjunto de $m$ tipos de itens menores que devem ser cortados a partir dos objetos maiores em estoque para atender uma dada demanda $d_{i}, i=1, \ldots, m$. O problema consiste em produzir os itens demandados de forma a minimizar uma função objetivo, por exemplo, 
minimizar a perda de material, ou minimizar custos, entre outros. Tratamos dois tipos de problemas de corte de estoque: o problema unidimensional, por exemplo, corte de rolos de papel, bobinas de aço etc, e o problema bidimensional, por exemplo, chapas de madeira, placas de aço, de vidro, entre outras várias aplicações. Consideremos agora os seguintes dados:

\section{Objetos em estoque:}

$K:$ número de tipos de objetos diferentes disponíveis em estoque;

$e_{k}$ : disponibilidade em estoque do objeto tipo $k$;

$L_{k}$ : comprimento do objeto tipo $k$ (caso unidimensional);

$L_{k} \times W_{k}$ : largura e comprimento do objeto tipo $k$ (caso bidimensional).

\section{Itens demandados:}

$m:$ número de tipos de itens demandados;

$d_{i}$ : demanda do item tipo $i$;

$\ell_{i}$ : comprimento do item tipo $i$ (caso unidimensional);

$\ell_{i} \times w_{i}$ : largura e comprimento do item tipo $i$ (caso bidimensional).

Um padrão de corte é a maneira particular de como um objeto em estoque é cortado para a produção de itens demandados. Sejam $N_{k}$ o número de padrões de corte para o objeto tipo $k, k=1, \ldots, K$ e $\alpha_{i j k}$ o número de itens do tipo $i$ no padrão de corte $j$ referente ao objeto tipo $k$. Um vetor $\mathbf{a}_{j k}=\left(\alpha_{1 j k}, \alpha_{2 j k}, \ldots, \alpha_{m j k}\right)^{t}$ representa o $j$-ésimo padrão de corte para o objeto tipo $k$ em estoque, e deve satisfazer as condições:

$$
\begin{aligned}
& \ell_{1} \alpha_{1 j k}+\ell_{2} \alpha_{2 j k}+\ldots+\ell_{m} \alpha_{m j k} \leq L_{k} \\
& 0 \leq \alpha_{i j k} \leq d_{i} \text { e } \alpha_{i j k} \text { inteiro, } i=1, \ldots, m .
\end{aligned}
$$

É comum que outras restrições sejam necessárias para representar um padrão de corte como, por exemplo, o número limitado de facas (Gilmore e Gomory, [16]), número de estágios de corte (Zak [68]), compartimentação (Hoto [28], Hoto et al. [29], Marques [35], Marques e Arenales [36]) entre outros.

A Figura 2.1 apresenta um exemplo de problema de corte de estoque unidimensional. Na Figura 2.1.a vemos dois tipos de objetos disponíveis em estoque para serem cortados, cujas dimensões são $L_{1}$ e $L_{2}$. Na Figura 2.1.b vemos três tipos de itens demandados, com dimensões $\ell_{1}, \ell_{2}$ e $\ell_{3}$. Na Figura 2.1.c estão apresentados dois padrões de corte factíveis, 


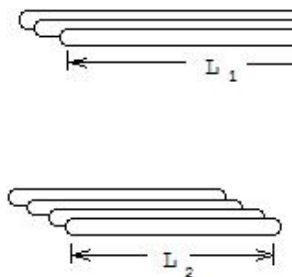

(a)

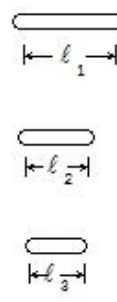

(b)
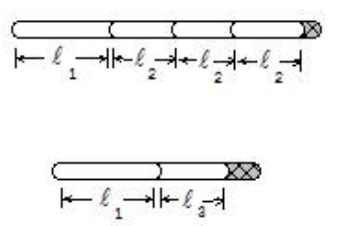

(c)

Figura 2.1: Problema de corte undimensional: (a) objetos disponíveis para corte, (b) itens demandados e (c) dois padrões de corte.

um para o objeto tipo 1 que é dado por $\mathbf{a}_{j 1}=(1,3,0)^{t}$ com uma perda e o outro para o objeto tipo 2 , que é dado por $\mathbf{a}_{j 2}=(1,0,1)^{t}$ e tem uma perda.

Para a construção de padrões de corte bidimensionais, algumas restrições de corte surgem naturalmente na prática ou são impostas para simplificações como, por exemplo, cortes do tipo guilhotinados (Figura 2.2.a.b) e não-guilhotinados (Figura 2.2.c). Várias abordagens para se construir um padrão de corte bidimensional, exatas, aproximadas ou heurísticas, podem ser encontradas na literatura (Herz [21], Wang [64], Oliveira e Ferreira [46], Morabito e Arenales [43], Hifi e Zissimopoulos [25]).

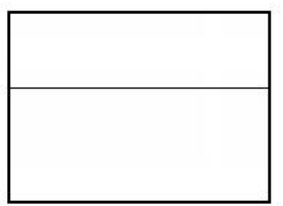

(a)

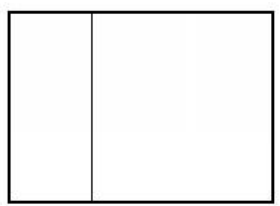

(b)

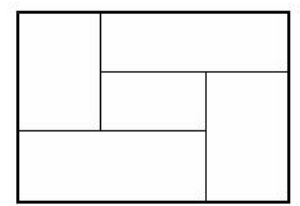

(c)

Figura 2.2: Tipos de padrões de corte bidimensionais: (a) guilhotinado vertical, (b) guilhotinado horizontal, (c) não-guilhotinado.

Os cortes na Figura 2.2 podem ser chamados de "cortes elementares", os quais podem ser aplicados em seqüência e combinados, gerando padrões de corte. A Figura 2.3.c ilustra padrões de corte obtidos por uma seqüência de cortes guilhotinados e são chamados padrôes de corte guilhotinados.

A Figura 2.3 apresenta um exemplo de problema de corte de estoque bidimensional. $\mathrm{Na}$ Figura 2.3.a, dois tipos de placas estão disponíveis em estoque para serem cortadas, cujas dimensões são $L_{1} \times W_{1}$ e $L_{2} \times W_{2}$. Na Figura 2.3.b vemos quatro tipos de itens demandados, com dimensões $\ell_{1} \times w_{1}, \ell_{2} \times w_{2}, \ell_{3} \times w_{3}$ e $\ell_{4} \times w_{4}$. Na Figura 2.3.c estão representados dois padrões de corte guilhotinados, um para a placa tipo 1 , o qual associ- 


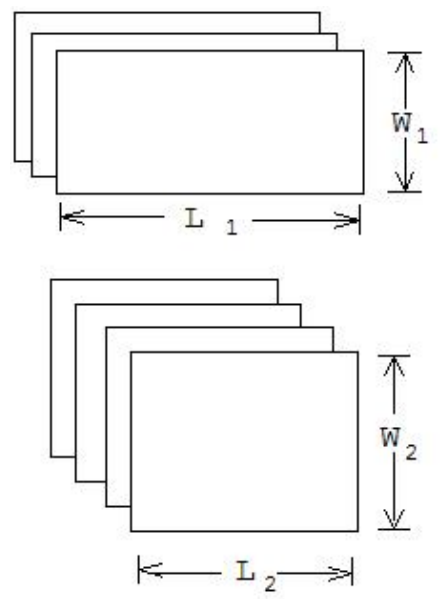

(a)

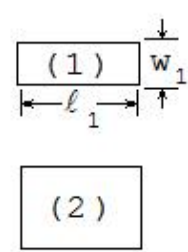

(3)

(4)

(b)

\begin{tabular}{|l|l|l|}
\hline \multicolumn{2}{|c|}{$(4)$} & \multicolumn{1}{|c|}{$(4)$} \\
\hline$(2)$ & $(2)$ & $(2)$ \\
\hline
\end{tabular}

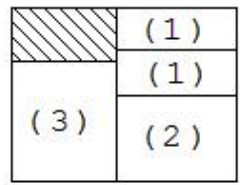

(c)

Figura 2.3: Problema de corte bidimensional: (a) placas disponíveis para corte, (b) itens demandados e (c) dois padrões de corte.

amos o vetor $\mathbf{a}_{j 1}=(0,3,0,2)^{t}$ e o outro para a placa tipo 2 , cujo vetor associado é dado por $\mathbf{a}_{j 2}=(2,1,1,0)^{t}$ e tem uma perda.

Considere também $c_{j k}$ como o custo de cortar um objeto tipo $k$ segundo o $j$-ésimo padrão de corte, $j=1, \ldots, N_{k}, k=1, \ldots, K$. Se objetivamos minimizar a perda total de material, o custo do padrão de corte $j$ para o objeto tipo $k$ é:

problema unidimensional: $c_{j k}=L_{k}-\sum_{i=1}^{m} \ell_{i} \alpha_{i j k}$,

problema bidimensional: $c_{j k}=L_{k} W_{k}-\sum_{i=1}^{m} \ell_{i} w_{i} \alpha_{i j k}$.

As variáveis de decisão são dadas por:

$x_{j k}$ : número de objetos do tipo $k$ cortados segundo o padrão de corte $j$.

O problema de corte de estoque com vários tipos de objetos disponíveis em estoque em quantidades limitadas pode ser formulado da seguinte forma: determine as freqüências $x_{j k}, j=1, \ldots, N_{k}, k=1, \ldots, K$, que minimize a perda total de material, atenda toda a demanda e não exceda a quantidade de cada tipo de objeto disponível em estoque e é modelado por: 


$$
\begin{array}{lll}
\operatorname{minimizar} & \sum_{j=1}^{N_{1}} c_{j 1} x_{j 1}+\ldots+\sum_{j=1}^{N_{K}} c_{j K} x_{j K} & \\
\text { sujeito a: } & \sum_{j=1}^{N_{1}} \alpha_{i j 1} x_{j 1}+\ldots+\sum_{j=1}^{N_{K}} \alpha_{i j K} x_{j K}=d_{i}, & i=1, \ldots, m, \\
& \sum_{j=1}^{N_{k}} x_{j k} \leq e_{k}, & k=1, \ldots, K, \\
& x_{j k} \geq 0, \text { inteiro, } & j=1, \ldots, N_{k}, k=1, \ldots, K .
\end{array}
$$

Para simplificar a notação, reescrevemos o modelo matemático (2.2) na forma matricial:

$$
\begin{array}{ll}
\text { minimizar } & \mathbf{c}^{t} \mathbf{x} \\
\text { sujeito a: } & \mathbf{A} \mathbf{x}=\mathbf{d} \\
& \mathbf{E x} \leq \mathbf{e} \\
& \mathbf{x} \geq \mathbf{0}, \text { inteiro, }
\end{array}
$$

em que cada coluna da matriz $\mathbf{A} \in \mathbb{N}^{m \times n}$ é um vetor associado a um padrão de corte e $\mathbf{E} \in \mathbb{B}^{K \times n}$ é uma matriz de 0 's e $1^{\prime}$ s que representa as restrições de disponibilidade em estoque dos objetos ${ }^{1}$ e $n=\sum_{k=1}^{K} N_{k}$. Além disso, o vetor $\mathbf{c} \in \mathbb{R}^{n}$ é o vetor com o custo referente a cada coluna do conjunto de restrições do modelo, o vetor $\mathbf{d} \in \mathbb{N}^{m}$ é o vetor com as demandas dos itens e o vetor $\mathbf{e} \in \mathbb{N}^{K}$ é o vetor com as disponibilidades em estoque dos objetos.

A condição de integralidade sobre as variáveis $x_{j k}$ é comumente encontrada em problemas de corte de estoque e torna estes problemas difíceis de serem resolvidos computacionalmente. Outra dificuldade é o alto número de possíveis padrões de corte (colunas), inviáveis de serem determinados a priori. Para contornar estas dificuldades, Gilmore e Gomory $[15,16,17]$ propuseram relaxar a condição de integralidade e resolver o problema de otimização linear resultante pelo método simplex com geração de colunas, no qual a cada iteração uma coluna é gerada para fazer parte da solução. O método fornece uma solução ótima contínua para o problema de corte de estoque. Ao final, técnicas de arredondamento podem ser utilizadas para determinar soluções inteiras para o problema de corte de estoque. Esta solução inteira pode ser determinada por procedimentos heurísticos que vêm sendo desenvolvidos por vários pesquisadores, como Pinto [48], Poldi [49], Poldi e Arenales [50, 51], Stadtler [59], Wäscher e Gau [65]. No Apêndice A, alguns desses procedimentos heurísticos são revisados, e no Capítulo 5, alguns são estendidos para o problema de corte estoque multiperíodo.

\footnotetext{
${ }^{1} \mathbb{B}$ é o conjunto binário $\{0,1\}$
} 


\section{$2.2 \quad$ O problema de dimensionamento de lotes}

O problema de dimensionamento de lotes (PDL) é um problema de planejamento que envolve a determinação de quanto produzir em cada um dos períodos de um horizonte de planejamento. O objetivo é encontrar um plano de produção com custo mínimo que atenda a demanda dos produtos sem violar a capacidade de produção disponível. Algumas características que influenciam a modelagem e complexidade do problema de dimensionamento de lotes são:

Horizonte de planejamento: intervalo de tempo para o qual a produção é planejada. Pode ser finito ou infinito, contínuo ou discreto e rolante (o planejamento é detalhado apenas para os primeiros períodos, os quais são implementados).

Número de estágios: Um sistema é dito monoestágio quando os itens a serem produzidos são independentes, isto é, nenhum segue ou antecede o outro. Um sistema é dito multiestágio quando a produção de um determinado item depende da produção de outro item, o qual é chamado item componente.

Número de tipos de itens: pode ser produzido um único tipo de item ou múltiplos tipos de itens.

Estoque: no problema de dimensionamento de lotes, pode ser permitido o atendimento da demanda com ou sem atraso. Em geral, são atribuídos custos aos estoques ou atrasos.

Restrições de capacidade: os recursos disponíveis para a produção podem ser ilimitados ou limitados.

Preparação para produção: outra característica importante para a solução do problema de dimensionamento de lotes é a existência ou não de custos e tempos associados à preparação para a produção de um determinado item.

O problema de dimensionamento de lotes com restrições de capacidade é definido a seguir. Para isso, consideremos os índices, parâmetros e variáveis de decisão seguintes.

\section{Índices:}

$i=1, \ldots, N$ : número de tipos de itens finais demandados;

$t=1, \ldots, T:$ número de períodos do horizonte de planejamento.

\section{Parâmetros:}

$c_{i t}$ : custo de produção do item tipo $i$ no período $t$;

$h_{i t}$ : custo de estoque do item tipo $i$ no final do período $t$; 
$s_{i t}$ : custo de preparação para produzir o item tipo $i$ no período $t$;

$d_{i t}$ : demanda de itens tipo $i$ no período $t$;

$b_{i}$ : tempo necessário para produzir uma unidade do item tipo $i$;

$f_{i}$ : tempo de preparação para produção de itens tipo $i$;

$C_{t}$ : limite de capacidade (em unidade de tempo) no período $t$;

$Q$ : limitante superior.

\section{Variáveis de decisão:}

$x_{i t}$ : número de itens do tipo $i$ produzidos no período $t$;

$I_{i t}$ : estoque do item tipo $i$ no final do período $t$;

$z_{i t}$ : variável binária que indica a produção ou não de item tipo $i$ no período $t$.

\section{Modelo Matemático:}

$$
\begin{aligned}
& \text { minimizar } \sum_{t=1}^{T} \sum_{i=1}^{N}\left(c_{i t} x_{i t}+h_{i t} I_{i t}+s_{i t} z_{i t}\right) \\
& \text { sujeito a: } \quad x_{i t}+I_{i, t-1}-I_{i t}=d_{i t}, \quad i=1, \ldots, N ; t=1, \ldots, T \text {; } \\
& \sum_{i=1}^{N}\left(b_{i} x_{i t}+f_{i} z_{i t}\right) \leq C_{t}, \quad t=1, \ldots, T ; \\
& x_{i t} \leq Q z_{i t}, \quad i=1, \ldots, N ; t=1, \ldots, T \text {; } \\
& x_{i t}, I_{i t} \geq 0, \quad i=1, \ldots, N ; t=1, \ldots, T \text {; } \\
& I_{i 0}=0, z_{i t} \in\{0,1\}, \quad i=1, \ldots, N ; t=1, \ldots, T \text {. }
\end{aligned}
$$

Primeiramente, consideremos o problema de dimensionamento de lotes sem as restrições de capacidade, que são dadas pelo segundo conjunto de restrições no modelo (2.4). Neste caso, o problema pode ser decomposto em $N$ subproblemas, um para cada item e, cada subproblema, pode ser resolvido usando o algoritmo ótimo de programação dinâmica de Wagner-Whitin (Wagner e Whitin [63], Evans [11]).

Agora, considerando o problema (2.4), de acordo com Maes [34], encontrar uma solução factível para problemas de dimensionamento de lotes limitados e que consideram tempo de preparação (setup time) é um problema NP-Completo. Assim, a maioria das técnicas de resolução encontradas na literatura são heurísticas muitas delas baseadas em relaxação lagrangiana e dedicadas à resolução de problemas específicos (Bahl et al. [2], Billington et al. [4], Toledo [60], Trigeiro et. al. [61]). Nas seções seguintes apresentamos as definições dos modelos integrados. 
Poldi, K. C.

\subsection{Problemas acoplados}

Os problemas de corte de estoque e dimensionamento de lotes aparecem em diversas indústrias de manufatura, tais como indústrias de papel, metalúrgica, móveis, entre outras. Nestas indústrias, a matéria prima é, geralmente, produzida ou comprada em tamanhos grandes e padronizados, estocada e depois reduzida a tamanhos menores para então, ser usada na composição dos produtos finais.

PDL
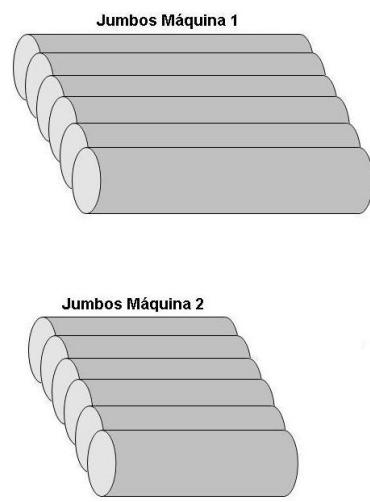

PCE
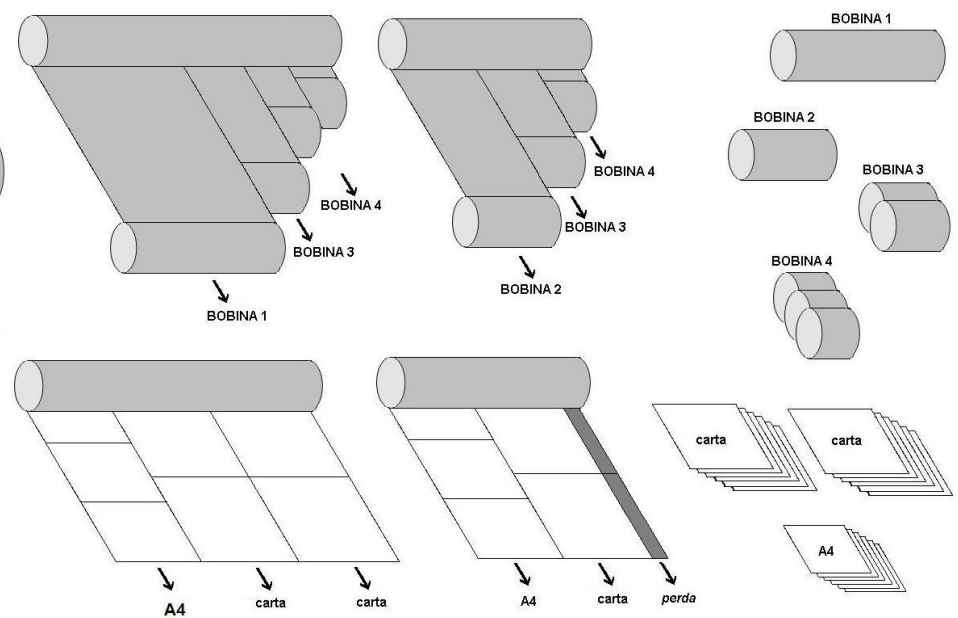

Figura 2.4: Dimensionamento de lotes e corte.

O planejamento coordenado destas atividades faz diminuir os custos operacionais, daí a importância em estudar problemas acoplados. Na indústria papeleira, o problema acoplado consiste em determinar a quantidade de bobinas-jumbo (matéria-prima do processo de corte) que deve ser produzida em cada período do horizonte de planejamento, de forma a atender a carteira de pedidos, evitar atrasos, estoques e minimizar a perda de material durante o processo de corte. A Figura 2.4 ilustra esse processo produtivo.

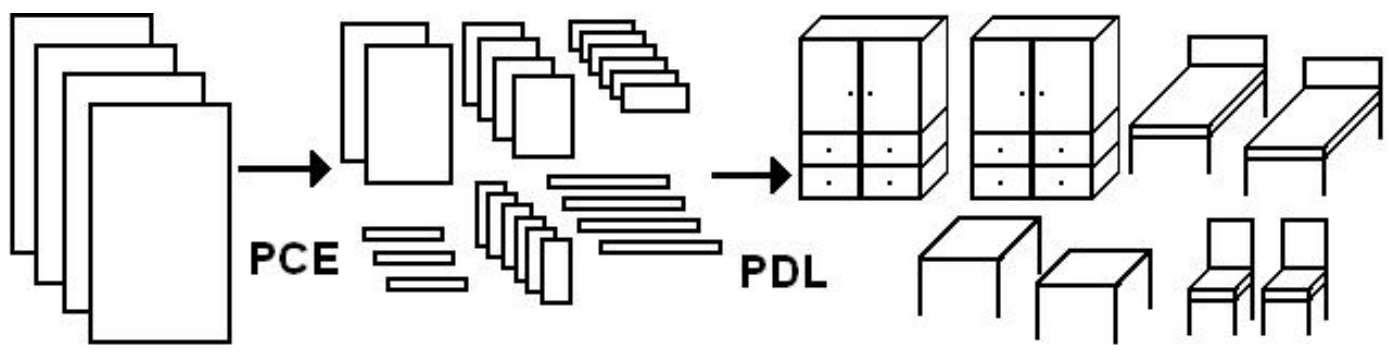

Figura 2.5: Produção na indústria de móveis. 
Na indústria de móveis, o problema acoplado consiste em determinar a quantidade de produtos finais que devem ser produzidos em cada período do horizonte de planejamento, minimizando os custos associados ao estoque e preparação e, também, a perda ocorrida no processo de corte das placas em peças. Na Figura 2.5 é ilustrado esse processo.

\subsubsection{Problema acoplado na indústria de papel}

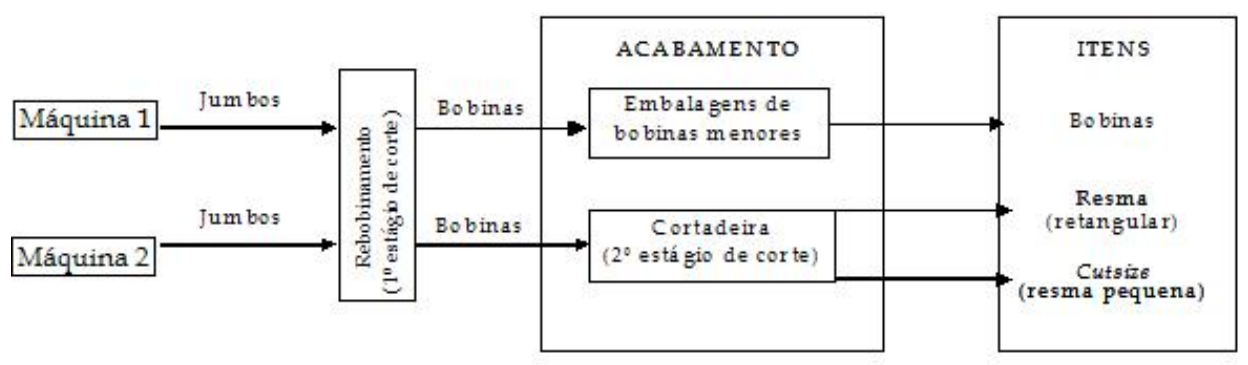

Figura 2.6: Processo simplificado de produção de uma indústria de papel.

Poltroniere [53, 54] estuda um problema que combina dimensionamento de lotes e corte de estoque, em uma indústria papeleira. Nesta indústria, a produção é baseada numa carteira de pedidos e em itens para estoque. Estão disponíveis para produção máquinas que produzem bobinas-jumbo (bobinas grandes de papel). As bobinas-jumbo passam, então, para o setor de rebobinamento, onde são realizados cortes longitudinais, que fornecem bobinas menores (intermediárias). Já no setor de acabamento, uma parte dessas bobinas intermediárias é embalada e vendida. As demais passam pela cortadeira que, por cortes transversais e longitudinais, produzem resmas de vários tamanhos (de acordo com a demanda). Pode ocorrer estoque de bobinas intermediárias durante o processo que, posteriormente, entrarão no setor de acabamento. Este processo simplificado é ilustrado na Figura 2.6.

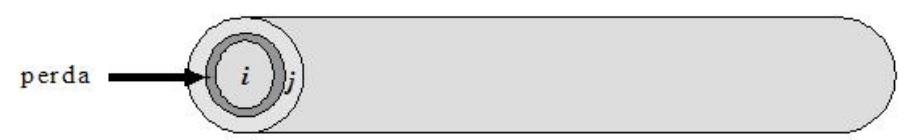

Figura 2.7: Bobina-jumbo com gramatura $i$, perda de papel e gramatura $j$.

O que define o tipo da bobina-jumbo é a máquina na qual ela foi produzida (largura máxima) e a gramatura do papel. Uma mesma bobina-jumbo pode conter papel de gramaturas diferentes. A mudança de uma gramatura para outra gera perda de papel (veja Figura 2.7). Essa perda é dependente da seqüência, ou seja, mudar da gramatura $i$ para a gramatura $j$ gera uma perda, não necessariamente igual a mudança de $i$ para $k$. Temos, portanto, o problema de seqüenciamento de preparações de máquinas. Poltroniere considera, por simplificação, essa perda independente da seqüência. 
A demanda de itens finais (carteira de pedidos e itens para estoque) pode ser agregada por gramatura. Dessa forma, teríamos um conjunto de itens de cada gramatura para cada período do horizonte de planejamento. Portanto, as decisões de planejamento no problema integrado consistem em escolher quais bobinas-mestre (definida pela sua gramatura e seu comprimento) e em que quantidades (tamanhos dos lotes) devem ser produzidas em cada período, de forma a atender a carteira de pedidos, evitar atrasos e estoques indesejados, minimizando não somente os custos de produção, preparação e estoque (problema de dimensionamento de lotes), mas também a perda de material durante o processo de corte (problema de corte de estoque).

Poltroniere [53, 54] apresenta um modelo matemático inteiro-misto que combina as decisões de planejamento de produção e de corte das peças, cujo objetivo é um compromisso entre custos de produção, preparação, estoque e perdas com o corte. No modelo proposto, as bobinas-jumbo são "divididas" em bobinas menores, denominadas bobinasmestre, com peso pré-estabelecido, e apenas um tipo de gramatura.

Na modelagem matemática do problema acoplado na indústria de papel temos a seguinte notação:

\section{Índices:}

$t=1, \ldots, T:$ número de períodos do horizonte de planejamento;

$k=1, \ldots, K:$ número de gramaturas;

$m=1, \ldots, M:$ número de máquinas disponíveis. A máquina $m$ produz bobinasmestre de largura $L_{m}$;

$j=1, \ldots, N_{m}$ : número de padrões de corte para as bobinas-mestre do tipo $m$;

$i=1, \ldots, N f$ : número de tipos de itens demandados;

$\{1, \ldots, N f\}=S(1) \cup S(2) \cup \ldots \cup S(K)$, em que $S(k)=\{i$ tal que o item $i$ tem gramatura $k\}$.

\section{Parâmetros:}

$c_{k m t}$ : custo de produção de bobina-mestre de gramatura $k$ na máquina $m$ no período $t$

$h_{k t}$ : custo de estoque de bobina-mestre de gramatura $k$ no final período $t$;

$s_{k m t}$ : custo de preparação da máquina $m$ para produzir a bobina-mestre de gramatura $k$ no período $t$;

$c p_{k t}:$ custo/cm de perda de papel de gramatura $k$ no processo de corte, no período $t$

$\sigma_{i t}$ : custo/ton de estocagem de itens do tipo $i$ no final do período $t$;

$C_{m t}$ : limite de capacidade (ton) da máquina $m$ no período $t$;

$\mathbf{d}_{k t}$ : vetor da demanda de itens de gramatura $k$ no período $t$, de dimensão $|S(k)|$;

$\rho_{k}$ : peso específico da bobina-mestre de gramatura $k$; 
$\eta_{i k}$ : peso do item tipo $i$ de gramatura $k$ (o peso do item tipo $i$ de gramatura $k$ e largura $\ell_{i}$ é dado por $\eta_{i k}=\rho_{k} \ell_{i}$;

$D_{k t}$ : demanda (ton) de papel de gramatura $k$ no período $t$;

$b_{k m}$ : peso da bobina-mestre de gramatura $k$ produzida na máquina $m$, e é dado por: $b_{k m}=L_{m} \rho_{k}$;

$f_{k m}$ : peso do papel desperdiçado na preparação da máquina $m$ para a produção da bobina-mestre de gramatura $k$;

$\mathbf{a}_{j m}$ : vetor associado ao padrão de corte $j$ para a bobina-mestre de largura $L_{m}$; a coordenada $i$ deste vetor define o número de itens do tipo $i$ no padrão de corte;

$p_{j m}$ : perda $(\mathrm{cm})$ de papel no padrão de corte $j$ utilizado para cortar a bobina-mestre de largura $L_{m}$;

$Q$ : número grande.

\section{Variáveis de decisão:}

$x_{k m t}$ : número de bobinas-mestre de gramatura $k$ produzidas na máquina $m$ no período $t$;

$w_{k m t}$ : estoque de bobinas-mestre de gramatura $k$ produzidas na máquina $m$ no final período $t$;

$z_{k m t}$ : variável binária que indica a produção ou não da bobina-mestre de gramatura $k$ na máquina $m$ no período $t$;

$y_{k m t}^{j}$ : número de bobinas-mestre de gramatura $k$ produzida na máquina $m$ no período $t$, cortadas usando o padrão $j$;

$\mathbf{e}_{k t}$ : vetor de estoque de itens de gramatura $k$ no período $t$. Sua dimensão é $|S(k)|$, e cada componente $e_{i k t}$ representa o número de itens tipo $i$ estocados no final do período $t$.

\section{Observações:}

1. O parâmetro $D_{k t}$ que representa a quantidade total de papel do tipo $k$ que deve estar disponível no período $t$, não é um dado do problema, pois depende da perda que ocorre durante o processo de corte. Por definição, ele deve ser $D_{k t}=\sum_{i \in S(K)} \eta_{i k} d_{i k t}+$ perda. Como a perda é desconhecida, inicialmente introduzimos um novo parâmetro $\theta$, que é uma estimativa para a perda.

2. Por outro lado, o parâmetro $D_{k t}$ pode ser expresso em termos das variáveis que determinam o número de bobinas-mestre do tipo $k$ que deve ser cortado no período $t$, isto é, $D_{k t}=\sum_{m=1}^{M} \sum_{j=1}^{N_{m}} b_{k m} y_{k m t}^{j}$. 
Assim, Poltroniere [53, 54] propôs a seguinte formulação matemática para o problema de corte integrado à programação da produção:

sujeito a:

$$
\begin{aligned}
\operatorname{minimizar} & \sum_{t=1}^{T} \sum_{m=1}^{M} \sum_{k=1}^{K}\left(c_{k m t} x_{k m t}+h_{k t} b_{k m} w_{k m t}+s_{k m t} z_{k m t}\right)+ \\
& +\sum_{t=1}^{T} \sum_{k=1}^{K} c p_{k t}\left(\sum_{m=1}^{M} \sum_{j=1}^{N_{m}} p_{j m} y_{k m t}^{j}\right)+\sum_{t=1}^{T} \sum_{k=1}^{K} \sum_{i \in S(k)} \sigma_{i t} \eta_{i k} e_{i k t}
\end{aligned}
$$

$\sum_{m=1}^{M}\left(b_{k m} x_{k m t}+b_{k m} w_{k, m, t-1}-b_{k m} w_{k m t}\right)=D_{k t}$,

$$
k=1, \ldots, K ; t=1, \ldots, T
$$

$\sum_{k=1}^{K}\left(b_{k m} x_{k m t}+f_{k m} z_{k m t}\right) \leq C_{m t}$

$$
m=1, \ldots, M ; t=1, \ldots, T
$$

$\sum_{m=1}^{M} \sum_{j=1}^{N_{m}} a_{j m} y_{k m t}^{j}+e_{k, t-1}-e_{k t}=d_{k t}$,

$$
k=1, \ldots, K ; t=1, \ldots, T
$$

$\sum_{j=1}^{N_{m}} y_{k m t}^{j}=x_{k m t}+w_{k, m, t-1}-w_{k m t}$

$$
\begin{aligned}
& k=1, \ldots, K ; m=1, \ldots, M ; t=1, \ldots, T \\
& k=1, \ldots, K ; m=1, \ldots, M ; t=1, \ldots, T \\
& k=1, \ldots, K ; m=1, \ldots, M \\
& k=1, \ldots, K ; m=1, \ldots, M ; t=1, \ldots, T \\
& k=1, \ldots, K ; m=1, \ldots, M ; t=1, \ldots, T
\end{aligned}
$$

$x_{k m t} \leq Q z_{k m t}$,

$w_{k m 0}=0, e_{k 0}=0$,

$x_{k m t} \geq 0, w_{k m t} \geq 0$, e inteiros,

$z_{k m t} \in\{0,1\}$,

$y_{k m t}^{j} \geq 0, e_{k t} \geq 0$, e inteiros,

$$
j=1, \ldots, N_{M} ; k=1, \ldots, K ; m=1, \ldots, M ; t=1, \ldots, T .
$$

Objetivo: A função objetivo (2.5) considera custos de produção, preparação e estoque de bobinas-mestre, custos com as perdas de papel durante o processo de corte, e custos de estoque de itens finais.

(1) Custos de produção, preparação e estocagem das bobinas-mestre:

$$
\sum_{t=1}^{T} \sum_{m=1}^{M} \sum_{k=1}^{K}\left(c_{k m t} x_{k m t}+h_{k t} b_{k m} w_{k m t}+s_{k m t} z_{k m t}\right) .
$$

(2) Custos de perda no processo de corte:

$$
\sum_{t=1}^{T} \sum_{k=1}^{K} c p_{k t}\left(\sum_{m=1}^{M} \sum_{j=1}^{N_{m}} p_{j m} y_{k m t}^{j}\right) .
$$


(3) Custos de estoque de itens finais:

$$
\sum_{t=1}^{T} \sum_{k=1}^{K} \sum_{i \in S(k)} \sigma_{i t} \eta_{i k} e_{i k t}
$$

Equações de balanço de estoque de itens: As restrições (2.6) representam as equações de balanço de estoque. A quantidade de papel de gramatura $k$ produzida no período $t$, mais a quantidade estocada no final do período anterior $t-1$, menos o que vai ser estocado no final do período atual $t$, tem que ser igual à demanda da gramatura $k$ deste período.

$$
\sum_{m=1}^{M}\left(b_{k m} x_{k m t}+b_{k m} w_{k, m, t-1}-b_{k m} w_{k m t}\right)=D_{k t}, \quad k=1, \ldots, K ; t=1, \ldots, T .
$$

Observe que as variáveis $x_{k m t}$ e $w_{k m t}$ estão multiplicadas por $b_{k m}=L_{m} \rho_{k}$, pois a demanda de papel para o PDL é dada em peso.

Capacidade de produção: As restrições (2.7) asseguram que a capacidade de produção não seja excedida, ou seja, a quantidade de papel produzido mais a quantidade de papel desperdiçado na mudança de uma gramatura para outra (perda de preparação) deve ser menor que a capacidade de produção da máquina $m$ em cada período $t$.

$$
\sum_{k=1}^{K}\left(b_{k m} x_{k m t}+f_{k m} z_{k m t}\right) \leq C_{m t}, \quad m=1, \ldots, M ; t=1, \ldots, T .
$$

Equações de balanço de estoque de itens finais: O conjunto de restrições(2.8) assegura que a demanda de itens finais seja atendida. O somatório $\sum_{j=1}^{N_{m}} a_{j m} y_{k m t}^{j}$ fornece um vetor com o número de itens de cada tipo cortados no período $t$.

$$
\sum_{m=1}^{M} \sum_{j=1}^{N_{m}} a_{j m} y_{k m t}^{j}+e_{k, t-1}-e_{k t}=d_{k t}, \quad k=1, \ldots, K ; t=1, \ldots, T .
$$

Restrições de capacidade no corte: As restrições de limitação da capacidade no corte aparecem em (2.9), assegurando que a quantidade produzida de bobinas-mestre $x_{k m t}$ mais a quantidade disponível em estoque no período $t-1$ seja suficiente para atender a demanda de itens finais de gramatura $k$ no período $t$.

$$
\sum_{j=1}^{N_{m}} y_{k m t}^{j}=x_{k m t}+w_{k, m, t-1}-w_{k m t}, \quad k=1, \ldots, K ; m=1, \ldots, M ; t=1, \ldots, T .
$$


Estas são as restrições de acoplamento dos dois problemas, pois incluem ambas as variáveis $x_{k m t}$, que definem o tamanho dos lotes (PDL), e $y_{k m t}^{j}$, que definem a quantidade de bobinas-mestre utilizadas no corte (PCE).

Restrições de preparação: As restrições (2.10) são restrições de preparação, isto é, se existe produção de bobinas-mestre de gramatura $k\left(x_{k m t}>0\right)$ ao longo do período $t$, então $z_{i t}=1$, caso contrário $z_{i t}=0$.

$$
x_{k m t} \leq Q z_{k m t}, \quad k=1, \ldots, K ; m=1, \ldots, M ; t=1, \ldots, T .
$$

Estoques iniciais: Os estoques iniciais de todos os itens são considerados nulos (2.11), sem perda de generalidade.

$$
w_{k m 0}=0, e_{k 0}=0, \quad k=1, \ldots, K ; m=1, \ldots, M .
$$

Isto porque, se o estoque inicial for diferente de zero, ele pode ser abatido das demandas dos primeiros períodos do horizonte de planejamento até que se torne nulo.

Restrições de integralidade e não-negatividade: São dadas pelas restrições (2.12), (2.13) e (2.14):

$$
\begin{array}{ll}
x_{k m t} \geq 0, w_{k m t} \geq 0 \text { e inteiros, } & k=1, \ldots, K ; m=1, \ldots, M ; t=1, \ldots, T ; \\
z_{k m t} \in\{0,1\}, & k=1, \ldots, K ; m=1, \ldots, M ; t=1, \ldots, T ; \\
y_{k m t}^{j} \geq 0, e_{k t} \geq 0 \text { e inteiros, } & j=1, \ldots, N_{M} ; k=1, \ldots, K ; m=1, \ldots, M ; t=1, \ldots, T .
\end{array}
$$

No modelo acoplado, o problema de dimensionamento de lotes é do tipo monoestágio, com múltiplos itens, em um ambiente com máquinas paralelas distintas e restrições de capacidade. O problema de encontrar uma solução factível quando consideramos perdas na preparação da máquina é NP-completo. Devido à dificuldade de resolver este problema, métodos exatos têm utilidade limitada. Além disso, as restrições de corte possuem dois fatores que tornam essa formulação ainda mais difícil de ser resolvida. O primeiro é a restrição de integralidade sobre as variáveis, que pode ser relaxada e o problema resolvido pelo método simplex. O segundo fator é o número grande de variáveis (uma variável para cada padrão), podendo, em problemas práticos, ser da ordem de centenas de milhares. Para contornar esse problema, Gilmore e Gomory [15] propuseram uma técnica de geração de colunas que é bastante eficiente para resolver a relaxação linear. Como podemos ver, mesmo quando tratados separadamente, esses problemas são de difícil solução. Poltroniere propõe duas heurísticas para a solução do problema acoplado, baseadas em relaxação lagrangiana.

\section{Um subproblema de corte multiperíodo}

Considere que as variáveis relacionadas ao de dimensionamento de lotes sejam fixadas no modelo (2.5)-(2.14). Assim, resta-nos um problema de corte de estoque (PCE) 
com uma característica especial, sua demanda e disponibilidade de objetos para corte (determinada pelo (PDL)) estão divididos em um horizonte de planejamento finito.

$$
\begin{aligned}
& \sum_{m=1}^{M} \sum_{j=1}^{N_{m}} a_{j m} y_{k m t}^{j}+e_{k, t-1}-e_{k t}=d_{k t}, \\
& \sum_{j=1}^{N_{m}} y_{k m t}^{j}=x_{k m t}+w_{k, m, t-1}-w_{k m t}, \quad k=1, \ldots, K ; t=1, \ldots, T \\
& y_{k m t}^{j} \geq 0, e_{k t} \geq 0, \text { e inteiros }, j=1, \ldots, N_{M} ; k=1, \ldots, K ; m=1, \ldots, M ; t=1, \ldots, T
\end{aligned}
$$

Tais restrições, com $x_{k m t}$ fixadas caracterizam um problema de corte de estoque, o qual tem a demanda dos itens distribuída ao longo de um horizonte de planejamento e deve ser resolvido de forma acoplada. Poltroniere decompôs o problema em períodos e propôs uma heurística de transferência de itens entre períodos. A resolução eficiente do problema de corte multiperíodo contribui para a solução de problemas de programação da produção acoplados.

\subsubsection{Problema acoplado na indústria de móveis}

Em 2001, Gramani [18], como já foi mencionado, estudou um problema acoplado na indústria de móveis, o qual consiste em decidir a quantidade de produtos finais a serem produzidos em cada período do horizonte de planejamento, tal que minimize não somente os custos de produção, preparação e estoque (problema de dimensionamento de lotes), mas também a quantidade de placas a serem cortadas em peças a fim de compor os produtos finais demandados (problema de corte de estoque).

Uma relação importante existente no modelo está entre a demanda de um produto final e a demanda de seus itens (peças). A demanda no período $t$ de um produto final $i$, $d_{i t}$, ocorre externamente e as quantidades são determinadas pelo cliente. Tendo conhecida a produção dos produtos finais, é fácil obter a demanda interna dos itens, que é dada por $\sum_{i} r_{p i} x_{i t}$, em que $r_{p i}$ denota a quantidade necessária de peças do tipo $p$ para produzir uma unidade do produto final $i$, e $x_{i t}$ denota a quantidade produzida do produto final $i$ no período $t$.

Um outro ponto que aproxima à prática é a inclusão da capacidade da serra em cada período. Temos de assegurar que o tempo gasto para cortar as placas não excede o tempo disponível. Observe que com a inclusão das restrições de capacidade de serra em cada período, ao resolvermos os problemas de forma separada, provavelmente encontraremos infactibilidades na produção, enquanto que se resolvermos os problemas de forma combinada, podemos antecipar a produção de certos itens, de forma a obter uma melhor utilização das máquinas ou evitar períodos em que os limites de capacidade de serra tenham sido ultrapassados. 
Hipóteses adicionais foram consideradas por Gramani [18] na modelagem matemática do problema:

- considerou-se apenas um tamanho para as placas em estoque, digamos $L \times W$, disponível em quantidade suficiente para atender a demanda;

- o período é tratado como um turno de trabalho em uma empresa;

- o custo de preparação se houver produção em um determinado turno também é considerado.

Na modelagem matemática do problema acoplado na indústria de móveis temos a seguinte notação:

\section{Índices:}

$t=1, \ldots, T:$ número de períodos (ou turnos de trabalho);

$p=1, \ldots, P$ : número de diferentes tipos de peças a serem cortadas;

$j=1, \ldots, N$ : número de diferentes padrões de corte para a placa $L \times W$ a fim de produzir as peças requeridas;

$i=1, \ldots, M$ : número de diferentes produtos finais demandados.

\section{Parâmetros:}

$c_{i t}$ : custo de produção do produto $i$ no período $t$;

$h_{i t}$ : custo de estocagem do produto $i$ no final do período $t$;

$h p_{p t}$ : custo de estocagem da peça do tipo $p$ (componentes para produtos finais) no final do período $t$;

$d_{i t}$ : demanda do produto final $i$ no período $t$;

$r_{p i}$ : número de peças do tipo $p$ necessárias para formar uma unidade do produto final $i$;

$C_{t}$ : tempo disponível para serra no período $t$;

$v_{j}$ : tempo gasto para cortar uma placa no padrão de corte $j$;

$b_{t}$ : capacidade de serra (em horas) no período $t$;

$s_{i t}$ : custo de preparação para produzir o produto $i$ no período $t$;

$a_{p j}$ : número de peças do tipo $p$ no padrão $j$.

\section{Variáveis:}

$x_{i t}$ : quantidade do produto $i$ produzido no período $t$;

$I_{i t}$ : quantidade do produto $i$ em estoque no fim do período $t$;

$I P_{p t}$ : quantidade da peça do tipo $p$ em estoque no fim do período $t$;

$y_{j t}$ : quantidade de placas cortadas usando o padrão de corte $j$ no período $t$;

zit : variável binária : $z_{i t}=1$ se $x_{i t}>0$; zero, caso contrário. 
O modelo matemático inteiro-misto para o problema combinado de corte de estoque e dimensionamento de lotes foi proposto por Gramani [18] da seguinte forma:

$$
\begin{aligned}
& \operatorname{minimizar} \sum_{i=1}^{M} \sum_{t=1}^{T}\left(c_{i t} x_{i t}+h_{i t} I_{i t}+s_{i t} z_{i t}\right)+\sum_{j=1}^{N} \sum_{t=1}^{T} c p \cdot y_{j t}+\sum_{p=1}^{P} \sum_{t=1}^{T} h p_{p t} I P_{p t} \\
& \text { sujeito a: } x_{i t}+I_{i, t-1}-I_{i t}=d_{i t} \text {, } \\
& i=1, \ldots, M ; t=1, \ldots, T \\
& \sum_{j=1}^{N} a_{p j} y_{j t}+I P_{p, t-1}-I P_{p t}=\sum_{i=1}^{M} r_{p i} x_{i t}, \quad p=1, \ldots, P ; t=1, \ldots, T \\
& \sum_{j=1}^{N} v_{j} y_{j t} \leq C_{t} \\
& t=1, \ldots, T \\
& x_{i t} \leq Q z_{i t}, \\
& i=1, \ldots, M ; t=1, \ldots, T \\
& x_{i t}, I_{i t} \geq 0 \text {, } \\
& i=1, \ldots, M ; t=1, \ldots, T \\
& y_{j t} \geq 0 \text { e inteiros, } \\
& j=1, \ldots, N ; t=1, \ldots, T \\
& I P_{p t} \geq 0 \text {, } \\
& p=1, \ldots, P ; t=1, \ldots, T \\
& z_{j t} \in\{0,1\} \text {, }
\end{aligned}
$$

Objetivo: O objetivo do modelo consiste em minimizar (2.18): os custos dos produtos, usando, $c_{i t}, h_{i t}$ e $s_{i t}$ como os custos de produção, estoque e preparação, respectivamente; e os custos do processo de corte, usando, $c p$, como os custos de placas e $h p_{p t}$ como custos de estoque das peças do tipo $p$ no período $t$. Na prática, o objetivo visa encontrar um planejamento de produção ótimo de tal modo que minimize o número de placas a serem cortadas, como também os custos de produção, estoque e preparação. Logo,

$$
\sum_{i=1}^{M} \sum_{t=1}^{T}\left(c_{i t} x_{i t}+h_{i t} I_{i t}+s_{i t} z_{i t}\right)+\sum_{j=1}^{N} \sum_{t=1}^{T} c p \cdot y_{j t}+\sum_{p=1}^{P} \sum_{t=1}^{T} h p_{p t} I P_{p t} .
$$

Balanço de estoque de produtos: Esse conjunto de restrições (2.19) considera o balanço de estoque de produtos, assegurando que a demanda (externa) de cada período seja atendida sem atraso, $I_{i t} \geq 0, i=1, \ldots, M ; t=1, \ldots, T$. Sem perda de generalidade, o estoque inicial é considerado nulo. Logo,

$$
x_{i t}+I_{i, t-1}-I_{i t}=d_{i t}, \quad i=1, \ldots, M ; t=1, \ldots, T .
$$

Balanço de estoque de peças: Esse conjunto de restrições (2.20) assegura que a demanda (interna) de peças seja satisfeita. A quantidade de peças do tipo $p$ a serem produzidas é dada por $\sum_{j=1}^{N} a_{p j} y_{j t}, t=1, \ldots, T$, e considerando a produção do produto $i$ 
dada por $x_{i t}$, para cada período $t$, a demanda de peças pode ser facilmente calculada por $\sum_{i} r_{p i} x_{i t}, p=1, \ldots, P ; t=1, \ldots, T$. Sem perda de generalidade, o estoque inicial de peças é considerado nulo. Logo,

$$
\sum_{j=1}^{N} a_{p j} y_{j t}+I P_{p, t-1}-I P_{p t}=\sum_{i=1}^{M} r_{p i} x_{i t}, \quad p=1, \ldots, P ; t=1, \ldots, T .
$$

Observe que essas restrições são as únicas que acoplam os dois problemas, pois incluem ambas as variáveis, $x_{i t}$ que definem o tamanho dos lotes (PDL) e $y_{j t}$ que definem a quantidade de placas utilizadas (cortadas) (PCE).

Capacidade de serra: Existe uma capacidade limite de serra, representada pelas restrições (2.21). Note que o tempo gasto para cortar uma placa depende do padrão de corte utilizado na mesma. Por exemplo, um padrão de corte 2-estágios requer menos tempo de produção do que um padrão de corte 3-estágios. Temos que assegurar que o tempo gasto para cortar placas nos diversos padrões de corte, não exceda o tempo limite, $C_{t}$, em cada período. Portanto,

$$
\sum_{j=1}^{N} v_{j} y_{j t} \leq C_{t}, \quad t=1, \ldots, T
$$

Produção: Representado pelas restrições (2.22). Se existe produção ao longo do período $t$ então $z_{i t}=1$, caso contrário $z_{i t}=0$. Portanto,

$$
x_{i t} \leq Q z_{i t}, \quad i=1, \ldots, M ; t=1, \ldots, T,
$$

em que $Q$ é um número grande.

Restrições de integralidade e não-negatividade: São dadas pelas restrições (2.23), $(2.24)$ e $(2.25)$ :

$$
\begin{array}{ll}
y_{j t} \geq 0 \text { e inteiros, } & j=1, \ldots, N ; t=1, \ldots, T \\
I P_{p t} \geq 0, & p=1, \ldots, P ; t=1, \ldots, T \\
z_{j t} \in\{0,1\}, & i=1, \ldots, M ; t=1, \ldots, T .
\end{array}
$$

A alta complexidade do modelo matemático do problema combinado (2.18)-(2.26) deve-se a três fatores: (1) a integralidade das variáveis $y_{j t} ;(2)$ as variáveis binárias de preparação $z_{i t}$ e (3) a grande quantidade de padrões de corte $a_{p j}$.

Devido a estas dificuldades, na prática as empresas resolvem o problema combinado decompondo-o em dois subproblemas: no problema de dimensionamento de lotes e no problema de corte de estoque, em que a literatura dispõe de métodos de resolução para cada um dos problemas, separadamente. Mas resolvendo-se o problema decomposto, 
mesmo obtendo a solução ótima para os dois problemas e agregando suas soluções, pode não ser compensador do ponto de vista do custo de produção global, conforme Gramani [18].

\section{Um subproblema de corte multiperíodo}

Considere que o problema de dimensionamento de lotes (PDL) esteja resolvido para o modelo (2.18)-(2.26). Ou seja, os valores das variáveis $x_{i t}$ são conhecidos e, por conseqüência, $I_{i t}$ e $z_{i t}$.

Assim, resta-nos um problema de corte de estoque (PCE) com uma característica especial, sua demanda (determinada pelo (PDL)) está dividida em um horizonte de planejamento finito.

$$
\begin{aligned}
& \operatorname{minimizar} \sum_{j=1}^{N} \sum_{t=1}^{T} c p \cdot y_{j t}+\sum_{p=1}^{P} \sum_{t=1}^{T} h p_{p t} I P_{p t} \\
& \text { sujeito a: } \sum_{j=1}^{\bar{N}^{1}} a_{p j} y_{j t}+I P_{p, t-1}-I P_{p t}=\sum_{i=1}^{M} r_{p i} x_{i t}, \quad p=1, \ldots, P ; t=1, \ldots, T \\
& \sum_{j=1} v_{j} y_{j t} \leq C_{t} \\
& y_{j t} \geq 0 \text { e inteiros, } \quad j=1, \ldots, N ; t=1, \ldots, T \\
& I P_{p t} \geq 0 \\
& p=1, \ldots, P ; t=1, \ldots, T \text {. }
\end{aligned}
$$

Este subproblema de corte multiperíodo difere do subproblema do modelo acoplado anterior (2.15)-(2.17), pois introduz uma restrição de capacidade (2.29), enquanto o anterior traz a disponibilidade de objetos como restrição.

Embora Gramani [18] não tenha considerado a limitação de disponibilidade de objetos em estoque (supôs que os objetos em estoque eram suficientes para atender a demanda), podemos incluir uma restrição que limita a disponibilidade de objetos em estoque, por período, a qual contabiliza a quantidade restante do período anterior, juntamente com novos objetos adquiridos no período. Tais restrições captam uma atividade importante no planejamento da produção, correspondente à aquisição de matéria-prima para o estoque, ou fabricação desta, como no modelo acoplado da indústria de papel. A disponibilidade de objetos em estoque, por período, é dada por:

$$
\begin{array}{ll}
\sum_{j=1}^{N} y_{j t}+I O_{t-1}+I O_{t}=e_{t}, & t=1, \ldots, T \\
I O_{t} \geq 0, & t=1, \ldots, T
\end{array}
$$


em que $I O_{t}$ é o número de objetos em estoque no final do período $t$ e $e_{t}$ é o número de objetos adquiridos no período $t$. Veja restrição (2.9), com $M=1$, em que a quantidade de objetos produzidos no período: $x_{t}$ (omitimos os índices $k$ e $m$ ) é uma decisão importante de um estágio anterior. Na indústria de móveis, $e_{t}$ (i.e., a quantidade de placas de madeira adquiridas) é uma decisão que deve ser planejada de acordo com a produção. No modelo de corte multiperíodo incluímos tais restrições.

No próximo capítulo distinguimos dois problemas de corte multiperíodo: o problema irrestrito, ou seja, sem limitação na capacidade de máquina e o problema restrito, ou seja, com limitação na capacidade de máquina. 


\section{Capítulo 3}

\section{Problemas de corte de estoque multiperíodo}

O termo "irrestrito" será usado para referir-se a problemas de corte de estoque multiperíodo, sem limitação na capacidade da máquina de corte, em cada período de tempo do horizonte de planejamento. Por outro lado, o termo "restrito" será usado para problemas de corte de estoque multiperíodo com restrições adicionais, que representam a limitação na capacidade da máquina de corte em cada período de tempo do horizonte de planejamento.

\subsection{Problemas de corte de estoque multiperíodo irres- trito}

\subsubsection{Unidimensional}

No problema de corte de estoque multiperíodo (PCEM) as demandas dos itens ocorrem em períodos diversos de um horizonte de planejamento finito, sendo possível antecipar ou não a produção de itens. Os objetos não utilizados em um período ficam disponíveis no próximo, juntamente com possíveis novos objetos adquiridos ou produzidos pela própria empresa. A seguir, apresentamos um modelo de otimização linear inteira de grande porte, cujo objetivo pondera as perdas nos cortes, os custos de estoque de objetos e itens.

\section{Índices:}

$t=1, \ldots, T:$ número de períodos no horizonte de planejamento;

$k=1, \ldots, K$ : número de tipos (comprimentos) de objetos disponíveis em estoque;

$j=1, \ldots, N_{k}$ : número de padrões de corte para o objeto tipo $k, k=1, \ldots, K$;

$i=1, \ldots, m:$ número de tipos de itens a serem cortados. 


\section{Dados:}

$L_{k}:$ comprimento do objeto tipo $k, k=1, \ldots, K$;

$e_{k t}:$ quantidade adquirida/produzida de objetos tipo $k$ no período $t, k=1, \ldots, K, t=$ $1, \ldots, T\left(\mathbf{e}_{t}\right.$ : vetor de dimensão $K$ cujas componentes são $\left.e_{k t}\right)$;

$\ell_{i}$ : comprimento do item tipo $i, i=1, \ldots, m$;

$d_{i t}$ : demanda o item tipo $i$ no período $t, i=1, \ldots, m, t=1, \ldots, T\left(\mathbf{d}_{t}\right.$ : vetor de dimensão $m$ cujas componentes são $d_{i t}$ );

$\alpha_{i j k t}$ : número de itens do tipo $i$ no $j$-ésimo padrão de corte para o objeto tipo $k$, no período $t$ ( $\mathbf{a}_{j k t}$ : vetor de dimensão $m$ cujas componentes são $\left.\alpha_{i j k t}\right)$.

\section{Parâmetros:}

$c_{j k t}$ : custo de cortar o objeto tipo $k$ segundo o $j$-ésimo padrão de corte do período $t, j=1, \ldots, N_{k}, k=1, \ldots, K, t=1, \ldots, T$ (tipicamente proporcional à perda de material);

$c r_{i t}$ : custo de estocar o item tipo $i$ no final período $t, i=1, \ldots, m, t=1, \ldots, T$;

$c s_{k t}$ : custo de estocar o objeto tipo $k$ no final período $t, k=1, \ldots, K, t=1, \ldots, T$.

\section{Variáveis de decisão:}

$x_{j k t}$ : número de objetos tipo $k$ cortados conforme o padrão de corte $j$, no período $t$

$r_{i t}$ : número de itens do tipo $i$ que são antecipados para o período $t\left(\mathbf{r}_{t}\right.$ : vetor de dimensão $m$ cujas componentes são $r_{i t}$ );

$s_{k t}$ : número de objetos do tipo $k$ que sobram no final do período $t$.

Sem perda de generalidade, consideramos os estoques iniciais nulos, $r_{i 0}=0, i=$ $1, \ldots, m$, e $s_{k 0}=0, k=1, \ldots, K$.

\section{Modelo matemático:}

$$
\begin{aligned}
\operatorname{minimizar} & \sum_{t=1}^{T}\left(\sum_{j=1}^{N_{1}} c_{j 1 t} x_{j 1 t}+\sum_{j=1}^{N_{2}} c_{j 2 t} x_{j 2 t}+\ldots+\sum_{j=1}^{N_{K}} c_{j K t} x_{j K t}+\sum_{i=1}^{m} c r_{i t} r_{i t}+\sum_{k=1}^{K} c s_{k t} s_{k t}\right) \\
\text { sujeito a: } & \sum_{j=1}^{N_{1}} \mathbf{a}_{j 1 t} x_{j 1 t}+\sum_{j=1}^{N_{2}} \mathbf{a}_{j 2 t} x_{j 2 t}+\ldots+\sum_{j=1}^{N_{K}} \mathbf{a}_{j K t} x_{j K t}+\mathbf{r}_{\mathbf{t}-\mathbf{1}}-\mathbf{r}_{\mathbf{t}}=\mathbf{d}_{t}, t=1, \ldots, T \\
& \sum_{j=1}^{N_{k}} x_{j k t}-\mathbf{s}_{k,(t-1)}+\mathbf{s}_{k t}=e_{k t}, k=1, \ldots, K, t=1, \ldots, T \\
& x_{j k t} \geq 0, \text { inteiros }, r_{i t} \geq 0, s_{k t} \geq 0, j=1, \ldots, N_{k}, k=1, \ldots, K, t=1, \ldots, T .
\end{aligned}
$$


A função objetivo no problema (3.1), a ser minimizada, consiste no custo total devido às perdas de material de todos os objetos, em todos os períodos e ao custo de estoque de itens e objetos.

A antecipação da produção de alguns itens pode aumentar custos de estoque de itens $\left(c r_{i t}\right)$ (a rigor, uma penalidade imposta pelo gerente de produção para traduzir a inconveniência de administrar estoques de itens); mas por outro lado, pode permitir uma melhor combinação dos itens, o que faz diminuir a perda de material. Portanto, estas variáveis $r_{i t}$ permitem ao gerente de produção analisar combinações de itens que não seriam consideradas em um modelo estático.

O primeiro conjunto de restrições e as restrições de não-negatividade das variáveis de estoque asseguram que a demanda original seja cumprida. O segundo conjunto de restrições assegura que a quantidade de objetos cortados em cada período não ultrapasse a disponibilidade. Os objetos adquiridos/produzidos em um dado período $t$ não utilizados são somados aos objetos que estarão disponíveis no próximo período, "pagando-se" o custo de estoque $c s_{k t}$. Ao considerarmos os custos de estoque todos nulos, a tendência é de que a produção de itens seja antecipada, que, por sua vez, é limitada pela disponibilidade dos objetos em estoque no período, eliminando a possibilidade de toda a produção ocorrer no primeiro período do horizonte de planejamento.

O modelo (3.1) é de grande porte com $T(m+K)$ restrições e $T K\left(\sum_{k=1}^{K} N_{k}+2 m\right)$ variáveis. Em situações práticas, apresenta centenas de restrições e milhões de variáveis e a matriz de restrições é estruturada e esparsa. A relaxação linear fornece, em geral, uma boa aproximação para este problema e, neste trabalho consideramos o problema de corte multiperíodo com a relaxação linear de (3.1). Embora os parâmetros na função objetivo possam ser genéricos, utilizamos neste trabalho os custos da seguinte forma:

1. O parâmetro custo associado a um padrão de corte é: $c_{j k t}=\gamma\left(L_{k}-\sum_{i=1}^{m} \ell_{i} \alpha_{i j k t}\right)$, ou seja, é a perda do $j$-ésimo padrão de corte para o objeto tipo $k$, no período $t$, multiplicado pelo custo unitário de material perdido, $\gamma$.

2. O parâmetro custo de adiantar a produção de itens de um período para outro é definido por: $c r_{i t}=\alpha \ell_{i}$, em que $\alpha$ é o custo por comprimento de item estocado.

3. O parâmetro custo de estocar objetos de um período para outro é definido por: $c s_{k t}=\beta L_{k}$, em que $\beta$ é o custo por comprimento de item estocado.

\section{Um exemplo ilustrativo (PCEM unidimensional)}

Primeiramente apresentamos um exemplo pequeno de problema de corte de estoque multiperíodo, juntamente com a solução lote-por-lote (estoques de itens nulos, $r_{i t}=0$ ), e a solução multiperíodo, relaxando-se a condição de integralidade. No próximo capítulo é explicado em detalhes o método multiperíodo desenvolvido. 
Poldi, K. C.

Tabela 3.1: Dados dos objetos disponíveis em estoque.

\begin{tabular}{c|c|c|c}
\hline \multicolumn{4}{c}{ Aquisição/produção de objetos } \\
\hline & período 1 & período 2 & período 3 \\
\hline$L_{1}=960$ & $e_{11}=10$ & $e_{12}=12$ & $e_{13}=10$ \\
$L_{2}=570$ & $e_{21}=8$ & $e_{22}=10$ & $e_{23}=10$ \\
\hline
\end{tabular}

Tabela 3.2: Dados dos itens a serem produzidos.

\begin{tabular}{c|c|c|c}
\hline \multicolumn{4}{c}{ Demanda } \\
\hline & período 1 & período 2 & período 3 \\
\hline$\ell_{1}=224$ & $d_{11}=20$ & $d_{12}=29$ & $d_{13}=16$ \\
$\ell_{2}=162$ & $d_{21}=28$ & $d_{22}=36$ & $d_{23}=13$ \\
$\ell_{3}=91$ & $d_{31}=22$ & $d_{32}=29$ & $d_{33}=38$ \\
\hline
\end{tabular}

Suponha que temos $T=3$ períodos de tempo e, para cada um deles, temos $K=2$ tipos de objetos em estoque cujos dados (comprimentos e disponibilidade em estoque) são dados na Tabela 3.1 e $m=3$ tipos de itens a serem produzidos cujos dados (comprimentos e demandas) são dados na Tabela 3.2. Os custos de estocar itens ( $c r)$ e os custos de estocar objetos $(c s)$ foram considerados nulos neste exemplo.

\section{Solução lote-por-lote}

Esta é a solução do problema quando cada período é tratado independentemente, ou seja, a cada período é resolvido um problema de corte de estoque.

Tabela 3.3: Solução lote-por-lote: primeiro período $(t=1)$.

\begin{tabular}{|c|c|c|}
\hline Objeto $k$ & $x_{j k 1}$ & Padrão de corte \\
\hline 1 & 7,54 & $\left(\begin{array}{llll}2 & 2 & 2\end{array}\right)^{T}$ \\
\hline 1 & 1,07 & $\left(\begin{array}{lll}2 & 3 & 0\end{array}\right)^{T}$ \\
\hline 1 & 1,38 & $\left(\begin{array}{lll}0 & 3 & 5\end{array}\right)^{T}$ \\
\hline 2 & 2,77 & $\left(\begin{array}{llll}1 & 2 & 0\end{array}\right)^{T}$ \\
\hline
\end{tabular}


Tabela 3.4: Solução lote-por-lote: segundo período $(t=2)$.

\begin{tabular}{|c|c|c|}
\hline Objeto $k$ & $x_{j k 2}$ & Padrão de corte \\
\hline 1 & 7,77 & $\left(\begin{array}{llll}2 & 2 & 2\end{array}\right)^{T}$ \\
\hline 1 & 3,54 & $\begin{array}{llll}2 & 3 & 0 & )^{T}\end{array}$ \\
\hline 1 & 0,69 & $\begin{array}{llll}0 & 5 & 1 & )^{T}\end{array}$ \\
\hline 2 & 6,38 & $\left(\begin{array}{llll}1 & 1 & 2\end{array}\right)^{T}$ \\
\hline
\end{tabular}

Perda total de material $=192,23$

Tabela 3.5: Solução lote-por-lote: terceiro período $(t=3)$.

\begin{tabular}{|c|c|c|}
\hline Objeto $k$ & $x_{j k 3}$ & Padrão de corte \\
\hline 1 & 1,28 & $\left(\begin{array}{llll}1 & 0 & 8\end{array}\right)^{T}$ \\
\hline 1 & 0,57 & $\left(\begin{array}{lll}3 & 0 & 3\end{array}\right)^{T}$ \\
\hline 2 & 13,0 & $\left(\begin{array}{llll}1 & 1 & 2\end{array}\right)^{T}$ \\
\hline
\end{tabular}

Perda total de material $=44,86$

A perda total de material na solução lote-por-lote é:

$$
160,46+192,23+44,86=\mathbf{3 9 7}, \mathbf{5 5} .
$$

Observe que a solução lote-por-lote é formada pela solução de três problemas estáticos (um por período) e para obtenção de solução inteira são comuns procedimentos heurísticos os quais tomam como base a solução relaxada para cada período. Tais procedimentos podem ser encontrados em Wascher e Gau [65], Belov e Scheithauer [3], Poldi e Arenales [50, 51], entre outros.

\section{Solução multiperíodo}

A seguir, apresentamos a solução do problema (3.1), considerando os dados nas Tabelas 3.1 e 3.2 .

Tabela 3.6: Solução multiperíodo: primeiro período $(t=1)$.

\begin{tabular}{|c|c|c|}
\hline Objeto $k$ & $x_{j k 1}$ & Padrão de corte \\
\hline 1 & 8,2 & $\left(\begin{array}{llll}2 & 2 & 2\end{array}\right)^{T}$ \\
\hline 1 & 1,7 & $\left(\begin{array}{lll}0 & 3 & 5\end{array}\right)^{T}$ \\
\hline 2 & 2,8 & $\left(\begin{array}{llll}1 & 2 & 0\end{array}\right)^{T}$ \\
\hline 2 & 0,8 & $\left(\begin{array}{lll}1 & 1 & 2\end{array}\right)^{T}$ \\
\hline
\end{tabular}


A disponibilidade total de objetos do tipo 1 é utilizada no período 1 . Neste período, também são utilizados 3,6 objetos do tipo 2. Como sua disponibilidade em estoque é de 8 unidades, a sobra de 4, 4 é somada à aquisição/produção de objetos do tipo 2 no período 2. A produção do item tipo 3 foi adiantada em 4,5 unidades.

Tabela 3.7: Solução multiperíodo: segundo período $(t=2)$.

\begin{tabular}{|c|c|c|}
\hline Objeto $k$ & $x_{j k 2}$ & Padrão de corte \\
\hline 1 & 10,7 & $\left(\begin{array}{llll}2 & 2 & 2\end{array}\right)^{T}$ \\
\hline 1 & 1,3 & $\left(\begin{array}{lll}0 & 3 & 5\end{array}\right)^{T}$ \\
\hline 2 & 10,7 & $\left(\begin{array}{lll}1 & 1 & 2\end{array}\right)^{T}$ \\
\hline
\end{tabular}

No segundo período, cuja solução é dada na Tabela 3.7, a disponibilidade do objeto tipo 1 é $e_{12}=12$, pois não houve sobra deste tipo de objeto do período anterior. A disponibilidade em estoque do objeto tipo 2 é $e_{22}=10$ mais o que sobrou do período anterior 4,4 , ou seja, $e_{12}=10+4,4=14$, 4 . A produção de itens do tipo 1 foi adiantada em 3 unidades, a produção de itens do tipo 2 não foi adiantada e a produção do item tipo 3 foi adiantada em 24,8 unidades, do período 3 para o período 2 .

Tabela 3.8: Solução multiperíodo: terceiro período $(t=3)$.

\begin{tabular}{c|c|cc}
\hline Objeto $k$ & $x_{j k 3}$ & \multicolumn{2}{|c}{ Padrão de corte } \\
\hline 1 & 6,5 & $\left(\begin{array}{lll}2 & 2 & 2\end{array}\right)^{T}$ \\
\hline \multicolumn{2}{c}{ Perda total de material $=39$}
\end{tabular}

No período 3, a disponibilidade do objeto tipo 1 não é alterada, pois não houve sobra deste tipo de objeto no período anterior. A disponibilidade em estoque do objeto tipo 2 é alterada (soma-se a quantidade que sobrou no período anterior) para $e_{23}=10+3,7=$ 13,7. A produção de todos os itens demandados é cumprida. As sobras de objetos em estoque são: 3,5 unidades do objeto tipo 1 e 13,7 unidades do objeto tipo 2.

No Capítulo 5, propomos procedimentos para obtenção de soluções inteiras para o problema de corte multiperíodo.

A perda total de material na solução multiperíodo é:

$$
144,7+110,3+39=\mathbf{2 9 4}
$$

Comparando as soluções lote-por-lote e multiperíodo, nota-se a solução multiperíodo foi muito melhor, apresentando perda de material $26 \%$ menor que a solução desacoplada para este exemplo. 


\subsubsection{Bidimensional}

O modelo para o problema de corte de estoque multiperíodo (3.1) apresentado no início também pode ser utilizado para resolver problemas de corte de outras dimensões (bidimensional, tridimensional). A diferença consiste, principalmente, na geração das colunas/padrões de corte, quando surge um problema de corte, que pode ser unidimensional, bidimensional etc. Esses métodos de resolução do problema de corte (subproblema gerador de coluna) são detalhados no Apêndice A. Foram considerados padrões de corte guilhotinados e, para construir tais padrões foi utilizada a abordagem grafo E/OU, descrita no Apêndice A. Vejamos agora um exemplo do problema de corte de estoque multiperíodo bidimensional.

\section{Um exemplo ilustrativo (PCEM bidimensional)}

Apresentamos agora um exemplo de problema de corte de estoque bidimensional. Exibimos a solução lote-por-lote (estoques de itens nulos, $r_{i t}=0$ ), e a solução multiperíodo, relaxando-se a condição de integralidade.

Tabela 3.9: Dados dos objetos disponíveis em estoque.

\begin{tabular}{c|c|c|c}
\hline \multicolumn{4}{c}{ Aquisição/produção de objetos } \\
\hline & período 1 & período 2 & período 3 \\
\hline$L_{1} \times W_{1}=140 \times 120$ & $e_{11}=17$ & $e_{12}=15$ & $e_{13}=15$ \\
$L_{2} \times W_{2}=100 \times 100$ & $e_{21}=30$ & $e_{22}=15$ & $e_{23}=15$ \\
\hline
\end{tabular}

Tabela 3.10: Dados dos itens a serem produzidos.

\begin{tabular}{c|c|c|c}
\hline \multicolumn{4}{c}{ Demanda } \\
\hline & período 1 & período 2 & período 3 \\
\hline$\ell_{1} \times w_{1}=59 \times 51$ & $d_{11}=77$ & $d_{12}=28$ & $d_{13}=50$ \\
$\ell_{2} \times w_{2}=50 \times 48$ & $d_{21}=10$ & $d_{22}=40$ & $d_{23}=27$ \\
$\ell_{3} \times w_{3}=34 \times 28$ & $d_{31}=79$ & $d_{32}=51$ & $d_{33}=34$ \\
\hline
\end{tabular}

Suponha que temos $T=3$ períodos de tempo e, para cada um deles, temos $K=$ 2 tipos de objetos em estoque cujos dados (dimensões: $L_{i} \times W_{i}$ e quantidade adquirida/produzinda de objetos em estoque: $e_{k t}$ ) são na Tabela 3.9 e $m=3$ tipos de itens a serem produzidos cujos dados (dimensões: $\ell_{i} \times w_{i}$ e demandas: $d_{i t}$ ) são dados na Tabela 3.10. Os custos de estocar itens $(c r)$ e os custos de estocar objetos $(c s)$ foram considerados 
nulos neste exemplo. Isto estimula melhores combinações entre os itens para comporem padrões de corte, já que a perda é o único componente da função objetivo.

\section{Solução lote-por-lote}

Esta é a solução do problema quando cada período é tratado independentemente, ou seja, a cada período é resolvido um problema de corte de estoque.

Tabela 3.11: Solução lote-por-lote: primeiro período $(t=1)$.

\begin{tabular}{|c|c|c|}
\hline Objeto $k$ & $x_{j k 1}$ & Padrão de corte \\
\hline 1 & 17,0 & $\left(\begin{array}{llll}4 & 0 & 4\end{array}\right)^{T}$ \\
\hline 2 & 5,0 & $\left(\begin{array}{llll}1 & 2 & 0\end{array}\right)^{T}$ \\
\hline 2 & 2,2 & $\begin{array}{llll}1 & 0 & 5 & )^{T}\end{array}$ \\
\hline 2 & 1,8 & $\left(\begin{array}{llll}1 & 0 & 0 & )^{T}\end{array}\right.$ \\
\hline
\end{tabular}

Perda total de material $=44699,00$

Tabela 3.12: Solução lote-por-lote: segundo período $(t=2)$.

\begin{tabular}{|c|c|c|}
\hline Objeto $k$ & $x_{j k 2}$ & Padrão de corte \\
\hline 1 & 7,000 & $\left(\begin{array}{llll}4 & 0 & 4\end{array}\right)^{T}$ \\
\hline 1 & 1,353 & $\left(\begin{array}{lll}0 & 0 & 17\end{array}\right)^{T}$ \\
\hline 2 & 10,000 & $\left(\begin{array}{llll}0 & 4 & 0\end{array}\right)^{T}$ \\
\hline
\end{tabular}

Perda total de material $=11525,45$

Tabela 3.13: Solução lote-por-lote: terceiro período $(t=3)$.

\begin{tabular}{|c|c|c|}
\hline Objeto $k$ & $x_{j k 3}$ & Padrão de corte \\
\hline 1 & 8,50 & $\begin{array}{llll}4 & 0 & 4 & )^{T}\end{array}$ \\
\hline 1 & 4,00 & $\left(\begin{array}{llll}4 & 0 & 0 & )^{T}\end{array}\right.$ \\
\hline 2 & 6,75 & $\left(\begin{array}{llll}0 & 5 & 0\end{array}\right)^{T}$ \\
\hline
\end{tabular}

Perda total de material $=29882,00$

A perda total de material na solução lote-por-lote é:

$$
44699,00+11525,45+29882,00=\mathbf{8 6 1 0 6 , 4 5} .
$$

A solução lote-por-lote é formada pela solução de três problemas de corte de estoque, um por período, e para obtenção de solução inteira são comuns procedimentos heurísticos, 
os quais tomam como base a solução relaxada para cada período. Tais procedimentos podem ser encontrados em Wascher e Gau [65], Belov e Scheithauer [3], Poldi e Arenales [50, 51], entre outros. Alguns deles são revisados no Apêndice A.

\section{Solução multiperíodo}

A seguir, apresentamos a solução multiperíodo, obtida pela resolução do problema (3.1), com os dados das Tabelas 3.9 e 3.10 .

Tabela 3.14: Solução multiperíodo: primeiro período $(t=1)$.

\begin{tabular}{|c|c|c|}
\hline Objeto $k$ & $x_{j k 1}$ & Padrão de corte \\
\hline 1 & 16,882 & $\left(\begin{array}{lll}4 & 0 & 4\end{array}\right)^{T}$ \\
\hline 1 & 0,118 & $\left(\begin{array}{lll}0 & 0 & 17\end{array}\right)^{T}$ \\
\hline 2 & 14,515 & $\left(\begin{array}{lll}0 & 4 & 0\end{array}\right)^{T}$ \\
\hline 2 & 9,470 & $\left(\begin{array}{lll}1 & 2 & 1\end{array}\right)^{T}$ \\
\hline
\end{tabular}

A disponibilidade total de objetos do tipo 1 é utilizada no período 1 . Neste período, também são utilizados 23, 985 objetos do tipo 2. Como sua disponibilidade em estoque é de 30 unidades, a sobra de 6,015 é somada à aquisição/produção de objetos do tipo 2 no período 2. A produção do item tipo 2 foi adiantada em 67 unidades, isto é, toda a demanda do item tipo 2 para o horizonte de planejamento é produzida no período 1 .

Tabela 3.15: Solução multiperíodo: segundo período $(t=2)$.

\begin{tabular}{|c|c|c|}
\hline Objeto $k$ & $x_{j k 2}$ & Padrão de corte \\
\hline 1 & 14,588 & $\left(\begin{array}{llll}4 & 0 & 4\end{array}\right)^{T}$ \\
\hline 1 & 0,412 & $\left(\begin{array}{lll}0 & 0 & 17\end{array}\right)^{T}$ \\
\hline
\end{tabular}

No segundo período, cuja solução é dada na Tabela 3.15, a disponibilidade do objeto tipo 1 é $e_{12}=15$, pois não houve sobra deste tipo de objeto do período anterior. A disponibilidade em estoque do objeto tipo 2 é $e_{22}=15$ mais o que sobrou do período anterior 6,015 , ou seja, $e_{12}=15+6,015=21,015$. A produção de itens do tipo 1 foi adiantada em 30,353 unidades. Não houve produção de itens do tipo 2 pois já fora totalmente adiantada para o período 1 , e a produção do item tipo 3 foi adiantada em 14, 353 unidades, do período 3 para o período 2. 
Tabela 3.16: Solução multiperíodo: terceiro período $(t=3)$.

\begin{tabular}{c|c|ccc}
\hline Objeto $k$ & $x_{j k 3}$ & \multicolumn{3}{|c}{ Padrão de corte } \\
\hline 1 & 4,9118 & $\left(\begin{array}{llll}4 & 0 & 4\end{array}\right)^{T}$ \\
\hline \multicolumn{2}{c}{ Perda total de material $=4695,68$}
\end{tabular}

No período 3, a disponibilidade do objeto tipo 1 não é alterada, pois não houve sobra deste tipo de objeto no período anterior. A disponibilidade em estoque do objeto tipo 2 é alterada (soma-se a quantidade que sobrou no período anterior) para $e_{23}=15+21,015=$ 36,015. A produção de todos os itens demandados é cumprida. As sobras de objetos em estoque são: 10,088 unidades do objeto tipo 1 e 30,015 unidades do objeto tipo 2.

A perda total de material na solução multiperíodo é:

$$
33751,22+14200,00+4695,68=\mathbf{5 2 6 4 6 , 9 0 .}
$$

Comparando as soluções lote-por-lote e multiperíodo, nota-se que a solução multiperíodo foi muito melhor, apresentando perda de material $38 \%$ menor que a solução desacoplada para este exemplo. Este exemplo simples mostra como o problema de corte de estoque multiperíodo permite a análise de combinações convenientes de itens, aparentemente imperceptíveis, e torna-se uma ferramenta de apoio à decisão de grande utilidade.

Além disso, a antecipação de itens sugerida pelo modelo multiperíodo pode não ser feita na prática, ou seja, corta-se apenas os itens necessários para atender a demanda do período atual e estoca-se os "pedaços" de objetos que sobraram para serem cortados quando for conveniente.

As soluções, tanto para o período 1 como para o período 2 apresentaram padrões de corte (a saber: $\left.\left(\begin{array}{lll}0 & 0 & 17\end{array}\right)^{T}\right)$ com alto número de um tipo de item, neste caso o item tipo 3 . Isto tende a fazer com que as freqüências associadas sejam pequenas (no primeiro período foi $x_{211}=0,118$ e no segundo período $x_{212}=0,412$ ), tornando o "arredondamento" da solução, para se obter uma solução inteira, mais difícil. Para contornar esta dificuldade, Haessler [24] sugere que os padrões de corte tenham as quantidades de itens limitadas a $10 \%$ da demanda.

Com técnicas de arredondamento mais elaboradas, tais padrões de corte são excluídos "naturalmente". Por exemplo, se $x_{111}=16,882$ for arredondado pra $x_{111}=17$, então a produção do item do tipo 3 será: $17 \times 4=68$ e o padrão $\left(\begin{array}{lll}0 & 0 & 17\end{array}\right)^{T}$ deve ser arredondado para zero. Uma demanda residual de itens do tipo 3 limita "naturalmente" a construção de novos padrões de corte (Veja procedimentos de arredondamento no Apêndice A e em Poldi [49]). 


\subsection{Problema de corte de estoque multiperíodo restrito}

O problema de corte de estoque multiperíodo pode apresentar restrições adicionais. Talvez a mais freqüente seja a restrição de capacidade de máquina. Assim, incluímos no modelo restrições de capacidade. Considere novamente os seguintes índices, parâmetros e variáveis de decisão.

\section{Índices:}

$t=1, \ldots, T:$ número de períodos no horizonte de planejamento;

$k=1, \ldots, K:$ número de tipos (comprimentos) de objetos disponíveis em estoque;

$j=1, \ldots, N_{k}:$ número de padrões de corte para o objeto tipo $k, k=1, \ldots, K$;

$i=1, \ldots, m:$ número de tipos de itens a serem cortados.

\section{Dados:}

$L_{k}:$ comprimento do objeto tipo $k, k=1, \ldots, K$;

$e_{k t}$ : quantidade adquirida/produzida de objetos tipo $k$ no período $t, k=1, \ldots, K, t=$ $1, \ldots, T$ (e $\mathbf{e}_{t}$ : vetor de dimensão $K$ cujas componentes são $\left.e_{k t}\right)$;

$\ell_{i}$ : comprimento do item tipo $i, i=1, \ldots, m$;

$d_{i t}$ : demanda o item tipo $i$ no período $t, i=1, \ldots, m, t=1, \ldots, T\left(\mathbf{d}_{t}\right.$ : vetor de dimensão $m$ cujas componentes são $d_{i t}$ );

$\alpha_{i j k t}$ : número de itens do tipo $i$ no $j$-ésimo padrão de corte para o objeto tipo $k$, no período $t$ ( $\mathbf{a}_{j k t}$ : vetor de dimensão $m$ cujas componentes são $\left.\alpha_{i j k t}\right)$;

$b_{j k t}$ : recurso necessário (tempo de corte) para cortar o padrão de corte $j$ associado ao objeto tipo $k$, no período $t, j=1, \ldots, N_{k}, k=1, \ldots, K, t=1, \ldots, T$;

$C a p_{t}$ : capacidade de corte disponível no período $t$.

\section{Parâmetros:}

$c_{j k t}$ : custo de cortar o objeto tipo $k$ segundo o $j$-ésimo padrão de corte do período $t, j=1, \ldots, N_{k}, k=1, \ldots, K, t=1, \ldots, T$;

$c r_{i t}$ : custo de estocar o item tipo $i$ no final período $t, i=1, \ldots, m, t=1, \ldots, T$;

$c s_{k t}$ : custo de estocar o objeto tipo $k$ no final período $t, k=1, \ldots, K, t=1, \ldots, T$.

\section{Variáveis de decisão:}

$x_{j k t}$ : número de objetos tipo $k$ cortados conforme o padrão de corte $j$, no período $t$ 
$r_{i t}$ : número itens do tipo $i$ que são antecipados para o período $t\left(\mathbf{r}_{t}\right.$ : vetor de dimensão $m$ cujas componentes são $r_{i t}$ );

$s_{k t}$ : número de objetos do tipo $k$ que sobram no final do período $t$.

\section{Modelo matemático:}

$$
\begin{aligned}
\operatorname{minimizar} & \sum_{t=1}^{T}\left(\sum_{j=1}^{N_{1}} c_{j 1 t} x_{j 1 t}+\sum_{j=1}^{N_{2}} c_{j 2 t} x_{j 2 t}+\ldots+\sum_{j=1}^{N_{K}} c_{j K t} x_{j K t}+\sum_{i=1}^{m} c r_{i t} r_{i t}+\sum_{k=1}^{K} c s_{k t} s_{k t}\right) \\
\text { sujeito a: } & \sum_{j=1}^{N_{1}} \mathbf{a}_{j 1 t} x_{j 1 t}+\sum_{j=1}^{N_{2}} \mathbf{a}_{j 2 t} x_{j 2 t}+\ldots+\sum_{j=1}^{N_{K}} \mathbf{a}_{j K t} x_{j K t}+\mathbf{r}_{\mathbf{t}-\mathbf{1}}-\mathbf{r}_{\mathbf{t}}=\mathbf{d}_{t}, t=1, \ldots, T \\
& \sum_{j=1}^{N_{k}} x_{j k t}-\mathbf{s}_{k,(t-1)}+\mathbf{s}_{k t}=e_{k t}, k=1, \ldots, K, t=1, \ldots, T \\
& \sum_{k=1}^{K} \sum_{j=1}^{N_{K}} b_{j k t} x_{j k t} \leq C a p_{t}, t=1, \ldots, T \\
& x_{j k t} \geq 0, \text { inteiros }, r_{i t} \geq 0, s_{k t} \geq 0, j=1, \ldots, N_{k}, k=1, \ldots, K, t=1, \ldots, T .
\end{aligned}
$$

A função no problema (3.2), a ser minimizada, consiste no custo total devido às perdas de material de todos os objetos, em todos os períodos e ao custo de estoque de itens e objetos.

O primeiro conjunto de restrições e as restrições de não-negatividade das variáveis de estoque asseguram que a demanda original seja cumprida. O segundo conjunto de restrições e a não-negatividade das variáveis de estoque asseguram que as quantidades de objetos cortados em cada período não ultrapassem as disponibilidades. Os objetos disponíveis em um dado período $t$ não utilizados são somados aos objetos que estarão disponíveis no próximo período, "pagando-se" o custo de estoque $c s_{k t}$. O terceiro conjunto de restrições garante que a capacidade de corte em cada período não seja ultrapassada.

O modelo (3.2) é resolvido de forma análoga ao problema de corte de estoque multiperíodo sem limitação de capacidade. O método de solução é detalhado no próximo capítulo. O modelo para o problema de corte de estoque multiperíodo restrito (3.2), da mesma forma que o modelo irrestrito, é utilizado para problemas unidimensionais e bidimensionais; como já foi dito no capítulo anterior, devemos mudar o gerador de colunas, ou seja, geramos padrões de corte unidimensional ou bidimensional.

Testes computacionais para o problema de corte de estoque multiperíodo com limitação de capacidade são apresentados no Capítulo 6.

No próximo capítulo apresentamos o método de solução utilizado para resolver problemas de corte de estoque multiperíodo. 


\section{Capítulo 4}

\section{Método de solução para o problema multiperíodo}

Alguns métodos clássicos da literatura, referenciados neste capítulo, são descritos no Apêndice A. Tais métodos serviram como base para o desenvolvimento do método proposto para resolução do problema de corte de estoque multiperído. Neste capítulo, estão alguns detalhes da implementação do método para resolução do problema multiperíodo.

\subsection{Matriz básica inicial}

A base inicial adotada consiste de padrões de corte homogêneos para o objeto maior e a solução lote-por-lote (estoques de itens nulos, $r_{i t}=0$ ). Assim, além das colunas associadas aos padrões de corte homogêneos, a base é completada com as colunas associadas aos estoques dos objetos (variáveis $s_{k t}$ ), as quais são facilmente construídas. Os padrões de corte homogêneos são dados por:

$$
b_{i i}=\min \left\{\left\lfloor\frac{L}{\ell_{i}}\right\rfloor, d_{i}\right\} \quad b_{i j}=0, i=1, \ldots, m, j=1, \ldots, m, i \neq j,
$$

em que $\lfloor x\rfloor$ é o maior inteiro menor ou igual a $x$; e, $L=\max \left\{L_{k}, k=1, \ldots, K\right\}$. No exemplo considerado no Capítulo $3, L=L_{1}=960$. Para evitar infactibilidades triviais, supomos que $\max _{k}\left\{L_{k}\right\} \geq \min _{i}\left\{\ell_{i}\right\}$. Entretanto, pode-se ter exemplares com $\min _{k}\left\{L_{k}\right\}<$ $\max _{i}\left\{\ell_{i}\right\}$ e a escolha acima garante padrões de corte factíveis. A matriz básica é denotada por B. 
Poldi, K. C.

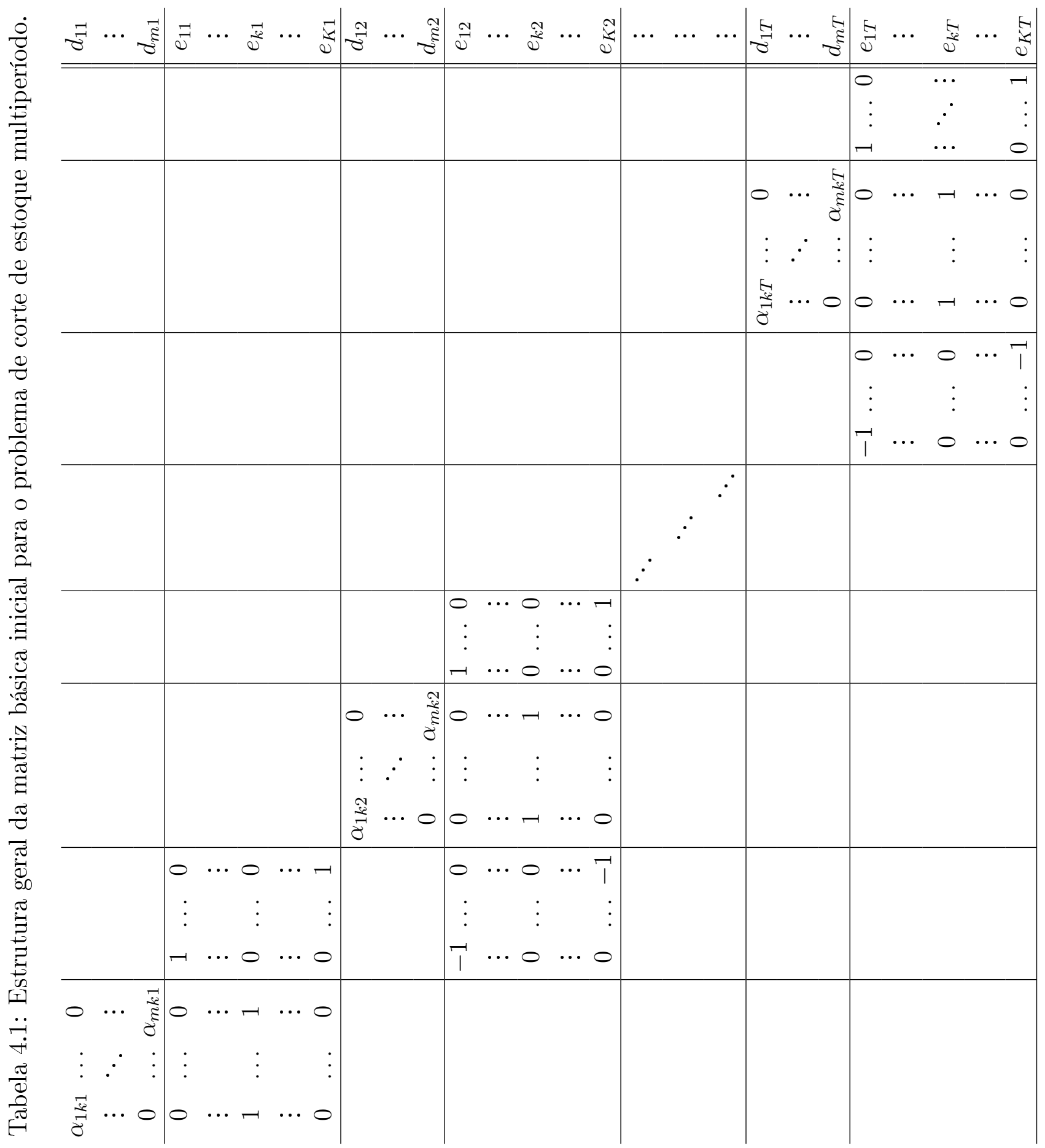


A dimensão das matrizes básicas é $T(m+K) \times T(m+K)$, em que $T$ é o número de períodos, $m$ é o número de itens e $K$ é o número de tipos de objetos em estoque. A matriz básica inicial e o termo independente têm a estrutura dada na Tabela 4.1, em que:

- cada coluna da matriz básica tem $T(m+K)$ elementos, agrupados em $T$ blocos de $m+K$ elementos;

- a coluna da variável $x_{j k t}$, tem apenas o bloco $t$ não nulo, o qual é formado pelos $m$ elementos do vetor associado ao $j$-ésimo padrão de corte para o objeto tipo $k$ no período $t$, seguido de zeros para os demais elementos, exceto na posição $k$ com 1. Por exemplo, a primeira coluna da matriz, correspondente à variável $x_{121}$, tem $\mathrm{o}$ primeiro $(t=1)$ bloco não nulo de $m+k$ elementos;

- a coluna da variável $s_{k t}$ (considerando que haja sobra de objetos do tipo $k$ no período t) tem 2 blocos não nulos: bloco $t$ e $t+1$, com o elemento +1 na posição $m+k$ do bloco $t$ e -1 na posição $m+k$ do bloco $t+1$. Caso a sobra de objetos seja negativa $\left(s_{k t}<0\right)$, isto é, a disponibilidade de objetos do tipo $k$ foi excedida no período $t$, então consideramos uma variável artificial $s_{k t}^{a}=-s_{k t}$ com custo M-grande, de modo que não pertença a uma solução ótima, a menos que o problema seja infactível.

Além disso, utilizamos dois vetores auxiliares para facilitar a identificação de cada coluna. Cada um desses vetores tem $T(m+K)$ componentes, um para cada coluna. Um deles é o identificador de períodos, que tem cada componente igual ao número correspondente ao período ao qual aquela coluna corresponde. O outro vetor, chamado de vetor id, identifica cada coluna da matriz da seguinte forma. Seja id $[i]=j, i=1, \ldots, T(m+K)$.

- Se $j=0$, a $i$-ésima coluna da matriz corresponde a uma variável artificial.

- Se $j>0$, a $i$-ésima coluna da matriz corresponde a um padrão de corte para o objeto em estoque do tipo $j$.

- Se $-K \leq j<-1$, a $i$-ésima coluna da matriz corresponde à variável sobra de objetos do tipo $-j$ para o próximo período.

- Se $-(K+m) \leq j<-K$, a $i$-ésima coluna da matriz corresponde à variável antecipação da produção do tipo $-(K+j)$.

A solução básica inicial $\mathbf{B} \mathbf{x}_{\mathbf{B}}=\mathbf{d}$ é calculada facilmente por substituição de variáveis.

\subsection{Cálculo do vetor multiplicador simplex: $\pi$}

O vetor dos custos básicos é dado como segue:

(a) para as variáveis básicas associadas aos padrões de corte id $[i]>0$, o coeficiente é a perda no padrão multiplicada por $\gamma$; 
(b) para as variáveis básicas associadas à sobra de objetos $-K \leq \mathrm{id}[i]<-1$, o coeficiente é o custo de estocar objetos;

(c) para as variáveis artificiais id $[i]=0$, o coeficiente é $M$ (número grande).

Agora, com o vetor dos custos básicos definido, basta calcular o vetor multiplicador simplex $\pi, \mathbf{B}^{T} \pi=\mathbf{c}$.

\subsection{Cálculo dos custos relativos}

Temos quatro tipos de variáveis não básicas:

1. $r_{i t}$ (estoque de itens). O custo relativo é dado por: $c r_{i t}+\pi_{i t}-\pi_{i, t+1}$;

2. $s_{k t}$ (estoque de objetos). O custo relativo é dado por: $c s_{k t}-\pi_{m+k, t}+\pi_{m+k, t+1}$;

3. $s_{k T}$ (folga do objeto tipo $k$ no último período $T$. Difere do tipo 2 , pois o bloco $T+1$ não existe). O custo relativo é dado por: $c s_{k T}-\pi_{m+k, T}$;

4. $x_{j k t}$ (padrão de corte). O custo relativo é dado por: $c_{j k t}=\sum_{i=1}^{m} \alpha_{i j k t} \pi_{i, t}-\pi_{m+k, t}$.

$\mathrm{Na}$ implementação calculamos inicialmente os custos relativos dos três primeiros tipos, pois são bem simples e escolhemos o menor deles para entrar na base. Caso seja não-negativo, então calculamos os custos relativos referentes aos padrões de corte (quarto tipo), para todos os objetos disponíveis em estoque e para todos os períodos do horizonte de planejamento. Este cálculo envolve a resolução de $T K$ problemas da mochila e consiste na fase mais árdua da geração de colunas. Para amenizar, adaptamos o algoritmo de programação dinâmica de Yanasse e Soma [27] (seção A.2.1) e resolvemos o problema da mochila para o maior objeto disponível em estoque e resgatamos dele as soluções intermediárias para os problemas com objetos menores. Isso faz com que sejam resolvidos $T$ problemas da mochila, ao invés de $T K$, a cada iteração do método simplex.

A partir daqui os passos do método simplex com geração de colunas não sofrem alterações; calcula-se a direção simplex, escolhe-se a variável a sair da base e faz-se as atualizações das variáveis. Vejamos um exemplo na próxima seção.

\subsection{Exemplo}

Consideremos o exemplo de problema de corte de estoque unidimensional multiperíodo apresentado no Capítulo 3, novamente descrito nas Tabelas 4.2 e 4.3 a seguir.

Fazemos uma iteração do método proposto para a solução do problema. 
Tabela 4.2: Dados dos objetos disponíveis em estoque.

\begin{tabular}{c|c|c|c}
\hline \multicolumn{4}{c}{ Aquisição/produção de objetos } \\
\hline & período 1 & período 2 & período 3 \\
\hline$L_{1}=960$ & $e_{11}=10$ & $e_{12}=12$ & $e_{13}=10$ \\
$L_{2}=570$ & $e_{21}=8$ & $e_{22}=10$ & $e_{23}=10$ \\
\hline
\end{tabular}

Tabela 4.3: Dados dos itens a serem produzidos.

\begin{tabular}{c|c|c|c}
\hline \multicolumn{4}{c}{ Demanda } \\
\hline & período 1 & período 2 & período 3 \\
\hline$\ell_{1}=224$ & $d_{11}=20$ & $d_{12}=29$ & $d_{13}=16$ \\
$\ell_{2}=162$ & $d_{21}=28$ & $d_{22}=36$ & $d_{23}=13$ \\
$\ell_{3}=91$ & $d_{31}=22$ & $d_{32}=29$ & $d_{33}=38$ \\
\hline
\end{tabular}

- Determine a matriz básica inicial B, composta por padrões de corte homogêneos (ou seja, padrões com apenas um tipo de item). A matriz básica inicial está representada a seguir, lembrando que a última coluna refere-se ao termo independente.

\begin{tabular}{|c|c|c|c|c|c|c|c|c|c|c|c|c|c|c|c|}
\hline $\begin{array}{c}x_{121} \\
\downarrow\end{array}$ & $\begin{array}{c}x_{221} \\
\downarrow\end{array}$ & $\begin{array}{c}x_{321} \\
\downarrow\end{array}$ & $\begin{array}{c}s_{11}^{a} \\
\downarrow\end{array}$ & $\begin{array}{c}s_{21} \\
\downarrow\end{array}$ & $\begin{array}{c}x_{122} \\
\downarrow\end{array}$ & $\begin{array}{c}x_{222} \\
\downarrow\end{array}$ & $\begin{array}{c}x_{322} \\
\downarrow\end{array}$ & $\begin{array}{c}s_{12}^{a} \\
\downarrow\end{array}$ & $\begin{array}{c}s_{22} \\
\downarrow\end{array}$ & $\begin{array}{c}x_{123} \\
\downarrow\end{array}$ & $\begin{array}{c}x_{223} \\
\downarrow\end{array}$ & $\begin{array}{c}x_{323} \\
\downarrow\end{array}$ & $\begin{array}{c}s_{13}^{a} \\
\downarrow\end{array}$ & $\begin{array}{c}s_{21}^{a} \\
\downarrow\end{array}$ & $\left(\begin{array}{c}(\mathbf{d}, \mathbf{e}) \\
\downarrow\end{array}\right.$ \\
\hline 4 & 0 & 0 & & & & & & & & & & & & & 20 \\
\hline 0 & 5 & 0 & & & & & & & & & & & & & 28 \\
\hline 0 & 0 & 10 & & & & & & & & & & & & & 22 \\
\hline 1 & 1 & 1 & -1 & 0 & & & & & & & & & & & 10 \\
\hline 0 & 0 & 0 & 0 & 1 & & & & & & & & & & & 8 \\
\hline & & & & & 4 & 0 & 0 & & & & & & & & 29 \\
\hline & & & & & 0 & 5 & 0 & & & & & & & & 36 \\
\hline & & & & & 0 & 0 & 10 & & & & & & & & 29 \\
\hline & & & +1 & 0 & 1 & 1 & 1 & -1 & 0 & & & & & & 12 \\
\hline & & & 0 & -1 & 0 & 0 & 0 & 0 & 1 & & & & & & 10 \\
\hline & & & & & & & & & & 4 & 0 & 0 & & & 16 \\
\hline & & & & & & & & & & 0 & 5 & 0 & & & 13 \\
\hline & & & & & & & & & & 0 & 0 & 10 & & & 38 \\
\hline & & & & & & & & +1 & 0 & 1 & 1 & 1 & 1 & 0 & 10 \\
\hline & & & & & & & & 0 & -1 & 0 & 0 & 0 & 0 & 1 & 10 \\
\hline
\end{tabular}


- Faça: $\quad$ PARE $=$ Falso e IT $=1 .\{$ A variável lógica PARE terá valor Falso até que a condição de otimalidade seja verificada e IT é o número da iteração atual. \}

Enquanto PARE $=$ Falso, faça:

\{ Início da iteração Simplex \}

- Determine a solução básica corrente: $\mathbf{B x}_{\mathbf{B}}=\mathbf{d}$.

Para a solução inicial, as variáveis $x_{j k t}$ são determinadas diretamente (por exemplo, $x_{121}=20 / 4=5$ ), bem como as folgas dos objetos que não são utilizados (por exemplo, $\left.s_{21}=8\right)$. As folgas do objeto maior, para cada período, são conseqüentemente calculadas (por exemplo, $s_{11}=10-x_{111}-x_{211}-x_{311}+s_{10}=-2,8$ ). Como a variável de folga $s_{11}$ tem valor negativo (i.e., a solução lote-por-lote com os padrões homogêneos é infactível), usamos a variável artificial $s_{11}^{a}$ (isto corresponde a transportar objetos do período $t+1$ para o período $t$ ). Desta forma temos uma base factível. Neste exemplo, foram necessárias variáveis artificiais em todos os períodos (colunas 4, 9 e 14), pois as quantidades utilizadas de objetos tipo 1 ultrapassam as suas disponibilidades em cada período. $\mathrm{O}$ vetor $\mathbf{x}_{\mathrm{B}}$ com a solução básica inicial é o seguinte:

$$
\mathbf{x}_{\mathbf{B}}=\left[\begin{array}{lllllllllllllll}
5 & 5,6 & 2,2 & 2,8 & 8 & 7,25 & 7,2 & 2,9 & 8,15 & 18 & 4 & 2,6 & 3,8 & 8,55 & 20
\end{array}\right]^{T}
$$

- Determine a solução dual (vetor multiplicador simplex): $\mathbf{B}^{T} \pi=\mathbf{c}_{\mathbf{B}}$.

O vetor com os custos básicos correspondente é dado por:

$$
\mathbf{c}_{\mathbf{B}}=\left[\begin{array}{lllllllllllllll}
64 & 150 & 50 & M & 0 & 64 & 150 & 50 & M & 0 & 64 & 150 & 50 & M & 0
\end{array}\right]^{T}
$$

Os custos das variáveis que representam padrões de corte são dados pelas perda no padrão. Os custos das variáveis de folga de objetos do tipo 2, que não foram utilizados é zero e os custos das variáveis artificiais é um número grande: M-grande, que consideramos 10000, então, temos o seguinte vetor de custos básicos:

$$
\mathbf{c}_{\mathbf{B}}=\left[\begin{array}{lllllllllllllll}
64 & 150 & 50 & 10000 & 0 & 64 & 150 & 50 & 10000 & 0 & 64 & 150 & 50 & 10000 & 0
\end{array}\right]^{T}
$$

Efetuando $\mathbf{B}^{T} \pi=\mathbf{c}_{\mathbf{B}}$, temos o seguinte vetor multiplicador simplex:

$\pi=[7516 ; 6030 ; 3005 ;-30000 ; 0 ; 5016 ; 4030 ; 2005 ;-20000 ; 0 ; 2516 ; 2030 ; 1005 ;-10000 ; 0]^{T}$ 
- Calcular os custos relativos: \{ gera uma coluna para entrar na base: a, com custo: $\left.\hat{c}_{a}\right\}$

Caso unidimensional: algoritmo de Yanasse e Soma [67] adaptado é aplicado.

Caso bidimensional: a abordagem em grafo E/OU é aplicada.

Porém, antes de entrar com um padrão de corte, verificamos se é possível a entrada de alguma outra variável, que podem ser: adiantar itens, folga de objetos em estoque. Como estas colunas são formadas apenas de zeros e uns, o custo computacional em calculá-las é muito menor que gerar um padrão de corte. Por isso, a cada iteração, primeiro testamos a possibilidade da entrada de variáveis de folga ou transferência de itens. Neste exemplo, na primeira iteração, todos estes custos relativos são valores maiores ou iguais a zero, então partimos para a resolução do problema da mochila, que determina a melhor coluna (padrão de corte) a entrar na base.

A solução do problema da mochila é o padrão de corte $a=(1,2,0)^{T}$, para o objeto do tipo 2, para o primeiro período, com custo básico (perda) igual a 22 e custo relativo $\hat{c}_{a}=-19554$. Assim, a coluna a entrar na base é a seguinte:

$$
\left[\begin{array}{llllllllllllllllll}
1 & 2 & 0 & 0 & 1 & \mid & 0 & 0 & 0 & 0 & 0 & \mid & 0 & 0 & 0 & 0 & 0 & ]^{T}
\end{array}\right.
$$

- Teste de otimalidade: Se $\hat{c}_{a} \geq 0$ então a solução é ótima. Pare = verdadeiro.

Porém $\hat{c}_{a}=-19554$ não satisfaz a condição de otimalidade, então:

- Determinamos a direção simplex.

- Determinamos o tamanho do passo: 4,30769 e a coluna a sair da base: $r=4$.

- Atualização: Atualizamos a base, substituindo a $k$-ésima coluna da matriz B por a, reavaliamos:

* o valor da solução básica: $\mathbf{x}_{\mathbf{B}}$;

* os custos básicos: $\mathbf{c}_{\mathrm{B}}$;

* o valor do multiplicador simplex: $\pi$

$* \mathrm{IT}=\mathrm{IT}+1$

e a iteração é repetida.

Esse é um método eficiente para determinar uma solução ótima para a relaxação linear do problema de corte de estoque multiperíodo. Porém, na prática, é necessário termos soluções inteiras para o problema, pois estas, é que são, de fato, implementadas. No próximo capítulo descrevemos duas abordagens propostas para o arredondamento da solução contínua. 
Poldi, K. C. 


\section{Capítulo 5}

\section{Abordagens de Arredondamento}

As estratégias de arredondamento desenvolvidas para o problema de corte de estoque multiperíodo são baseadas nos procedimentos heurísticos desenvolvidos para o problema de corte de estoque com um período. Um breve resumo destes procedimentos pode ser encontrado no Apêndice A, seção A.4.2, e o detalhamento pode ser encontrado em Poldi [49] e Poldi e Arenales [50, 51].

Como tratamos de um problema com vários períodos no horizonte de planejamento, as técnicas apresentadas neste capítulo são de horizonte rolante, ou seja, obtemos uma solução inteira para o primeiro período do horizonte e deixamos a solução fracionária para os próximos períodos.

Em uma segunda etapa, após o primeiro período já ter sido implementado, novos pedidos podem ser incluídos, ou pedidos podem ser cancelados. Assim, a carteira de pedidos é atualizada e temos um novo problema de corte multiperíodo, que por sua vez será resolvido e terá apenas a solução do seu primeiro período arredondada, ficando a solução dos próximos períodos fracionárias, porém úteis para auxiliar o gerente de produção na tomada de decisões.

Duas abordagens de arredondamento foram propostas, ambas seguem a mesma estrutura geral, descrita no algoritmo a seguir. Elas diferem apenas no passo 2. Assim, o passo 2 será especificado separadamente para cada abordagem, um na seção 5.1 e outro na seção 5.2 .

\section{Algoritmo: arredondamento multiperíodo}

\section{Passo 1:}

Resolva o problema de corte de estoque multiperíodo relaxado e considere: 
$\mathbf{A}^{\mathbf{1}}$ : matriz com os padrões de corte do primeiro período;

$\mathrm{x}^{\mathbf{1}}$ : vetor das freqüências dos padrões de corte do primeiro período;

$\mathbf{d}^{\mathbf{1}}$ : vetor com a demanda original do primeiro período;

$\mathbf{e}^{\mathbf{1}}$ : vetor com a disponibilidade dos objetos em estoque no primeiro período;

$\mathbf{r}^{\mathbf{1}}$ : vetor com a antecipação de itens para o primeiro período;

$\mathbf{d}^{2}$ : vetor com a soma das demandas dos períodos 2 a $\mathrm{T}$;

$\mathbf{e}^{\mathbf{e}}$ : vetor com a soma das disponibilidades dos objetos em estoque nos períodos 2

a T;

$n$ : o número de padrões de corte no primeiro período.

Arredonde todas as componentes do vetor de antecipação de itens $\mathbf{r}^{\mathbf{1}}$ para baixo;

Faça: $\mathbf{d r}=\mathbf{d}^{\mathbf{1}}+\mathbf{r}^{\mathbf{1}}$, ou seja, armazene no vetor $\mathbf{d r}$ a demanda original do período 1 mais a quantidade de antecipação, para cada item.

\section{Passo 2:}

Arredonde o vetor das freqüências: $\mathbf{x}^{\mathbf{1}}$ (ver Seções 5.1e 5.2).

\section{Passo 3:}

Atualize a demanda/produção de itens: $\mathbf{d r}$

Atualize a disponibilidade dos objetos em estoque: $\mathbf{e}^{\mathbf{1}}$

Se $\mathbf{A}^{\mathbf{1}} \mathbf{X}^{\mathbf{1}} \geq \mathbf{d}^{\mathbf{1}} \quad$ (ou seja, se atendeu a demanda original)

\section{então PARE.}

\section{Passo 4:}

Resolva um problema da mochila restrito à dr para cada tipo de objeto $k$ disponível em estoque.

Escolha o padrão de corte que apresentar a menor perda, dada por: $\varphi$

Seja $\ell_{\min }=\min \left\{\ell_{1}, \ell_{2}, \ldots, \ell_{m}\right\}$, ou seja, o menor item demandado.

$\operatorname{Se} \varphi \geq \ell_{\min } \quad$ (ou seja, ainda cabem itens no padrão de corte)

então resolva uma mochila irrestrita de tamanho $\varphi$ e complete o padrão.

Utilize o padrão de corte construído o número máximo possível de vezes.

Volte ao passo 3 .

\section{Fim-do-algoritmo}




\subsection{Abordagem A}

Na Abordagem A, o passo 2 é definido da seguinte forma.

Passo 2: $\quad$ arredondamento do vetor das freqüências: $\mathbf{x}^{\mathbf{1}}$ \}

Seja $n$ o número de padrões de corte no período 1.

$$
\text { Para } j=1, \ldots, n \text {, faça: } \quad x_{j k_{j}}^{1}=\left\lfloor x_{j k_{j}}^{1}\right\rfloor
$$

$\underline{\text { Fim-Passo } 2}$

Na seção seguinte, apresentamos um exemplo de aplicação da Abordagem A em um problema de corte de estoque multiperíodo. Porém antes, presentamos um exemplo ilustrativo.

\subsubsection{Exemplo}

Para exemplificar a Abordagem A, consideremos novamente o exemplo de problema de corte de estoque multiperíodo apresentado no Capítulo 3, que é descrito novamente nas Tabelas 5.1 e 5.2 a seguir.

Tabela 5.1: Dados dos objetos disponíveis em estoque.

\begin{tabular}{c|c|c|c}
\hline \multicolumn{4}{c}{ Aquisição/produção de objetos } \\
\hline & período 1 & período 2 & período 3 \\
\hline$L_{1}=960$ & $e_{11}=10$ & $e_{12}=12$ & $e_{13}=10$ \\
$L_{2}=570$ & $e_{21}=8$ & $e_{22}=10$ & $e_{23}=10$ \\
\hline
\end{tabular}

Tabela 5.2: Dados dos itens a serem produzidos.

\begin{tabular}{c|c|c|c}
\hline \multicolumn{4}{c}{ Demanda } \\
\hline & período 1 & período 2 & período 3 \\
\hline$\ell_{1}=224$ & $d_{11}=20$ & $d_{12}=29$ & $d_{13}=16$ \\
$\ell_{2}=162$ & $d_{21}=28$ & $d_{22}=36$ & $d_{23}=13$ \\
$\ell_{3}=91$ & $d_{31}=22$ & $d_{32}=29$ & $d_{33}=38$ \\
\hline
\end{tabular}

Passo 1: Resolver o problema de corte de estoque multiperído. Esta solução já foi apresentada no Capítulo 3, e é apresentada novamente na Tabela 5.3 a seguir. 
Tabela 5.3: Solução multiperíodo: primeiro período $(t=1)$.

\begin{tabular}{|c|c|c|c|}
\hline Objeto $k$ & $x_{j k 1}$ & Padrão de corte & Perda no padrão \\
\hline 1 & 8,2 & $\left(\begin{array}{llll}2 & 2 & 2\end{array}\right)^{T}$ & 6 \\
\hline 1 & 1,7 & $\left(\begin{array}{lll}0 & 3 & 5\end{array}\right)^{T}$ & 19 \\
\hline 2 & 2,8 & $\left(\begin{array}{lll}1 & 2 & 0\end{array}\right)^{T}$ & 22 \\
\hline 2 & 0,8 & $\left(\begin{array}{lll}1 & 1 & 2\end{array}\right)^{T}$ & 2 \\
\hline
\end{tabular}

Perda total de material $=144,7$

Da solução da Tabela 5.3, vemos que a demanda sugerida para o primeiro período pela solução do multiperíodo é $\left(\begin{array}{lll}20 & 28 & 26,5\end{array}\right)^{T}$. Ao olharmos a Tabela 5.2, vemos que a demanda original do período 1 é $\mathbf{d}^{\mathbf{1}}=\left(\begin{array}{lll}20 & 28 & 22\end{array}\right)^{T}$, ou seja, o vetor de antecipação de itens é dado por: $\mathbf{r}^{\mathbf{1}}=\left(\begin{array}{lll}0 & 0 & 4,5\end{array}\right)^{T}$. As componentes deste vetor são arrendondadas para o maior inteiro menor o valor, ou seja, os valores são truncados. Assim, temos o vetor de atencipação de itens $\mathbf{r}^{\mathbf{1}}=\left(\begin{array}{lll}0 & 0 & 4\end{array}\right)^{T}$, e a nova demanda para o período 1 é $\mathbf{d r}=\left(\begin{array}{lll}20 & 28 & 26\end{array}\right)^{T}$.

Passo 2: Arredondar as freqüências do primeiro período. Nesta abordagem, todas as freqüências são arredondadas para baixo. Ou seja, a partir da solução dada na Tabela 5.3 , temos a solução inteira parcial dada na Tabela 5.4 a seguir.

Tabela 5.4: Primeira aproximação para a solução inteira - Abordagem A.

\begin{tabular}{|c|c|c|c|}
\hline Objeto $k$ & $x_{j k 1}$ & Padrão de corte & Perda no padrão \\
\hline 1 & 8 & $\begin{array}{llll}2 & 2 & 2 & )^{T}\end{array}$ & 6 \\
\hline 1 & 1 & $\begin{array}{llll}0 & 3 & 5 & )^{T}\end{array}$ & 19 \\
\hline 2 & 2 & $\left(\begin{array}{lll}1 & 2 & 0\end{array}\right)^{T}$ & 22 \\
\hline
\end{tabular}

Perda total de material $=111$

Note que o último padrão de corte apresentado na Tabela 5.3 foi descartado, pois sua frequência era menor que 1.

Passo 3: Calculamos, agora a demanda residual e a nova disponibilidade de objetos em estoque. A disponibilidade de objetos em estoque atualizada é dada por: $\mathbf{e}_{1}=\left(\begin{array}{ll}1 & 6\end{array}\right)^{T}$.

A quantidade produzida na solução inteira parcial dada na Tabela 5.4 é: $\left(\begin{array}{llll}18 & 23 & 21\end{array}\right)^{T}$ e a demanda para o período 1 é $\left(\begin{array}{lll}20 & 28 & 26\end{array}\right)^{T}$, conforme foi determinado no passo 1 .

Portanto, a produção excedente (ou seja, adiantada) é dada por: $\left(\begin{array}{lll}-2 & -5 & -5\end{array}\right)^{T}$, ou seja, nenhum item foi adiantado e todos apresentam demanda residual a ser cumprida. (Isto é trivial na primeira iteração desta abordagem, já que todas as freqüências foram 
arredondadas para baixo). Assim, a demanda residual é dada por: $\left(\begin{array}{lll}2 & 5 & 5\end{array}\right)^{T}$

Passo 4: Resolvemos um problema da mochila para atender a demanda residual: $\left(\begin{array}{lll}2 & 5 & 5\end{array}\right)^{T}$. A solução para o objeto tipo 1 é o padrão de corte: $\left(\begin{array}{lll}2 & 2 & 2\end{array}\right)^{T}$ com perda igual a 6 e a solução para o objeto tipo 2 é dada por $\left(\begin{array}{lll}1 & 1 & 2\end{array}\right)^{T}$ com perda igual a 2 . Escolhemos o padrão de corte com menor perda, neste caso, o padrão de corte para o objeto 2 . Como a perda neste padrão é $2<\ell_{\min }=91$, não cabe mais nenhum item neste padrão, então ele é utilizado com a maior freqüência possível: $x_{421}=2$. Isto nos fornece a solução dada na Tabela 5.5.

Tabela 5.5: Segunda aproximação para a solução inteira - Abordagem A.

\begin{tabular}{|c|c|c|c|}
\hline Objeto $k$ & $x_{j k 1}$ & Padrão de Corte & Perda no padrão \\
\hline 1 & 8 & $\left(\begin{array}{llll}2 & 2 & 2\end{array}\right)^{T}$ & 6 \\
\hline 1 & 1 & $\left(\begin{array}{lll}0 & 3 & 5\end{array}\right)^{T}$ & 19 \\
\hline 2 & 2 & $\left(\begin{array}{llll}1 & 2 & 0\end{array}\right)^{T}$ & 22 \\
\hline 2 & 2 & $\left(\begin{array}{lll}1 & 1 & 2\end{array}\right)^{T}$ & 2 \\
\hline
\end{tabular}

Voltamos ao Passo 3: Reavaliamos a demanda residual e a nova disponibilidade de objetos em estoque. A disponibilidade de objetos em estoque atualizada é dada por: $\mathbf{e}_{1}=\left(\begin{array}{ll}1 & 4\end{array}\right)^{T}$.

A quantidade produzida na solução inteira parcial dada na Tabela 5.5 é: $\left(\begin{array}{lll}20 & 25 & 25\end{array}\right)^{T}$ e a demanda para o período 1 é $\left(\begin{array}{llll}20 & 28 & 26\end{array}\right)^{T}$.

Portanto, a produção excedente (ou seja, adiantada) é dada por: $\left(\begin{array}{lll}0 & -3 & -1\end{array}\right)^{T}$, ou seja, temos itens com demanda a ser atendida. Assim, a demanda residual é dada por; $\left(\begin{array}{lll}0 & 3 & 1\end{array}\right)^{T}$

Passo 4: Resolvemos um problema da mochila para atender a demanda residual: $\left(\begin{array}{lll}0 & 3 & 1\end{array}\right)^{T}$. A solução para o objeto tipo 1 é o padrão de corte: $\left(\begin{array}{lll}0 & 3 & 1\end{array}\right)^{T}$ com perda igual a 383 e a solução para o objeto tipo 2 é dada por $\left(\begin{array}{lll}0 & 3 & 0\end{array}\right)^{T}$ com perda igual a 84 . Escolhemos o padrão de corte com menor perda, neste caso, o padrão de corte para o objeto 2. Como a perda neste padrão é $84<\ell_{\min }=91$, não cabe mais nenhum item neste padrão, então ele é utilizado com a maior freqüência possível: $x_{521}=1$. Isso fornece a nova solução inteira, que é dada na Tabela 5.6 a seguir.

Voltamos ao Passo 3: Reavaliamos a demanda residual e a nova disponibilidade de objetos em estoque. A disponibilidade de objetos em estoque atualizada é dada por: $\mathbf{e}_{1}=\left(\begin{array}{ll}1 & 3\end{array}\right)^{T}$.

A quantidade produzida na solução inteira parcial dada na Tabela 5.6 é: $\left(\begin{array}{lll}20 & 28 & 25\end{array}\right)^{T}$ 
Tabela 5.6: Terceira aproximação para a solução inteira (que é a solução final) - Abordagem A.

\begin{tabular}{|c|c|c|c|}
\hline Objeto $k$ & $x_{j k 1}$ & Padrão de Corte & Perda no padrão \\
\hline 1 & 8 & $\left(\begin{array}{lll}2 & 2 & 2\end{array}\right)^{T}$ & 6 \\
\hline 1 & 1 & $\left(\begin{array}{lll}0 & 3 & 5\end{array}\right)^{T}$ & 19 \\
\hline 2 & 2 & $\left(\begin{array}{llll}1 & 2 & 0\end{array}\right)^{T}$ & 22 \\
\hline 2 & 2 & $\left(\begin{array}{lll}1 & 1 & 2\end{array}\right)^{T}$ & 2 \\
\hline 2 & 1 & $\left(\begin{array}{llll}0 & 3 & 0\end{array}\right)^{T}$ & 84 \\
\hline
\end{tabular}

e a demanda para o período 1 é $\left(\begin{array}{lll}20 & 28 & 26\end{array}\right)^{T}$.

Portanto, a produção excedente (ou seja, adiantada) é dada por: $\left(\begin{array}{lll}0 & 0 & -1\end{array}\right)^{T}$, ou seja, temos 1 item do tipo 3 a ser produzido. Porém, a demanda por este item não é original deste período, já que a solução multiperíodo sugeriu adiantar 4 itens do tipo 3 . (Veja passo 1). Assim, não é necessário criarmos outro padrão de corte para atender a demanda deste item, pois a demanda original do período 1 é completamente atendida pela solução inteira dada na Tabela 5.6. Assim, finalizamos o algoritmo.

A solução inteira para o primeiro período é a solução dada na Tabela 5.6.

Observação: A quantidade que foi realmente adiantada para o primeiro período é dada por: $\left(\begin{array}{lll}0 & 0 & 4\end{array}\right)^{T}$ (obtida no passo 1$)+\left(\begin{array}{lll}0 & 0 & -1\end{array}\right)^{T}$ (obtida na solução do problema residual). Ou seja o vetor de antecipação de itens, neste exemplo, é $\left(\begin{array}{lll}0 & 0 & 3\end{array}\right)^{T}$.

\subsection{Abordagem B}

Na Abordagem B, o passo 2 é definido da seguinte forma.

Passo 2: $\quad$ arredondamento do vetor das freqüências: $\mathbf{x}^{\mathbf{1}}$ \}

Seja $n$ o número de padrões de corte no período 1.

Seja $\varphi_{j}$ a perda no padrão de corte de corte $j$.

Seja $k_{j}$ o tipo de objeto cortado segundo o padrão de corte $j$.

Ordene o vetor de freqüências $\mathbf{x}^{\mathbf{1}}$ em ordem não-crescente.

Para $j=1, \ldots, n$, faça:

Se $\varphi_{j}<\mathrm{TOL}_{k_{j}}$ 


$$
\begin{aligned}
& \text { então } x_{j k_{j}}^{1}=\min \left\{\left\lceil x_{j k_{j}}^{1}\right\rceil, e_{k_{j}}^{1}\right\} ; \\
& \text { senão } x_{j k_{j}}^{1}=\min \left\{\left\lfloor x_{j k_{j}}^{1}\right\rfloor, e_{k_{j}}^{1}\right\} ;
\end{aligned}
$$

em que TOL é uma tolerância para a perda em um padrão de corte. Nos testes computacionais utilizamos $\mathrm{TOL}_{k_{j}}=1 \%$ do comprimento do objeto do tipo $k_{j}$.

$\underline{\text { Fim-Passo } 2}$

Na seção seguinte, apresentamos um exemplo de aplicação da Abordagem B em um problema de corte de estoque multiperíodo. Porém antes, presentamos um exemplo ilustrativo.

\subsubsection{Exemplo}

Para exemplificar a Abordagem B, consideremos novamente o exemplo da seção anterior, seção 5.1.1 é descrito nas Tabelas 5.1 e 5.2.

Passo 1: O passo 1 da Abordagem B é idêntico ao passo 1 da Abordagem A. Assim, temos o vetor de atencipação de itens dado por $\left(\begin{array}{lll}0 & 0 & 4\end{array}\right)^{T}$, a nova demanda para o período 1 dada por $\left(\begin{array}{lll}20 & 28 & 26\end{array}\right)^{T}$ e a solução relaxada dada na Tabela 5.3.

Passo 2: Arredondar as freqüências do primeiro período. As frequências devem ser ordenadas de forma não-crescente, ou seja, daremos prioridade aos padrões mais utilizados, pois o arredondamento será efetuado nesta ordem.

Primeiramente, arredondamos a freqüência do primeiro padrão de corte: $x_{111}=8,2$. Verificamos se este padrão satisfaz o critério de aspiração: perda menor ou igual a 1\%. O padrão satisfaz o critério de aspiração, então pode ser arredondado para o menor inteiro maior que ele, ou seja, "arredondar para cima". Verificamos a disponibilidade do objeto do tipo 1 no estoque, e constatamos que tal arredondamento é possível, assim, fazemos $x_{111}=9$ e o estoque de objetos é atualizado $e_{11}=10-9=1$.

Analisemos agora o segundo padrão de corte, cuja freqüência é $x_{211}=1,7$. Este padrão não satisfaz o critério de aspiração, pois ele produz perda superior a $1 \%$ de seu comprimento. Assim, o seu valor deve ser truncado, ou, "arredondado para baixo". Assim, $x_{211}=1$ e o estoque de objetos é atualizado $e_{11}=1-1=0$. Observe que, mesmo que esse padrão fosse aceito pelo critério e aspiração, sua frequência não seria arredondada para cima devido a disponibilidade do objeto no estoque ser de apenas uma unidade.

De maneira análoga, arredondamos a freqüência do terceiro padrão de corte: $x_{321}=$ 2 ,8. Este padrão não satisfaz o critério de aspiração, então o seu valor é arredondado para baixo. Assim, $x_{311}=2$ e o estoque de objetos é atualizado $e_{21}=8-2=6$.

Finalmente, a freqüência do quarto e último padrão de corte é arredondada: $x_{421}=$ 
Poldi, K. C.

0,8. Este padrão satisfaz o critério de aspiração, então o seu valor é arredondado para cima, desde que haja objeto disponível no estoque. Assim, fazemos $x_{421}=1$ e o estoque de objetos é atualizado $e_{21}=6-1=5$. No final do passo 2 , temos a solução inteira parcial dada na Tabela 5.7 a seguir.

Tabela 5.7: Primeira aproximação para a solução inteira - Abordagem B.

\begin{tabular}{|c|c|c|c|}
\hline Objeto $k$ & $x_{j k 1}$ & Padrão de corte & Perda no padrão \\
\hline 1 & 9 & $\left(\begin{array}{lll}2 & 2 & 2\end{array}\right)^{T}$ & 6 \\
\hline 1 & 1 & $\left(\begin{array}{llll}0 & 3 & 5\end{array}\right)^{T}$ & 19 \\
\hline 2 & 2 & $\left(\begin{array}{llll}1 & 2 & 0\end{array}\right)^{T}$ & 22 \\
\hline 2 & 1 & $\left(\begin{array}{llll}1 & 1 & 2\end{array}\right)^{T}$ & 2 \\
\hline
\end{tabular}

Perda total de material $=119$

Passo 3: Calculamos, agora a demanda residual e a nova disponibilidade de objetos em estoque. A disponibilidade de objetos em estoque atualizada é dada por: $\mathbf{e}_{1}=\left(\begin{array}{ll}0 & 5\end{array}\right)^{T}$.

A quantidade produzida na solução inteira parcial dada na Tabela 5.7 é: $\left(\begin{array}{lll}21 & 26 & 25\end{array}\right)^{T}$ e a demanda para o período 1 é $\left(\begin{array}{lll}20 & 28 & 26\end{array}\right)^{T}$, conforme foi determinado no passo 1 .

Portanto, a produção excedente (ou seja, adiantada) é dada por: $\left(\begin{array}{lll}1 & -2 & -1\end{array}\right)^{T}$, ou seja, temos 1 item do tipo que é adiantadado e precisamos produzir 2 itens do tipo 2 e 1 item do tipo 3 para completar a demanda do período 1. Assim, a demanda residual é dada por: $\left(\begin{array}{lll}0 & 2 & 1\end{array}\right)^{T}$

Passo 4: Resolvemos um problema da mochila para atender a demanda residual: $\left(\begin{array}{lll}0 & 2 & 1\end{array}\right)^{T}$. A rigor, deveríamos resolver um problema da mochila para cada um dos dois tipos de objetos disponíveis em estoque, porém como a disponibilidade do objeto do tipo 1 já está esgotada, resolvemos o problema da mochila apenas para o objeto do tipo 2; cuja solução é o padrão de corte $a_{521}=\left(\begin{array}{lll}0 & 2 & 1\end{array}\right)^{T}$ com perda igual a 155 .

Como a perda no padrão de corte gerado é maior que o menor item demandado $155>\ell_{\min }=91$, devemos preencher o espaço que sobra adiantando itens. Assim, um problema da mochila, cujo comprimento é a sobra, neste caso, 155 é resolvido. A solução é $\left(\begin{array}{lll}0 & 0 & 1\end{array}\right)^{T}$, (i. é, adiante um item do tipo 3) com perda igual a 64 . Como $64<\ell_{\min }=$ 91, não cabe mais nenhum item neste padrão, então o padrão de corte está concluído: $\left(\begin{array}{lll}0 & 2 & 2\end{array}\right)^{T}$; e é utilizado o maior número de vezes possível: $x_{521}=1$. Com isto, temos a solução dada na Tabela 5.8.

Voltamos ao Passo 3: Reavaliamos a demanda residual e a nova disponibilidade de objetos em estoque. A disponibilidade de objetos em estoque atualizada é dada por: $\mathbf{e}_{1}=\left(\begin{array}{ll}0 & 4\end{array}\right)^{T}$.

A quantidade produzida na solução inteira parcial dada na Tabela 5.8 é: $\left(\begin{array}{lll}21 & 28 & 27\end{array}\right)^{T}$ e a demanda para o período 1 é $\left(\begin{array}{lll}20 & 28 & 26\end{array}\right)^{T}$. Portanto, a produção excedente (ou seja, 
Tabela 5.8: Segunda aproximação para a solução inteira (que é a solução final) - Abordagem B.

\begin{tabular}{|c|c|c|c|}
\hline Objeto $k$ & $x_{j k 1}$ & Padrão de corte & Perda no padrão \\
\hline 1 & 9 & $\left(\begin{array}{llll}2 & 2 & 2\end{array}\right)^{T}$ & 6 \\
\hline 1 & 1 & $\left(\begin{array}{lll}0 & 3 & 5\end{array}\right)^{T}$ & 19 \\
\hline 2 & 2 & $\left(\begin{array}{lll}1 & 2 & 0\end{array}\right)^{T}$ & 22 \\
\hline 2 & 1 & $\left(\begin{array}{lll}1 & 1 & 2\end{array}\right)^{T}$ & 2 \\
\hline 2 & 1 & $\left(\begin{array}{lll}0 & 2 & 2\end{array}\right)^{T}$ & 64 \\
\hline
\end{tabular}

adiantada) é dada por: $\left(\begin{array}{lll}1 & 0 & 1\end{array}\right)^{T}$. Como a demanda original do período 1 foi completamente atendidada, finalizamos o algoritmo. A solução inteira para o primeiro período é a solução dada na Tabela 5.8.

Observação: É importante notar que quantidade que foi realmente adiantada para o primeiro período é dada por: $\left(\begin{array}{lll}0 & 0 & 4\end{array}\right)^{T}$ (obtida no passo 1$)+\left(\begin{array}{lll}1 & 0 & 1\end{array}\right)^{T}$ (obtida na solução do problema residual). Ou seja o vetor de antecipação de itens, neste exemplo, é $\left(\begin{array}{lll}1 & 0 & 5\end{array}\right)^{T}$.

Com este simples exemplo já pudemos notar que solução obtida pela Abordagem $B$ foi melhor que a solução obtida pela Abordagem A, a primeira produziu perda de 183 unidades e a segunda, 199 unidades. Essa superioridade na qualidade das soluções da Abordagem B sobre a Abordagem A é confirmada nos experimentos computacionais apresentados no Capítulo 6, seção 6.3.

No próximo capítulo, apresentamos alguns experimentos computacionais realizados para analisar as soluções encontradas para o problema de corte de estoque multiperíodo relaxado, e a seguir, as soluções obtidas pelos procedimentos para arredondamento propostos neste capítulo. 
Poldi, K. C. 


\section{Capítulo 6}

\section{Experimentos computacionais}

Neste capítulo mostramos os testes computacionais realizados para os problemas abordados: o problema de corte de estoque unidimensional muliperíodo, o problema de corte de estoque unidimensional muliperíodo com restrições adicionais de capacidade o problema de corte de estoque bidimensional muliperíodo. Também foram realizados testes computacionais para analisar as duas abordagens para arredondamento da solução do problema de corte de estoque multiperíodo. Tais procedimentos foram testados para os casos unidimensional e bidimensional. Os resultados estão descritos a seguir. Os algoritmos foram implementados em Delphi 6 e os testes foram executados em um microcomputador Pentium IV com 512Mb de RAM.

\subsection{Problema de corte de estoque multiperíodo unidi- mensional}

Realizamos testes computacionais com 160 exemplares gerados aleatoriamente para analisar os resultados do modelo multiperíodo (3.1), quando os parâmetros da função objetivo são alterados para representar situações em que estoque de itens ou objetos são inconvenientes e o efeito disto sobre a perda de material. Além disso, comparamos os resultados com a abordagem lote-por-lote, que é tipicamente utilizada na prática.

Na literatura encontramos o CUTGEN1, que é um gerador de problemas-teste para o problema de corte de estoque unidimensional, proposto por Gau e Wäscher [14]. Embora seja amplamente utilizado para testes com problemas de corte de estoque unidimensional, não pode ser aplicado em nossos testes. Um problema de corte de estoque multiperíodo envolve muito mais parâmetros, que um problema de corte clássico. Assim, desenvolvemos um gerador aleatório apropriado descrito a seguir. Os experimentos estão divididos em 8 classes de problemas e, para cada classe, foram gerados 20 problemas-teste. A seguir, mostramos em detalhes os critérios usados para gerar os dados e os resultados obtidos. 


\subsubsection{Gerador aleatório}

Para execução dos testes computacionais para problemas de corte de estoque multiperíodo unidimensional, fixamos alguns parâmetros, que estão listados a seguir:

- número de períodos: $T=3$ e 6 ;

- número de tipos de objetos em estoque: $K=3$ e 5 ;

- número de tipos de itens demandados: $m=10$ e 20;

- custo de padrões de corte: $c_{j k t}=\gamma\left(L_{k}-\sum_{i=1}^{m} \ell_{i} \alpha_{i j k t}\right)$, com $\gamma=1$;

- custo de estocar objetos: $\beta L_{k}$, consideramos $\beta=0 ; 0,1$ e 0,01 ;

- custo de estocar itens: $\alpha \ell_{i}$, consideramos $\alpha=0 ; 0,1$ e 0,01 .

Outros parâmetros necessários para os testes foram gerados aleatoriamente nos seguintes intervalos:

- comprimento dos objetos em estoque: $L_{k} \in\left[\begin{array}{ll}300 & 1000\end{array}\right]$;

- comprimento dos itens demandados: $\ell_{i} \in[0,1 \bar{L} \quad 0,4 \bar{L}]$, com $\bar{L}=\frac{\sum_{k=1}^{K} L_{k}}{K}$;

- estoque do objeto tipo $k$, no período de tempo $t: e_{k t} \in\left[\left\lceil\lambda_{t}\right\rceil 2\left\lceil\lambda_{t}\right\rceil\right]$, em que $\lambda_{t}=\frac{\sum_{i=1}^{m} \ell_{i} d_{i t}}{\sum_{k=1}^{K} L_{k}}$

- demanda dos itens: $d_{i t} \in\left[\begin{array}{ll}10 & 200\end{array}\right]$.

\subsubsection{Resultados computacionais - problema unidimensional ir- restrito}

Foram definidas 8 classes de problemas. Para cada classe foram gerados 20 problemasteste. Estas classes estão especificadas a seguir, na Tabela 6.1. 
Tabela 6.1: Caracterização das 8 classes para o problema de corte multiperíodo unidimensional.

\begin{tabular}{c|c|c|c}
\hline Classe & $\begin{array}{c}\text { Número de } \\
\text { períodos }(T)\end{array}$ & $\begin{array}{c}\text { Número de } \\
\text { objetos }(K)\end{array}$ & $\begin{array}{c}\text { Número de } \\
\text { itens }(m)\end{array}$ \\
\hline 1 & 3 & 3 & 10 \\
2 & 3 & 3 & 20 \\
3 & 3 & 5 & 10 \\
4 & 3 & 5 & 20 \\
5 & 6 & 3 & 10 \\
6 & 6 & 3 & 20 \\
7 & 6 & 5 & 10 \\
8 & 6 & 5 & 20 \\
\hline
\end{tabular}

Tabela 6.2: Valor da função objetivo para o problema de corte de estoque unidimensional multiperíodo (média dos 20 exemplos em cada classe) $\alpha=\beta=0$.

\begin{tabular}{c|r|r|r|r}
\hline Classe & Lote-por-lote & Multiperíodo & Diferença & Ganho \% \\
\hline 1 & 124,39 & 112,92 & 11,47 & $9,22 \%$ \\
2 & 33,44 & 30,61 & 2,82 & $8,46 \%$ \\
3 & 83,18 & 76,02 & 7,16 & $8,61 \%$ \\
4 & 11,34 & 9,59 & 1,75 & $15,43 \%$ \\
5 & 323,86 & 255,70 & 68,16 & $21,04 \%$ \\
6 & 79,61 & 54,39 & 25,21 & $31,67 \%$ \\
7 & 258,43 & 198,95 & 59,48 & $23,01 \%$ \\
8 & 99,46 & 94,83 & 4,63 & $4,66 \%$ \\
\hline Média & $\mathbf{1 2 6 , 7 1}$ & $\mathbf{1 0 4}, \mathbf{1 3}$ & $\mathbf{2 2 , 5 8}$ & $\mathbf{1 7 , 8 3} \%$ \\
\hline
\end{tabular}

Os resultados apresentados na Tabela 6.2 , foram obtidos considerando-se os parâmetros: custo de estocar objetos $\beta=0$ e custo de estocar itens $\alpha=0$. Assim, a função objetivo apresentada na Tabela 6.2 é a perda total obtida, já que os custos (de estocagem de objetos e itens) são nulos.

Na Tabela 6.2 observamos que a proibição de estoque (solução lote-por-lote) faz crescer a perda, em média, cerca de $20 \%$, de 104, 13 para 126,71. Com isto, o gerente tem como melhor avaliar o quanto custa esta decisão. Por outro lado, os altos níveis de estoque podem desestimular a adoção da solução, apesar da redução da perda de material. Esta é uma característica típica de problemas multiobjetivos, neste caso, a perda de material versus o estoque de itens. 
Outras soluções podem ser obtidas ao se variar os valores de $\alpha$, mantendo-se $\beta=0$. Valores altos para $\beta$ distorcem a solução, pois o modelo produzirá perdas altas para se livrar dos objetos em estoque.

A manutenção deste parâmetro na função objetivo faz sentido para problemas acoplados (Poltroniere et al. [53, 54]), o qual tende a inibir estoques de objetos (i.e., revisão na produção ou aquisição excessivas de objetos).

Tabela 6.3: Perda média e comprimento médio estocado nos 160 exemplos do problema de corte de estoque unidimensional multiperíodo, variando-se $\alpha$ e $\beta$.

\begin{tabular}{l|rr|rr|rr}
\hline & \multicolumn{2}{|c|}{$\beta=0$} & \multicolumn{2}{c|}{$\beta=0,01$} & \multicolumn{2}{c}{$\beta=0,1$} \\
\hline & perdido & estocado & perdido & estocado & perdido & estocado \\
\hline$\alpha=0$ & 104,13 & 33129,04 & 220,49 & 76313,02 & 254,08 & 76857,59 \\
$\alpha=0,01$ & 116,26 & 129,14 & 104,17 & 34068,14 & 254,08 & 76857,59 \\
$\alpha=0,1$ & 123,83 & 14,07 & 123,84 & 17,47 & 106,21 & 35263,82 \\
$\alpha=0,5$ & 125,42 & 3,64 & 125,44 & 3,64 & 125,87 & 3,63 \\
$\alpha=1$ & 126,72 & 0,00 & 126,72 & 0,00 & 126,72 & 0,00 \\
\hline
\end{tabular}

Na Tabela 6.3, para cada valor de $\alpha$ e $\beta$, temos dois valores, o primeiro representa a perda média e o segundo o comprimento total médio, de todos os itens, que são antecipados, ou seja, estocados.

Notamos que a dificuldade operacional com o estoque de itens, representada com valores mais altos para $\alpha$, reflete em um aumento substancial na perda de material. Tipicamente, o armazenamento de itens não é permitido na prática, embora não haja estudos para analisar sua viabilidade e o modelo multiperíodo (3.1) permite essa análise.

Por exemplo, a segunda coluna da Tabela $6.3(\beta=0)$, em que os custos de estocagem de objetos não são considerados, vemos que a perda aumenta na medida que os custos de estocagem de itens aumentam até o limite da solução lote-por-lote, em que qualquer estoque de itens é proibido (solução obtida para $\alpha$ grande).

Se os estoques necessários para a solução com $\alpha=0$ são demasiadamente grandes, o gerente de produção pode variar o valor de $\alpha$ e analisar soluções intermediárias. Por exemplo, a solução com $\alpha=0,01$, a qual representa que uma unidade de comprimento perdido é 100 vezes mais cara que uma unidade de comprimento estocada ( $\gamma$ foi fixado em 1), reduz o estoque a $0,35 \%$ (de 33129,04 para 129,14$)$, enquanto a perda aumenta em $12 \%$.

Quanto ao tempo computacional, em média foram necessários 3, 85 segundos por exemplar. Não houve variação significativa no tempo computacional entre os métodos lote-por-lote e multiperíodo. 


\subsubsection{Resultados computacionais - problema unidimensional res- trito}

O problema de corte de estoque multiperíodo também foi implementado com restrições de limitação na capacidade de corte em cada período do horizonte de planejamento. Os mesmos exemplares utilizados na seção 6.1.2 para o caso irrestrito foram utilizados aqui, para o caso restrito.

Tabela 6.4: Valor da função objetivo para o problema de corte de estoque unidimensional multiperíodo (média dos 160 exemplos) $\alpha=\beta=0$.

\begin{tabular}{r|r|r}
\hline Capacidade & Função objetivo & Acréscimo \% \\
\hline $100 \%$ & 104,13 & - \\
$98 \%$ & 109,37 & $5,03 \%$ \\
$95 \%$ & 111,71 & $7,27 \%$ \\
$90 \%$ & 116,09 & $11,49 \%$ \\
$85 \%$ & 149,86 & $43,91 \%$ \\
\hline
\end{tabular}

As restrições de capacidade referem-se ao total de objetos cortados em um período. A primeira coluna da Tabela 6.4 mostra a capacidade disponível, a segunda coluna apresenta o valor da função objetivo, ou seja, a perda total de material, e a terceira coluna apresenta a porcentagem de aumento da perda de material devido a escassez de capacidade.

A solução do problema multiperíodo irrestrito nos forneceu a capacidade que consideramos $100 \%$, ou seja, $100 \%$ da capacidade significa que temos a solução para o problema irrestrito.

A seguir, a capacidade disponível foi diminuída gradativamente, conforme pode ser visto na Tabela 6.4. Quando a capacidade foi reduzida a menos de $85 \%$ alguns exemplos tornaram-se infactívies e os testes foram interrompidos.

Mais uma vez, o modelo multiperíodo permite ao gerente de produção analisar o impacto que a limitação na capacidade da máquina de corte traz em termos de perda de material. Isto pode ser decisivo para uma política de expansão da capacidade instalada. Por exemplo, o aumento de $5 \%$ da capacidade (considere o aumento de $85 \%$ para $90 \%$ ) pode representar a redução de mais de $22 \%$ de desperdício de material, com a perda de 149, 86 diminuída para 116, 09. 


\subsection{Problema de corte de estoque multiperíodo bidi- mensional}

\subsubsection{Gerador aleatório}

Para execução dos testes computacionais para problemas de corte de estoque multiperíodo bidimensional, fixamos alguns parâmetros, que estão listados a seguir:

- número de períodos: $T=2$ e 3 ;

- número de tipos de objetos em estoque: $K=2$;

- número de tipos de itens demandados: $m=5,10,20$ e 40;

- custo de padrões de corte: $c_{j k t}=\gamma\left(L_{k} W_{k}-\sum_{i=1}^{m} \ell_{i} w_{i} \alpha_{i j k t}\right)$, com $\gamma=1$;

- custo de estocar objetos e itens: $\alpha=\beta=0$.

Outros parâmetros necessários para os testes foram gerados aleatoriamente nos seguintes intervalos:

- comprimento dos objetos em estoque: $L_{1} \times W_{1}=140 \times 120$ e $L_{2} \times W_{2}=100 \times 100$;

- comprimento dos itens demandados: $\ell_{i} \times w_{i} \in\left[\begin{array}{ll}20 & 80\end{array}\right] \times\left[\begin{array}{ll}20 & 80\end{array}\right]$;

- estoque do objeto tipo $k$, no período de tempo $t: e_{k t}=\left[\left(\frac{1,1}{K}\right)\left(\frac{\sum_{i=1}^{m} \ell_{i} w_{i} d_{i t}}{L_{k} W_{k}}\right)\right]$;

- demanda dos itens: $d_{i t} \in\left[\begin{array}{ll}1 & 200\end{array}\right]$.

\subsubsection{Resultados computacionais - problema bidimensional}

Foram definidas 8 classes de problemas bidimensionais. Para cada classe foram gerados 20 problemas-teste. Estas classes estão especificadas na Tabela 6.5. 
Tabela 6.5: Caracterização das 8 classes para o problema de corte multiperíodo bidimensional.

\begin{tabular}{c|c|c|c}
\hline Classe & $\begin{array}{c}\text { Número de } \\
\text { períodos }(T)\end{array}$ & $\begin{array}{c}\text { Número de } \\
\text { objetos }(K)\end{array}$ & $\begin{array}{c}\text { Número de } \\
\text { itens }(m)\end{array}$ \\
\hline 1 & 2 & 2 & 5 \\
2 & 2 & 2 & 10 \\
3 & 2 & 2 & 20 \\
4 & 2 & 2 & 40 \\
5 & 3 & 2 & 5 \\
6 & 3 & 2 & 10 \\
7 & 3 & 2 & 20 \\
8 & 3 & 2 & 40 \\
\hline
\end{tabular}

Os resultados apresentados na Tabela 6.6, foram obtidos considerando-se os parâmetros: custo de estocar objetos $\beta=0$ e custo de estocar itens $\alpha=0$. Assim, a função objetivo apresentada na Tabela 6.2 é a área total perdida, já que os custos (de estocagem de objetos e itens) são nulos.

Tabela 6.6: Valor da função objetivo (área total perdida) para o problema de corte de estoque bidimensional multiperíodo (média dos 20 exemplos em cada classe).

\begin{tabular}{c|r|r|r}
\hline Classe & Lote-por-lote & Multiperiodo & Ganho \% \\
\hline 1 & 78933,76 & 66460,59 & $16,58 \%$ \\
2 & 108417,55 & 87818,02 & $17,82 \%$ \\
3 & 1526827,27 & 1394770,27 & $10,46 \%$ \\
4 & 5461910,70 & 5295405,56 & $3,04 \%$ \\
5 & 124642,74 & 114488,10 & $8,72 \%$ \\
6 & 103513,45 & 87105,25 & $17,75 \%$ \\
7 & 2458400,27 & 2259759,71 & $10,45 \%$ \\
8 & 8351067,21 & 8047756,42 & $3,63 \%$ \\
\hline Média & $\mathbf{2 2 7 6 7 4 1 , 1 9}$ & $\mathbf{2 1 6 9 1 9 5 , 4 9}$ & $\mathbf{1 0 , 9 3 \%}$ \\
\hline
\end{tabular}

Na Tabela 6.6 observamos que a proibição de estoque entre períodos (solução lotepor-lote) faz crescer a perda, em média, cerca de 10\%. Com isto, o gerente de produção tem uma ferramenta que o auxilia na avaliação do quanto custa a decisão de estocar ou não itens cortados. Mais uma vez, ressaltamos que esta é uma característica típica de problemas multiobjetivos, neste caso, a perda de material versus o estoque de itens. 


\subsection{Abordagens de arredondamento}

Neste trabalho foram propostas dois procedimentos para determinar a solução inteira do problema de corte de estoque multiperíodo. Estas abordagens estão descritas no Capítulo 5 e, a seguir, apresentamos os testes computacionais realizados. Os problemas-testes utilizados nos experimentos computacionais foram os mesmos utilizados na seção 6.1.2.

Os valores para cada uma das 8 classes nas Tabelas 6.7, 6.8 e 6.9 a seguir, são as médias dos resultados obtidos para os 20 problemas-testes em cada uma das classes.

A coluna lote-por-lote na Tabela 6.7 refere-se a solução lote-por-lote arredondada. Foram aplicadas as três heurísticas de arredondamento de Poldi e Arenales [49, 51], que estão descritas no Apêndice A.4.2, e o melhor resultado obtido dentre os três foi o calculado para compor a segunda coluna da Tabela 6.7. A terceira e a quarta coluna da Tabela 6.7 apresentam os valores da função objetivo, que representa a perda, obtidas pelas Abordagens A e B, respectivamente, descritas no Capítulo 5. Podemos claramente observar que Abordagem $\mathrm{B}$ foi muito superior à Abordagem A, como também a solução lote-por-lote.

Tabela 6.7: Valor da função objetivo (perda) com arredondamento no primeiro período.

\begin{tabular}{c|r|r|r}
\hline Classe & Lote-por-lote & Abordagem A & Abordagem B \\
\hline 1 & 242,15 & 805,65 & 92,70 \\
2 & 179,90 & 894,20 & 104,85 \\
3 & 156,25 & 1029,90 & 131,25 \\
4 & 172,40 & 976,45 & 168,80 \\
5 & 254,75 & 733,00 & 96,00 \\
6 & 206,25 & 655,30 & 132,75 \\
7 & 217,00 & 1177,30 & 221,35 \\
8 & 205,65 & 888,50 & 162,75 \\
\hline Média & $\mathbf{2 0 4 , 3 2}$ & $\mathbf{8 9 5 , 4 0}$ & $\mathbf{1 3 8 , 8 0}$ \\
\hline
\end{tabular}

Além disso, podemos notar que em algumas classes a solução obtida pela Abordagem A foi pior que a solução lote-por-lote arredondada. Isso comprova que a estratégia de arredondamento gulosa pode não levar a bons resultados.

A antecipação de itens tende a ser grande na solução do problema de corte multiperíodo, de forma que a demanda dos itens nos períodos finais é menor. Com demanda menor, as combinações tendem a piorar o que implica no aumento da perda. Isso não acontece na solução lote-por-lote, já que há a antecipação de itens. Isso sugere que a solução do primeiro período obtida pelas Abordagens desenvolvidas sejam muito boas, pois têm mais possibilidades de combinação e os itens de difícil combinação tendem a ter 
sua produção sempre postergada. Assim, não podemos analisar apenas a solução inteira do primeiro período do problema de corte, que é dada na Tabela 6.7, precisamos ter ao menos uma estimativa de como se comporta a solução nos próximos períodos.

Tabela 6.8: Valor da função objetivo (perda) com arredondamento no primeiro período e solução relaxada dos demais períodos.

\begin{tabular}{c|r|r|r}
\hline Classe & Lote-por-lote & Abordagem A & Abordagem B \\
\hline 1 & 364,33 & 865,24 & 155,99 \\
2 & 207,33 & 908,12 & 120,71 \\
3 & 242,14 & 1076,77 & 181,28 \\
4 & 187,62 & 983,00 & 176,22 \\
5 & 886,72 & 929,63 & 294,42 \\
6 & 328,45 & 699,76 & 178,50 \\
7 & 766,73 & 1323,79 & 381,01 \\
8 & 447,52 & 958,72 & 235,24 \\
\hline Média & $\mathbf{4 2 8 , 8 3}$ & $\mathbf{9 6 8 , 1 3}$ & $\mathbf{2 1 5 , 4 2}$ \\
\hline
\end{tabular}

Como apenas o primeiro período é, de fato, implementado, só ele teve sua solução arredondada. Como podemos ver na Tabela 6.7, o problema de encontrar a solução inteira para o primeiro período foi bem resolvido pela Abordagem $\mathrm{B}$, apresentando perda bem inferior que as outras duas técnicas de solução. Porém, não basta termos uma solução muito boa para o primeiro e, nos próximos, não conseguirmos manter o padrão de qualidade das soluções. Como não é preciso explicitar solução inteira para os períodos futuros, calculamos duas estimativas para as perdas nos próximos períodos.

O cálculo destas estimativas foi conduzido da seguinte forma. Toda a demanda de itens e disponibilidade de objetos em estoque em todos os períodos do horizonte de planejamento foram somadas. Destes valores, foram subtraídos a produção do primeiro período, inclusive os itens que foram antecipados para o primeiro período. Desta forma, temos um "super período" que representa os períodos de 2 até $T$ (em que $T$ é o último período). Assim, uma solução para o "super período" nos fornece uma estimativa para as perdas nos períodos finais.

Resolvemos o "super período" de duas maneiras. Uma delas é a solução por programação linear. Assim, a perda do primeiro período arredondado somada à perda obtida pela relaxação linear nos fornece um limitante para a perda total. Estes valores são dados na Tabela 6.8 .

Outra forma foi determinar uma solução inteira para o "super período". O procedimento utilizado foram as três versões heurísticas de arredondamento propostas em Poldi e Arenales [50, 51] (brevemente descritas no Apêndice A, seção A.4.2) e computamos a melhor solução entre as três obtidas. Assim, a perda do primeiro período arredon- 
Tabela 6.9: Valor da função objetivo (perda) com arredondamento no primeiro período + arredondamento nos demais períodos.

\begin{tabular}{c|r|r|r}
\hline Classe & Lote-por-lote & Abordagem A & Abordagem B \\
\hline 1 & 832,20 & 1053,90 & 411,35 \\
2 & 721,20 & 1083,60 & 289,25 \\
3 & 613,65 & 1224,05 & 335,50 \\
4 & 522,10 & 1090,05 & 345,10 \\
5 & 2003,65 & 1159,40 & 482,90 \\
6 & 1524,55 & 943,55 & 375,30 \\
7 & 1690,30 & 1510,55 & 573,60 \\
8 & 1098,70 & 1119,50 & 425,80 \\
\hline Média & $\mathbf{1 1 2 5 , 7 9}$ & $\mathbf{1 1 4 8 , 0 7}$ & $\mathbf{4 0 4}, \mathbf{8 5}$ \\
\hline
\end{tabular}

dado somada à perda obtida para a solução inteira do "super período" fornece uma outra estimativa para a perda total. Estes valores são dados na Tabela 6.9.

Como podemos observar nas Tabelas 6.8 e 6.9, a Abordagem B continua a apresentar perdas menores que os outros dois métodos estudados. Assim, podemos concluir que é um procedimento eficiente para arredondamento da solução do problema de corte de estoque multiperído.

No próximo capítulo, apresentamos um estudo de caso do problema de corte de estoque bidimensional, com apenas um período, em uma indústria de esquadrias metálicas. 


\section{Capítulo 7}

\section{Conclusões e Propostas}

Problemas de corte de estoque em geral vêm sendo tratado na literatura como problemas com único período, enquanto na prática, no ambiente industrial, vários períodos são considerados. Nesta tese, um problema de corte em que a demanda e a aquisição de objetos ocorrem em um horizonte de planejamento foi considerado, tal problema foi chamado de problema de corte de estoque multiperíodo.

Uma extensão natural do método simplex com geração de colunas para tratar esse problema de grande porte foi implementada. Foram realizados experimentos computacionais, com problemas de corte de estoque multiperíodo unidimensional (restrito e irrestrito) e bidimensional gerados aleatoriamente. Tais experimentos mostram que ganhos efetivos podem ser obtidos usando-se o modelo de corte de estoque multiperíodo, quando comparado com a solução lote-por-lote, tipicamente utilizada na prática. Também foi realizado um estudo de caso em uma empresa de esquadrias de metálicas de pequeno porte. Neste caso, os problemas resolvidos foram bidimensionais e os resultados apresentados pelas heurísticas desenvolvidas mostraram-se muito competitivos.

Como pudemos observar na experiência que tivemos com o problema prático, constatamos, na prática, a solução relaxada é de pouca, ou nenhuma, utilidade. Assim, nesta tese, foram desenvolvemos dois procedimentos de arredondamento da solução do problema multiperíodo, baseado em horizonte rolante, ou seja, determinamos uma solução inteira factível apenas para o primeiro período, a qual será, de fato, implementada. As heurísticas de arredondamento propostas para problemas de corte com único período (Poldi [49]) puderam ser adaptadas para o arredondamento da solução do problema multiperíodo. Mais uma vez, como já havia sido observado, os experimentos computacionais realizados com as heurísticas de arredondamento mostraram que o arredondamento para o menor inteiro maior que o valor dado, apresentou melhores resultados que os obtidos por estratégias com truncamento.

Concluímos que o modelo para o problema de corte de estoque multiperíodo permite flexibilidade na análise de uma solução a ser implementada e, portanto, é uma ferramenta 
que permite ao gerente de produção uma visão global do problema para auxiliá-lo na tomada de decisões.

Como perspectivas de continuidade do trabalho, sugerimos considerar outras restrições no modelo (além da disponibilidade de estoque e capacidade de máquina, que foram tratadas nesta tese), como por exemplo, ao tratarmos itens perecíveis, as antecipações de produção de itens devem ser limitadas.

Embora o problema de corte de estoque multiperiodo seja em si uma contribuição à área de corte e empacotamento, por captar elementos da programação da produção em ambientes dinâmicos, pode também ser visto como um subproblema importante no planejamento e programação da produção. Assim, uma perspectiva natural de continuidade do trabalho é integrar esse método de solução na resolução de problemas acoplados (descritos na Introdução desta tese).

A abordagem apresentada pode ser facilmente adaptada para resolver problemas de corte de estoque tridimensional, bem como as heurísticas de arredondamentos propostas.

A antecipação de itens sugerida pelo modelo multiperíodo pode não ser feita na prática, ou seja, corta-se apenas os itens necessários para atender a demanda do período atual e estoca-se os "pedaços" de objetos que sobraram para serem cortados quando for conveniente. Essa decisão cabe ao gerente de produção e a solução do problema multiperíodo é uma ferramenta de apoio à tomada de decisões. 


\section{Apêndice A}

\section{Métodos de solução}

A condição de integralidade sobre as variáveis $x_{j k}$ no modelo (3.1) dificulta computacionalmente a resolução dos problemas de corte na medida em que $m$ (número de tipos de itens) cresce. Entretanto, Gilmore e Gomory [15, 16, 17] propuseram relaxar esta condição de integralidade sobre as variáveis $x_{j k}$ e resolver o programa linear resultante utilizando a técnica de geração de colunas. Esta estratégia consiste do método simplex que, a cada iteração, substitui um dos padrões básicos (coluna) por um novo padrão de corte (coluna) que melhora a solução básica corrente. Tal padrão de corte (coluna), no caso unidimensional, é gerado resolvendo-se um problema da mochila, e no caso bidimensional, um problema de corte bidimensional. A partir da solução ótima do problema relaxado, que geralmente não é inteira, determina-se uma solução inteira para o problema de corte de estoque original. Estudos computacionais em Poldi e Arenales [50, 51] mostram que heurísticas simples de arredondamento muitas vezes obtém soluções ótimas ou quase-ótimas.

\section{A.1 Método simplex com geração de colunas}

Em problemas práticos de corte de estoque, o número de variáveis (colunas) é muito maior que o número de restrições (linhas) e tipicamente, cada coluna está associada a um padrão de corte que apresentam um custo alto para ser calculado. Entretanto, durante as iterações do método simplex, temos de determinar uma nova coluna para entrar na base. Este problema torna-se impraticável devido ao grande número de colunas que devem ser investigadas. Para contornar este problema, Gilmore e Gomory [15], em 1961, propuseram uma técnica de geração de colunas que é bastante eficiente para resolver o problema.

Para descrevermos o método simplex com geração de colunas para resolver problemas de corte estoque, vamos considerar, por simplicidade, o problema de corte de estoque um único tipo de objeto disponível em estoque para ser cortado e a função objetivo é a 
minimização do número total de objetos cortados. O modelo matemático a ser considerado é o seguinte:

$$
\begin{array}{ll}
\text { minimizar } & \sum_{j=1}^{n} x_{j} \\
\text { sujeito a: } & \sum_{j=1}^{n} \alpha_{i j} x_{j}=d_{i}, i=1, \ldots, m \\
& x_{j} \geq 0, \text { inteiro, } j=1, \ldots, n .
\end{array}
$$

O procedimento consiste em gerar uma coluna $k$, isto é, um novo padrão de corte, utilizando o critério de Dantizg, que procura a variável $x_{k}$ com o menor custo relativo, o que sugere o seguinte sub-problema:

$$
\mathbf{c}_{k}-\pi^{T} \alpha_{k}=\min \left\{\mathbf{c}_{j}-\pi^{T} \alpha_{j}, \quad j=1,2, \ldots\right\}
$$

em que $\pi$ é o vetor multiplicador simplex de uma determinada iteração.

Se o custo relativo, $\mathbf{c}_{k}-\pi^{T} \alpha_{k} \geq 0$ (as variáveis básicas, incluídas no cálculo do mínimo acima, têm custos relativos nulos), então a solução básica atual é ótima, caso contrário, a coluna $\alpha_{k}$ entra na base.

$$
\min \left\{c_{j}-\pi^{T} \alpha_{j}\right\}=1-\max \left\{\pi^{T} \alpha_{j}\right\}
$$

Com isso, encontrar uma coluna não-básica, digamos $\left(\alpha_{1}, \alpha_{2}, \ldots, \alpha_{m}\right)^{T}$ que substituirá uma coluna básica, corresponde a resolver o problema:

maximizar $\quad \pi_{1} \alpha_{1}+\pi_{2} \alpha_{2}+\ldots+\pi_{m} \alpha_{m}$ sujeito a que $\left(\alpha_{1}, \alpha_{2}, \ldots, \alpha_{m}\right)^{T}$ corresponda a um padrão de corte.

A coluna $\alpha_{j}=\left(\alpha_{1}, \alpha_{2}, \ldots, \alpha_{m}\right)^{T}$ é gerada pela resolução de um problema de corte (problema da mochila, no unidimensional, sem restrições adicionais). Como a solução obtida por esse procedimento nos fornece a coluna $\alpha_{j}=\left(\alpha_{1}, \alpha_{2}, \ldots, \alpha_{m}\right)^{T}$ com o menor custo relativo, podemos garantir que :

- Se $c_{k}-\pi^{T} \alpha_{k}=0$, a solução é ótima (o menor custo relativo nunca será positivo, pois os custos relativos dos padrões de corte básicos são nulos);

- Se $c_{k}-\pi^{T} \alpha_{k}<0$, a coluna $\left(\alpha_{1}, \alpha_{2}, \ldots, \alpha_{m}\right)^{T}$ entra na base (a coluna a sair da base segue os passos usuais do método simplex). 
Apresentamos agora o algoritmo do método primal-simplex com geração de colunas, em uma versão simplificada, utilizado na resolução de problemas de corte de estoque.

\section{Algoritmo: Método simplex com geração de colunas (Gilmore e Gomory [15])}

FASE 1:

1.1 Determine uma matriz básica inicial B (composta por padrões de corte homogêneos (ou seja, padrões com apenas um tipo de item);

1.2 Faça: $\quad$ PARE $=$ Falso e IT $=1 .\{$ A variável lógica PARE terá valor Falso até que a condição de otimalidade seja verificada e IT é o número da iteração atual. \}

FASE 2:

Enquanto PARE $=$ Falso, faça:

\{ Início da iteração Simplex \}

2.1 Determine a solução básica corrente: $\mathbf{B x}_{\mathbf{B}}=\mathbf{d}$.

2.2 Determine a solução dual (vetor multiplicador simplex): $\mathbf{B}^{T} \pi=\mathbf{c}_{\mathbf{B}}$.

2.3 Calcule os custos relativos: \{ gera uma coluna para entrar na base: $\alpha$, com custo: $\hat{c}\}$. Resolva o problema de corte:

$$
\begin{aligned}
& \hat{c}=\max \widehat{\pi_{1}} \alpha_{1}+\widehat{\pi_{2}} \alpha_{2}+\ldots+\widehat{\pi_{m}} \alpha_{m} \\
& \text { sujeito a: }\left(\alpha_{1} \quad \alpha_{2} \quad \ldots \quad \alpha_{m}\right)^{T}: \\
& \text { vetor associado a um padrão de corte }
\end{aligned}
$$

em que o valor de utilidade do item tipo $i, \widehat{\pi}_{i}$ é uma função do vetor multiplicador $\pi$ calculado no passo 2.2 .

$2.4\{$ Teste de otimalidade $\}$

Se $\quad \hat{c} \geq 0$

então PARE = Verdadeiro $\{$ Solução atual é ótima e foi obtida em IT iterações. $\}$ senão Início

2.4.1 \{ Determine y as coordenadas básicas da direção simplex: \}

$$
\mathbf{B y}=\alpha
$$


2.4.2 \{ Determine o tamanho do passo \}

Encontre $k$ tal que:

$$
\frac{x_{B_{k}}}{y_{k}}=\operatorname{mínimo}\left\{\frac{x_{B_{i}}}{y_{i}} \mid y_{i}>0, \quad i=1, \ldots, m\right\} .
$$

\subsubsection{Atualização \}}

Atualize a base, substituindo a $k$-ésima coluna da matriz B por $\alpha$ (obtida no passo 2.3).

Faça: $\quad \mathrm{IT}=\mathrm{IT}+1$.

\section{Fim-senão}

\section{Fim-do-Algoritmo}

\section{A.2 O problema da mochila}

Nesta seção, descrevemos um problema muito conhecido na literatura e também muito utilizado: o problema da pochila, o qual é um subproblema importante no desenvolvimento de técnicas para encontrarmos a solução do problema de corte de estoque.

O problema da mochila pode ser enunciado como um problema de corte unidimensional: suponha que um objeto deva ser cortado ao longo de seu comprimento $L$ em itens de comprimentos $\ell_{i}, i=1, \ldots, m$. Cada item tem um valor associado que denominamos de valor de utilidade. Sendo assim, surge o problema de otimização combinatória com o objetivo de maximizar o valor total de utilidade.

Nos casos em que quantidade máxima de itens demandados não seja especificada, temos o problema da mochila irrestrito, caso contrário, o problema restrito.

\section{Variável de decisão:}

$\alpha_{i}$ : quantidade de itens do tipo $i$ cortados, $i=1, \ldots, m$.

\section{Modelo matemático:}

$$
\begin{aligned}
& \operatorname{maximizar} g(\mathbf{a})=v_{1} \alpha_{1}+v_{2} \alpha_{2}+\ldots+v_{m} \alpha_{m} \\
& \text { sujeito a: }\left\{\begin{array}{l}
\ell_{1} \alpha_{1}+\ell_{2} \alpha_{2}+\ldots+\ell_{m} \alpha_{m} \leq L \\
\alpha_{i} \geq 0, \text { e inteiros }, i=1, \ldots, m
\end{array}\right.
\end{aligned}
$$

em que:

$L$ : comprimento da peça em estoque; 
$m$ : número de tipos de itens;

$\ell_{i}$ : comprimento do item $i, i=1, \ldots, m$;

$v_{i}$ : valor de utilidade do item $i, i=1, \ldots, m$.

Neste trabalho, resolvemos o problema da mochila irrestrito usando um algoritmo de programação dinâmica (Yanasse e Soma [67]), descrito na seção A.2.1. Os algoritmos baseados em programação dinâmica são favoráveis à resolução de problemas com mais de um comprimento de objeto disponível para ser cortado, pois basta resolver o problema da mochila para o objeto de maior comprimento e temos, como subproduto, a solução para os objetos menores.

Nos casos do problema da mochila restrito, devemos considerar ainda:

$d_{i}$ : quantidade máxima de itens do tipo $i$ que pode ser cortados, $i=1, \ldots, m$.

\section{Modelo matemático:}

$$
\begin{aligned}
& \operatorname{maximizar} g(\mathbf{a})=v_{1} \alpha_{1}+v_{2} \alpha_{2}+\ldots+v_{m} \alpha_{m} \\
& \text { sujeito a: }\left\{\begin{array}{l}
\ell_{1} \alpha_{1}+\ell_{2} \alpha_{2}+\ldots+\ell_{m} \alpha_{m} \leq L \\
0 \leq \alpha_{i} \leq d_{i}, \text { e inteiros, } i=1, \ldots, m .
\end{array}\right.
\end{aligned}
$$

Para resolução do problema da mochila restrito utilizamos um algoritmo de enumeração implícita, descrito na seção A.2.2.

\section{A.2.1 Programação dinâmica}

Gilmore e Gomory [15] utilizaram um método de programação dinâmica (PD) para o problema de corte. Esse método consiste de uma fórmula recursiva para a resolução do problema da mochila utilizando uma estratégia de percorrer todas as possíveis decisões. Em 1987, Yanasse e Soma [67] propuseram um novo algoritmo para solução do problema da mochila unidimensional irrestrito. Tal algoritmo é pseudopolinomial e sua principal característica é a redução do tempo computacional e da utilização de memória para armazenamento quando comparado com outras implementações de programação dinâmica, os quais, em geral, calculam os custos (lucros, etc) para todos os estados em cada estágio antes de iniciar os cálculos do estágio seguinte, o que não acontece no algoritmo de Yanasse e Soma, daí a economia de tempo e memória computacionais.

Neste trabalho tratamos o problema de corte de estoque com vários comprimentos de objetos disponíveis para serem cortados e isso implica na resolução de mochilas de vários tamanhos. Para isso, basta aplicarmos o algoritmo para o objeto de maior comprimento e, no final, recuperamos as soluções para os objetos menores. Esta adaptação foi feita no passo 5 do algoritmo de Yanasse e Soma [67]. Por hipótese, considera-se que os comprimentos dos itens $\ell_{i}, i=1, \ldots, m$ estejam em ordem crescente. 


\section{Algoritmo: PD (Yanasse e Soma [67])}

Passo 0: $\quad$ Inicialização $\}$

$g(L)=-1 ; i=\ell_{1} ;$ ponteiro $=\ell_{1} ;$

Para $j=1, \ldots, m$ faça:

$$
\begin{aligned}
& g\left(\ell_{j}\right)=v_{j} \\
& \operatorname{solin}\left(\ell_{j}\right)=j
\end{aligned}
$$

Fim-Para

Enquanto $\ell_{1} \leq i \leq\left(L-\ell_{1}\right)$, faça:

Se $g(i)=0$, então $g(i)=-1$;

$$
i=i+1
$$

Fim-Enquanto

\section{$\underline{\text { Passo 1: }}$}

$\mathrm{j}=1$;

Enquanto $(j \leq m)$ e (ponteiro $\left.+\ell_{j} \leq L\right)$, faça:

Se (ponteiro $\left.+\ell_{j} \leq L-\ell_{1}\right)$ ou (ponteiro $+\ell_{j}=L$ )

então Início-1

$\operatorname{glin}\left(\right.$ ponteiro $\left.+\ell_{j}\right)=g($ ponteiro $)+v_{j}$

Se glin $\left(\right.$ ponteiro $\left.+\ell_{j}\right)>g\left(\right.$ ponteiro $\left.+\ell_{j}\right)$

então Início-2

$$
\begin{aligned}
& g\left(\text { ponteiro }+\ell_{j}\right)=g \operatorname{lin}\left(\text { ponteiro }+\ell_{j}\right) \\
& \text { solin }\left(\text { ponteiro }+\ell_{j}\right)=j ;
\end{aligned}
$$

Fim-Início-2

Fim-Início-1

$j=j+1$

Fim-Enquanto 
Passo 2:

ponteiro $=$ ponteiro +1 ;

Se ponteiro $>L-\ell_{1}$ então vá para o passo 3 ;

Se $g$ (ponteiro $)<0$ então vá para o passo 2 , senão vá para o passo 1 ;

\section{Passo 3:}

Se $g(L)<0$

então PARE. (O problema é infactivel)

senão $g(L)$ é o valor ótimo.

$\underline{\text { Passo 4: }}$

Para $i=1, \ldots, m$ faça: $\alpha_{i}=0$;

ponteiro $=\mathrm{L}$;

Passo 5:

Enquanto ponteiro $>0$, faça:

$$
\begin{aligned}
& \alpha_{\text {solin(ponteiro) }}=\alpha_{\text {solin (ponteiro })}+1 ; \\
& \text { ponteiro }=\text { ponteiro }-\ell_{\text {solin (ponteiro) }} ;
\end{aligned}
$$

Fim-Enquanto

\section{Fim-do-Algoritmo}

Observação: O passo 5 não foi implementado tal como está descrito aqui, ele foi modificado para determinar a solução das mochilas de tamanhos menores. Assim, basta aplicarmos o algoritmo para o objeto de maior comprimento e, no final, recuperamos as soluções para os objetos menores. Para isso, criamos um vetor auxiliar, no passo 5, que armazena as soluções das mochilas de tamanhos menores.

\section{A.2.2 Enumeração implícita}

O seguinte método da enumeração implícita (EI) foi proposto por Gilmore e Gomory [16], em 1963, para o problema da mochila. Este método é implementado utilizando uma busca em profundidade primeiro e consiste em enumerar implicitamente todas as soluções do problema da mochila. Para isto, utiliza-se limitantes para o problema que permitem que 
soluções "piores" que a atual sejam descartadas, sem perder a otimalidade. Este método é importante, pois a geração explícita de todas as possíveis soluções do problema da mochila, para exemplos de tamanhos moderados, se torna um trabalho quase impossível de ser computacionalmente resolvido.

Gilmore e Gomory também observaram que outras restrições simples, como o número limitado de facas, podem ser consideradas na busca. Outras restrições, como a limitação no número de itens - que torna a resolução por programação dinâmica mais difícil é também facilmente incluída na busca. Outros autores adaptaram este método para incluir na busca outras restrições menos convencionais (Morabito e Garcia [44], Marques e Arenales [36]).

O método de enumeração implícita para a resolução do problema da mochila restrito utilizado está descrito a seguir. Mais detalhes veja Marques [35].

\section{Algoritmo: EI (Gilmore e Gomory [16])}

Passo 1: $\{$ Defina o problema segundo as variáveis mais valiosas. $\}$

Faça: $\theta_{i}=\frac{v_{i}}{\ell_{i}}, i=1, \ldots, m$, e reordene as variáveis, tal que:

$$
\theta_{1} \geq \theta_{2} \geq \ldots \geq \theta_{m}
$$

Faça: $v_{m+1}=0, \quad \ell_{m+1}=1 \quad$ e $\quad g(\mathbf{a})=0$.

Passo 2: $\{$ Determine a solução inicial, utilizando busca em profundidade primeiro. $\}$

Determine a solução $\mathbf{a}=\left(\alpha_{1}, \alpha_{2}, \ldots, \alpha_{m}\right)$, tal que:

$$
\begin{gathered}
\alpha_{1}=\min \left\{\left\lfloor\frac{L}{\ell_{1}}\right\rfloor, d_{1}\right\} \quad \Rightarrow \quad \text { sobra }: L-\alpha_{1} \ell_{1} \\
\alpha_{2}=\min \left\{\left\lfloor\frac{L-\alpha_{1} \ell_{1}}{\ell_{2}}\right\rfloor, d_{2}\right\} \quad \Rightarrow \quad \text { sobra }: L-\alpha_{1} \ell_{1}-\alpha_{2} l_{2} \\
\vdots \\
\alpha_{k}=\min \left\{\left\lfloor\frac{L-\sum_{j=1}^{k-1} \ell_{j} \alpha_{j}}{\ell_{k}}\right\rfloor, d_{k}\right\} \quad k=2, \ldots, m
\end{gathered}
$$


Passo 3: $\{$ Avalie a solução corrente e armazene a mais valiosa. \}

Determine:

$$
g(\mathbf{a})=\sum_{i=1}^{m} v_{i} \alpha_{i} .
$$

(Considere inicialmente $\underline{G}=0$ ). Se $\underline{G}<g(\mathbf{a})$ então faça:

$$
\underline{G}=g(\mathbf{a})
$$

e guarde a solução correspondente: $\quad \mathbf{a}^{*}=\mathbf{a}$

Passo 4: $\{$ Teste a otimalidade e calcule o limitante superior. $\}$

Determine $k$ o maior índice tal que: $\alpha_{k} \neq 0$.

Se $\mathbf{a}=\mathbf{0}$ então PARE, a melhor solução guardada em $\mathbf{a}^{*}$ é uma solução ótima senão, calcule: $\quad\left(\right.$ Se $k=m$, considere $v_{m+1}=0$ e $\left.\ell_{m+1}=1.\right)$

$$
\bar{G}(\mathbf{a})=v_{1} \alpha_{1}+v_{2} \alpha_{2}+\ldots+v_{k}\left(\alpha_{k}-1\right)+\frac{v_{k+1}}{\ell_{k+1}}\left(L-\ell_{1} \alpha_{1}-\ell_{2} \alpha_{2}-\ldots-\ell_{k}\left(\alpha_{k}-1\right)\right)
$$

\section{Passo 5: $\{$ Backtracking $\}$}

\section{1: $\{$ Retorno longo $\}$}

Se $\bar{G}(\mathbf{a}) \leq \underline{G}$, então faça: $\quad \alpha_{k}=0 \quad$ e volte ao passo 4 .

5.2: \{ Retorno ao nó precedente e nova busca em profundidade. $\}$

Se $\bar{G}(\mathbf{a})>\underline{G}$, então faça: $\quad \alpha_{k} \leftarrow \alpha_{k}-1$ e defina a nova solução a:

$$
\alpha_{j}=\min \left\{\left\lfloor\frac{L-\sum_{i=1}^{j-1} \ell_{i} \alpha_{i}}{l_{j}}\right\rfloor, d_{j}\right\}, \quad j=k+1, \ldots, m
$$

e volte ao passo 3 . 
\{ A quantidade de itens do tipo $k+1, k+2, \ldots, m$ que é possível colocar no espaço que sobrou com a retirada de uma unidade do item tipo $k$. $\}$

\section{Fim-do-Algoritmo}

Ao final do algoritmo, $g(\mathbf{a})$ guarda o valor máximo para o problema (??). Ou seja, está determinado o padrão de corte $\left(\alpha_{1}^{*}, \alpha_{2}^{*}, \ldots, \alpha_{m}^{*}\right)^{T}$ mais valioso, uma vez que o algoritmo examina implicitamente todos os possíveis padrões de corte e determina o melhor deles.

\section{A.3 Abordagem grafo $\mathrm{E} / \mathrm{OU}$}

A abordagem em grafo E/OU para a resolução de problemas de porte foi inicialmente proposta por Morabito [38], para problemas de corte guilhotinado bidimensional irrestrito (o termo "irrestrito" é usado na literatura dos problemas de corte para designar que não há limitação sobre o número de itens num padrão de corte e "restrito" caso contrário) e não-estagiado (Morabito et al. [40]). Morabito [39] estendeu esta abordagem para problemas de corte guilhotinado irrestrito e restrito, considerando as dimensões unidimensional, bidimensional e tridimensional (Morabito e Arenales [43]).

A abordagem foi generalizada para problemas de corte diversos, incluindo cortes não-guilhotinados (Arenales e Morabito [42]). Vianna [62] estendeu a abordagem para diferentes processos de corte. Um grafo E/OU pode ser definido para representar todos os possíveis padrões de corte, em que os nós representam retângulos (no caso do problema de corte bidimensional, com placa e peças retangulares) e os arcos representam cortes. Um arco (corte) estabelece uma relação entre um nó $N$ do grafo (retângulo), com dois outros nós $N_{1}$ e $N_{2}$ (retângulos obtidos após o corte), portanto, um arco-E. Os nós $N_{1}$ e $N_{2}$ são chamados sucessores de $N$ e, $N$ predecessor de $N_{1}$ e $N_{2}$. Os padrões de corte são gerados examinando-se todas as possibilidades alternativas de corte (daí, arcos-OU) e uma delas é reproduzir o próprio retângulo N (chamado de corte-0, lê-se corte zero), ao qual nenhum outro corte será feito, indicando o final do processo de corte.

Um corte-0 é representado por um arco ordinário (isto é, aponta para um único nó). O nó inicial é representado pela placa $(L \times W)$ e os nós finais são aqueles originados de um corte-0 (sem perda de generalidade, associam-se aos retângulos finais um ou mais itens idênticos. Veja, por exemplo, o primeiro arco a esquerda emergindo da raiz na Figura A.1). Os cortes (verticais ou horizontais) podem ser restritos, sem perda de generalidade, a um conjunto finito, chamado de "conjunto de discretização", formado pelas combinações lineares não-negativas dos tamanhos dos itens (veja Herz [21]) e Morabito e Arenales [42] para sua construção). A Figura A.1 ilustra diversas seqüências de corte e, portanto, diversos padrões de corte. Por exemplo, três arcos-OU emergem da raiz, indicando alternativas diferentes para se obter três padrões de corte. Um padrão 


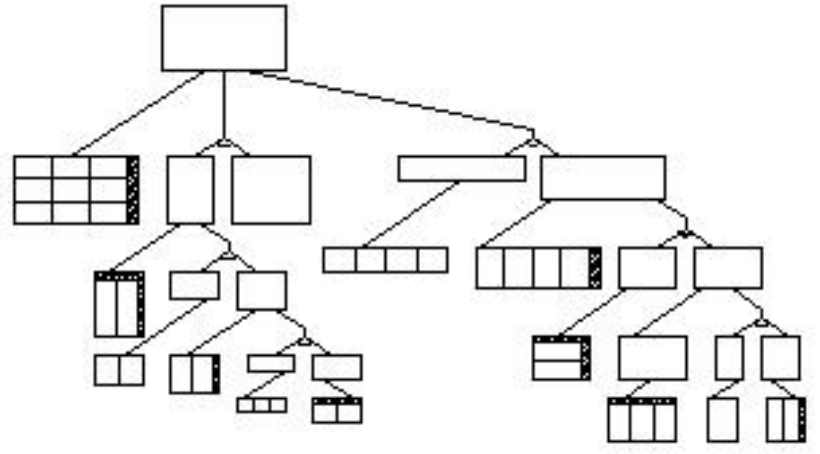

(a)

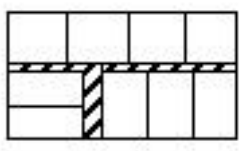

(b)

Figura A.1: (a) parte do grafo E/OU representando padrões de corte; (b) padrão de corte representado em destaque em (a).

de corte é bem definido seguindo-se uma seqüência de arcos-E (cortes), a partir da raiz (placa inicial) até nós finais (nós após cortes-0). Esta seqüência é chamada de caminho completo e todo padrão de corte tem um caminho completo associado. Um mesmo nó pode pertencer a seqüências diferentes (isto é, retângulos de mesmos tamanhos podem ser obtidos por diferentes seqüências de corte), o que caracteriza um ciclo. Apesar disto, por simplicidade de implementação, duplicamos tais nós (ou seja, nós diferentes podem representar retângulos idênticos, porém obtidos de seqüências de corte diferentes) e, portanto, trabalhamos com árvores (grafo conexo sem ciclos). O valor de utilidade do padrão de corte é a soma dos valores de utilidade dos nós finais do caminho completo associado.

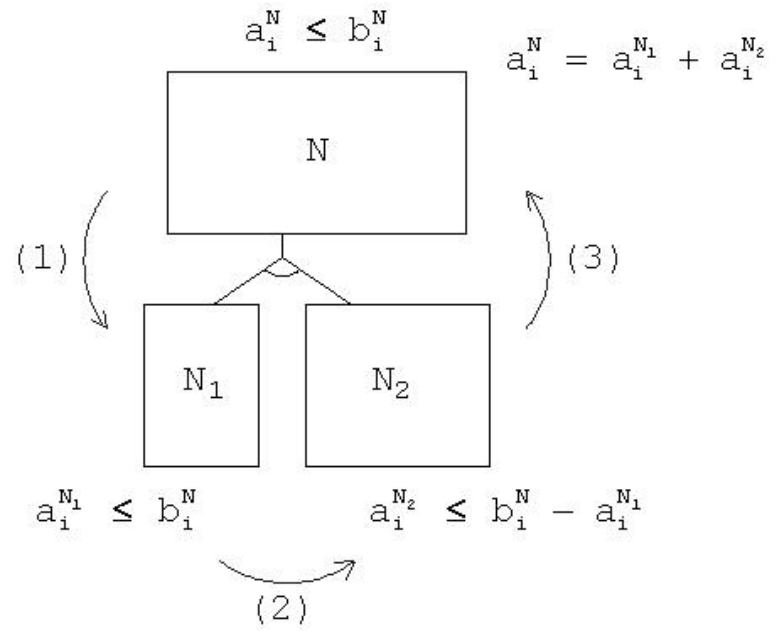

Figura A.2: Corte de um problema restrito. 
O número de possíveis caminhos completos no grafo E/OU (ou seja, o número de padrões de corte) pode ser enorme e computacionalmente impraticável. No caso do problema restrito, a decisão de produzir um item do tipo $i$ em um determinado nó do grafo E/OU depende da produção deste item nos demais nós do mesmo caminho (Figura A.2). Isto aumenta consideravelmente a dificuldade de resolução e Morabito e Arenales [43] propõem uma heurística simples para percorrer o grafo E/OU, que consiste em resolver o nó $N_{1}$ (veja (1) na Figura A.2) e com a demanda residual resolver o nó $N_{2}$ (veja (2) na Figura A.2), e vice-versa. Uma solução para o nó $N$ é então obtida (veja (3) na Figura A.2).

Para a resolução do problema de corte é utilizado um método de enumeração implícita, baseado numa busca no grafo E/OU que descreve o espaço de soluções possíveis. A estratégia de busca combina busca em profundidade (backtracking) com busca informada (hill-climbing). Durante o processo de busca é possível reduzir o número de nós explicitamente gerados a um conjunto finito formado pelas combinações lineares não-negativas das dimensões das peças. Enumerar explicitamente todos os caminhos do grafo, durante o processo de busca, é, na maioria das vezes, inviável. As soluções podem ser enumeradas implicitamente, ou seja, é possível descartar a expansão de um nó sem perder a solução ótima, usando limitantes.

A estratégia de busca utilizada combina duas estratégias (Morabito [39]):

- Backtracking: Variação da estratégia de busca em profundidade, que consiste em ramificar os nós gerados mais recentemente.

- Hill-climbing: Depois de expandir o nó até uma profundidade pré-determinada, escolhe-se o melhor caminho e todos os nós finais, na profundidade pré-determinada, são expandidos. Os demais caminhos são descartados (otimização local).

O uso de limitante na profundidade e também a estratégia hill-climbing levam a perda da otimalidade da solução na busca em grafo E/OU.

A seguir é apresentado o algoritmo que combina as duas estratégias de busca (backtracking e hill-climbing).

\section{Algoritmo: BT-HC (Morabito e Arenales [43])}

$\underline{\text { Passo 0: }}$

Considere a placa $(L \times W)$, os itens $\left(\ell_{i} \times w_{i}\right), i=1, \ldots, m$, e $M P$, a profundidade máxima permitida na busca backtracking. Considere o nó raiz como o nó que contém as informações da placa inicial. 


\section{Passo 1: $\{$ Backtracking $\}$}

Aplique a busca backtracking com profundidade $M P$ a partir do nó raiz.

\section{Passo 2: $\{$ Hill-Climbing $\}$}

Selecione o caminho mais promissor (pode-se usar a soma das soluções homogêneas em cada nó final do caminho) e descarte os demais. Para cada nó final do caminho gerado pela busca backtracking, verifique se é possível expandi-lo. Se for, retorne ao passo 1, considerando-o como nó raiz.

\section{Fim-do-Algoritmo}

\section{A.4 Métodos desenvolvidos para determinar soluções inteiras}

\section{A.4.1 Procedimento construtivo guloso}

Uma heurística utilizada na solução de problemas de corte de estoque é a heurística gulosa, classificada por alguns autores como heurística de repetição exaustiva (Hinxman [26], Poldi e Arenales [50, 51]):

\section{Algoritmo: Construtivo guloso}

Passo 1: Construa um bom padrão de corte para cada tipo de objeto que tenha disponibilidade em estoque $k=1, \ldots, K$;

Passo 2: Escolha dentre os padrões de corte gerados no passo 1 o que apresentar menor perda;

Passo 3: Use o padrão de corte escolhido no passo 2 o máximo possível, sem exceder a demanda dos itens e a disponibilidade do objeto associado (estratégia gulosa);

Passo 4: Atualize a demanda dos itens e o estoque dos objetos;

Passo 5: Se as demandas dos itens foram atendidas ou não houver mais disponibilidade de objetos então PARE. Senão, vá para o passo 1.

\section{Fim-do-Algoritmo}




\section{A.4.2 Procedimentos residuais}

Nas heurísticas residuais resolve-se a relaxação linear do problema de corte de estoque, obtém-se uma solução inteira aproximada, novamente, resolve-se a relaxação linear do problema residual, obtém-se uma solução inteira aproximada e, assim sucessivamente, até que a demanda residual se anule, ou a solução inteira aproximada do problema residual seja nula. Neste último caso, aplica-se algum método (heurístico ou exato) que resolve o problema residual final com poucos itens. A seguir, apresentamos uma estrutura geral dessas heurísticas.

\section{Algoritmo Residual - (Poldi e Arenales [51])}

Passo 1: $\{$ Início $\}$

Faça $\ell=0, \mathbf{r}^{0}=\mathbf{d}, \mathbf{s}^{0}=\mathbf{e} ;$

Passo 2: $\{$ Determinação da solução ótima contínua $\}$

Resolva o problema residual com $\mathbf{r}=\mathbf{r}^{\ell}$ e $\mathbf{s}=\mathbf{s}^{\ell}$;

Seja $\mathbf{x}^{\ell}$ a solução contínua (a técnica de geração de colunas é usada);

Se $\mathbf{x}^{\ell}$ for uma solução inteira, então PARE.

Passo 3: $\{$ Determinação da solução inteira aproximada $\}$

Determine uma solução inteira aproximada $\mathbf{y}^{\ell}$ para a solução contínua $\mathbf{x}^{\ell}$,

Se $\mathbf{y}^{\ell}$ for um vetor nulo, então vá para o passo final.

\section{Passo 4: $\{$ Atualização $\}$}

Determine a nova demanda residual e a nova disponibilidade de objetos em estoque

$\mathbf{r}^{\ell+1}=\mathbf{r}^{\ell}-\mathbf{A y}^{\ell}$

$\mathbf{s}^{\ell+1}=\mathbf{s}^{\ell}-\mathbf{E} \mathbf{y}^{\ell}$

$\ell=\ell+1$

Vá para o passo 2 .

Passo Final:

Resolva o problema residual final com poucos itens por algum método, heurístico ou exato.

\section{Fim-do-Algoritmo}


Em Poldi [49] e Poldi e Arenales [51] foram desenvolvidos procedimentos para obter uma solução inteira aproximada de uma solução contínua $\mathrm{x}^{\ell}$ no passo 3 do algoritmo residual. Nesses procedimentos o passo 3 é dividido em dois passos: passo de pré-processamento e passo de arredondamento.

Além disso, para esses procedimentos, o passo final do algoritmo residual não é mais utilizado, pois todas as demandas são completadas, já que a freqüência dos padrões de corte é arredondada para o inteiro superior ao fracionário obtido e o vetor $\mathbf{y}^{\ell}$ no passo 3 nunca será nulo.

No passo de pré-processamento ordena-se os padrões da solução contínua (obtidas no passo 2 do algoritmo residual) segundo um dos seguintes critérios: 1, 2 e 3, descritos a seguir. Por simplicidade de notação, considere $T$ padrões de corte, com freqüências não nulas, obtidos no passo 2 , enumerados por $1,2, \ldots, T$ e $k_{j}$ o objeto associado ao padrão de corte $j, j=1, \ldots, T$.

1. os padrões de corte são ordenados de acordo com os valores não crescentes das frequências, ou seja, $x_{1 k_{1}} \geq x_{2 k_{2}} \geq \ldots \geq x_{T k_{T}}$;

2. os padrões de corte são ordenados de acordo com os valores não decrescentes de suas perdas, ou seja, $c_{1 k_{1}} \leq c_{2 k_{2}} \leq \ldots \leq c_{T k_{T}}$;

3. os padrões de corte são ordenados de acordo com os valores não crescentes das partes fracionárias das frequências, ou seja, $f_{1 k_{1}} \geq f_{2 k_{2}} \geq \ldots \geq f_{T k_{T}}$, em que $f_{j k}=x_{j k}-\left\lfloor x_{j k}\right\rfloor$.

No passo de arredondamento, inicia-se com o primeiro padrão de corte, conforme uma das ordenações descritas anteriormente, e sua freqüência é arredondada para o inteiro superior: $y_{1 k_{1}}=\left\lceil x_{1 k_{1}}\right\rceil, y_{j k_{j}}=0, j=2, \ldots, T$. As condições de atendimento da demanda e disponibilidade de estoque são testadas e, caso haja violação, este valor é reduzido sucessivamente de uma unidade: $y_{1 k_{1}}=y_{1 k_{1}}-1$, até que tenhamos uma solução inteira aproximada. $\mathrm{O}$ valor de $y_{1 k_{1}}$ é fixado, repete-se o procedimento com o segundo padrão de corte e determina-se uma nova solução inteira aproximada: $y_{1 k_{1}}, y_{2 k_{2}}$ e $y_{j k_{j}}=0, j=$ $3, \ldots, T$. Repete-se o procedimento até o último padrão de corte. É importante salientar que a geração de colunas é feita usando-se o problema restrito, desta forma, cada padrão gerado pode ser utilizado no mínimo uma vez. Isto garante que a demanda residual fica menor, a cada iteração do método e, no final, a demanda residual é nula.

Todos estes procedimentos estão detalhados em Poldi [49]. 
Poldi, K. C. 


\section{Apêndice B}

\section{Um estudo de caso do problema de corte de estoque bidimensional}

Uma indústria de esquadrias metálicas de pequeno porte forneceu dados reais para podermos comparar as soluções das heurísticas desenvolvidas com procedimentos manuais.

Foram estudados 21 exemplos, resultantes da carteira de pedidos de uma semana, nos quais o número de tipos de itens varia entre 2 e 16, o número de tipos de placas a serem cortadas é de 1 a 3 tipos. A demanda dos itens é baixa, já que se trata de uma empresa de pequeno porte. O objetivo é a minimização da perda total de material (área). Utilizamos a profundidade 6 a cada estágio da busca em grafo E/OU, quando um caminho mais promissor é escolhido e os demais, descartados. Alguns detalhes sobre a abordagem grafo E/OU podem ser vistos no Apêndice A e também em Poldi et.al. [52], Morabito [39], Morabito e Arenales [43] e Vianna [62]

\section{B.1 Resultados}

A seguir, apresentamos as soluções obtidas pelos procedimentos descritos no Apêndice A, a saber: solução relaxada (contínua) obtida pelo método simplex com geração de colunas, heurística construtiva gulosa (seção A.4.1) e heurística residual (seção A.4.2). Apresentamos também a solução fornecida pela empresa. 
Poldi, K. C.

Tabela B.1: Porcentagem de perda de material.

\begin{tabular}{c|c|c|c|c}
\hline & $\begin{array}{c}\text { Geração } \\
\text { de colunas }\end{array}$ & $\begin{array}{c}\text { Heurística } \\
\text { residual }\end{array}$ & $\begin{array}{c}\text { Construtiva } \\
\text { gulosa }\end{array}$ & $\begin{array}{c}\text { Solução } \\
\text { do operador }\end{array}$ \\
\hline 1 & 6,96 & $\mathbf{1 4 , 7 1}$ & $\mathbf{1 4 , 7 1}$ & $\mathbf{1 4 , 7 1}$ \\
2 & 24,75 & $\mathbf{2 8 , 9 3}$ & $\mathbf{2 8 , 9 3}$ & $\mathbf{2 8 , 9 3}$ \\
3 & $\mathbf{4}, \mathbf{7 8}$ & $\mathbf{4 , 7 8}$ & $\mathbf{4}, \mathbf{7 8}$ & $\mathbf{4}, \mathbf{7 8}$ \\
4 & 7,88 & $\mathbf{8 , 1 9}$ & 11,35 & $\mathbf{8}, \mathbf{1 9}$ \\
5 & 5,37 & $\mathbf{6 , 0 4}$ & $\mathbf{6 , 0 4}$ & 10,52 \\
6 & 1,69 & $\mathbf{4 , 2 1}$ & $\mathbf{4 , 2 1}$ & $\mathbf{4}, \mathbf{2 1}$ \\
7 & 2,80 & $\mathbf{3 , 0 2}$ & 4,06 & 5,09 \\
8 & 3,40 & $\mathbf{9 , 2 9}$ & $\mathbf{9 , 2 9}$ & 15,77 \\
9 & 5,51 & $\mathbf{7 , 8 7}$ & 7,92 & $\mathbf{7}, \mathbf{8 7}$ \\
10 & 5,44 & $\mathbf{6 , 9 0}$ & $\mathbf{6 , 9 0}$ & $\mathbf{6 , 9 0}$ \\
11 & 2,57 & $\mathbf{3 , 9 8}$ & $\mathbf{3 , 9 8}$ & 10,84 \\
12 & 2,70 & $\mathbf{8 , 2 1}$ & $\mathbf{8}, \mathbf{2 1}$ & $\mathbf{8}, \mathbf{2 1}$ \\
13 & 2,84 & $\mathbf{6 , 3 8}$ & $\mathbf{6 , 3 8}$ & $\mathbf{6 , 3 8}$ \\
14 & 2,81 & $\mathbf{7 , 4 4}$ & $\mathbf{7 , 4 4}$ & 13,61 \\
15 & 5,82 & $\mathbf{1 0 , 0 1}$ & $\mathbf{1 0 , 0 1}$ & 14,75 \\
16 & 5,26 & $\mathbf{7 , 4 4}$ & $\mathbf{7 , 4 4}$ & 15,49 \\
17 & 2,35 & $\mathbf{6 , 1 6}$ & $\mathbf{6 , 1 6}$ & 12,86 \\
18 & 4,70 & $\mathbf{4 , 7 0}$ & $\mathbf{4 , 7 0}$ & 10,30 \\
19 & 2,18 & $\mathbf{3 , 6 9}$ & $\mathbf{3 , 6 9}$ & 8,51 \\
20 & 3,42 & $\mathbf{8 , 0 2}$ & 31,02 & $\mathbf{8}, \mathbf{0 2}$ \\
21 & 8,96 & $\mathbf{1 0 , 5 8}$ & $\mathbf{1 0 , 5 8}$ & $\mathbf{1 0 , 5 8}$ \\
\hline
\end{tabular}

A Tabela B.1 apresenta os resultados dos 21 exemplos práticos fornecidos pela empresa de estruturas metálicas. A segunda coluna da tabela apresenta a perda percentual de material de cada exemplo resolvido pelo método de geração de colunas. Esta solução não pode ser usada na prática por tratar-se de uma solução fracionária, na maioria das vezes, mas fornece um importante limitante inferior. 
A terceira e quarta colunas da Tabela B.1 apresentam as soluções encontradas pelos métodos desenvolvidos, a saber, a heurística gulosa construtiva, heurísticas de arredondamento nas versões 1, 2 e 3 (ver Apêndice A, seção A.4.2). As três versões da heurística apresentaram a mesma solução para todos os exemplos fornecidos pela empresa. Na última coluna da tabela apresentamos a solução que o operador utilizou na prática para resolver o problema e atender aos pedidos de seus clientes. Ressaltamos que, a solução apresentada pelo operador é baseada em sua experiência. Provavelmente utiliza uma heurística do tipo FFD ou algo similar.

Ainda, na Tabela B.1, destacamos com negrito as "melhores soluções" encontradas. Note que, nos 21 exemplos estudados, as abordagens residuais apresentaram resultados iguais aos resultados obtidos pelo operador em 11 exemplos e, melhores que o resultado fornecido pelo operador em 10 exemplos. A média do ganho da heurística nova em relação à solução do operador, nos 10 exemplos mencionados, é de 5,6\%.

Em 100\% dos exemplos, as heurísticas residuais de arredondamento apresentaram os melhores resultados. O operador obteve soluções similares em $50 \%$ dos casos e algumas vezes foi superior à heurística construtiva gulosa. O tempo computacional médio, para todos os procedimentos testados, variou de 1 a 40 segundos.

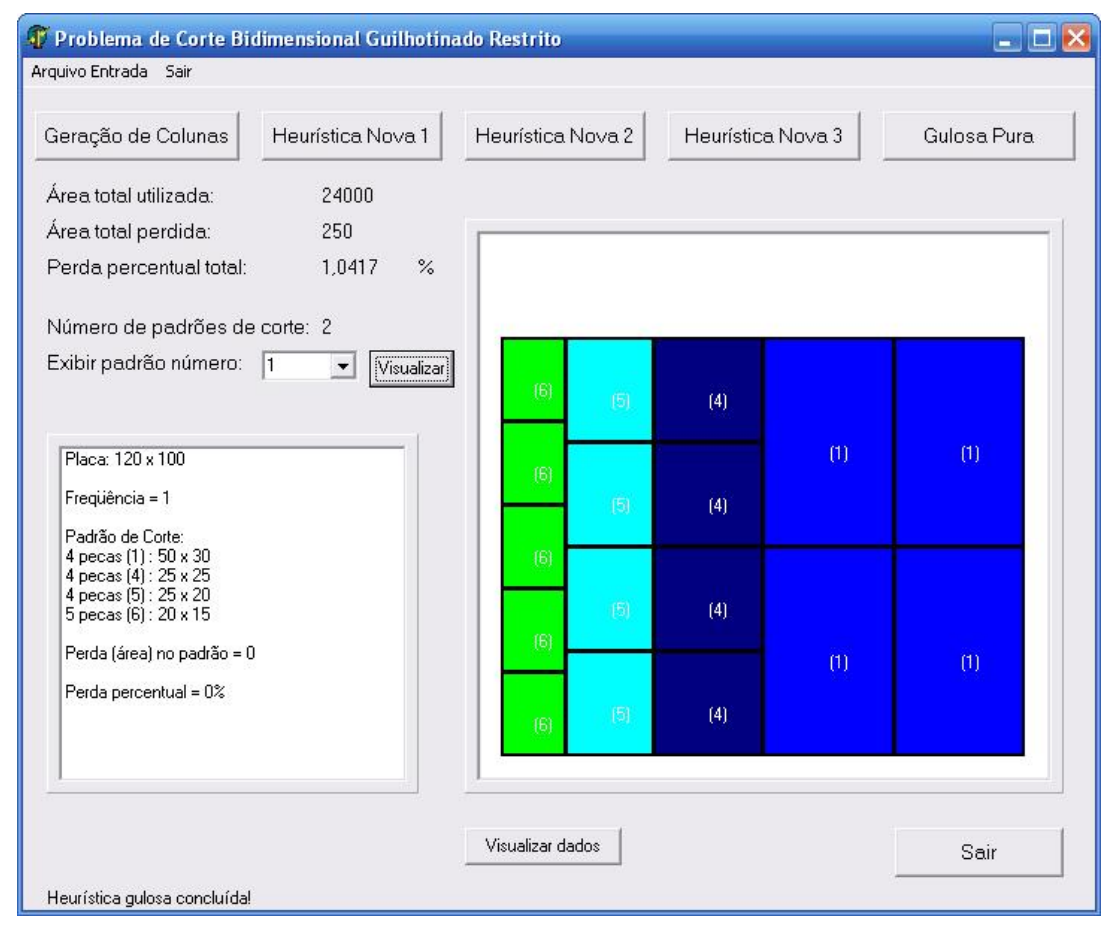

Figura B.1: Tela do programa em Delphi com um exemplo de padrão de corte bidimensional. 


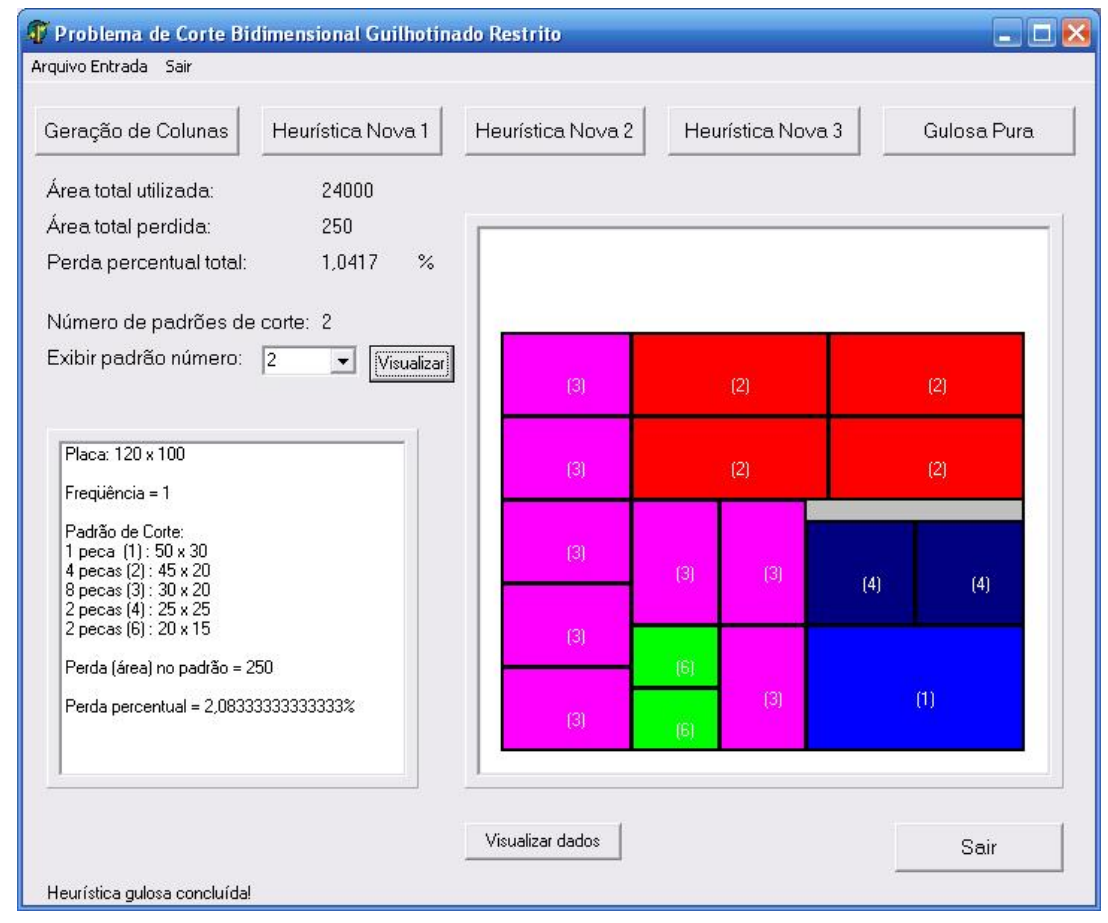

Figura B.2: Tela do programa em Delphi com outro exemplo de padrão de corte bidimensional.

As Figuras B.1 e B.2 mostram a interface da implementação em Delphi, com o desenho de dois padrões de corte bidimensional.

Este tudo pode ser visto com mais detalhes em Poldi et. al. [52]. 


\section{Referências Bibliográficas}

[1] AREnAleS, M. N., ARMEntAnO, V., MORABITO, R., YANASSE, H. H., (2007) "Pesquisa Pperacional". Elsevier, Rio de Janeiro.

[2] BAHL, H. C., RITZMAN, L. P., GUPTA, J. N. D., (1987) “Determining lot sizes and resource requirementes: a review". Operations Research 35(3): 329-345.

[3] BELOV, G., SCHEITHAUER, G., (2002) "A cutting plane algorithm for the onedimensional cutting stock problem with multiple stock lengths". European Journal of Operational Research, 141(2): 274-294.

[4] BILlingtON, P. J., McCLAIN J. O., THOMAS L. J., (1983) "Mathematical programming approaches to capacity MRP systems: review, formulation and problem reduction". Management Science 29(10): 1126-1141.

[5] CHVATAL, V., (1983) "Linear Programming”. W. H. Freeman, New York.

[6] CORREIA, M. H., OliveIRA, J. F., FERREIRA, J. S., (2004) "Reel and sheet cutting at a paper mill'. Computers \& Operations Research, 31(8): 1223-1243.

[7] DIEGEL, A., CHETTY, M., SCHALKWYK, S. e NAIDOO, S., (1994) "Setup combining in the trim loss problem". Working paper. University of Natal, Durban.

[8] DOWSLAND, K., DOWSLAND, W., (1992) "Packing problems". European Journal of Operational Research 56(1): 2-14.

[9] DREXL, A., KIMMS, A., (1997) "Lot sizing and scheduling - survey and extensions". European Journal of Operational Research, 99(2): 221-235.

[10] DYCKHOFF, H., KRUSE, H. J., ABEL, D., GAL, T., (1985) "Trim loss and related problems". Omega: The International Journal of Management Science, 13(1): 59-72.

[11] EVANS, J. R., (1985) "An efficient implementation of the Wagner-Whitin algorithm for dynamic lot sizing. Journal of Operations Management 5(2): 229-235.

[12] FARLEY, A. A., (1988) "Mathematical programming models for cutting stock problems in the clothing industry". The Journal of the Operational Research Society, 39(1): 41-53. 
[13] FOERSTER, H., WÄSCHER, G., (2000) "Pattern reduction in one-dimensional cutting stock problems". International Journal of Production Research, 38: 1657-1676.

[14] GAU, T., WÄSCHER, G., (1995) "CUTGEN1: A problem generator for the standard one-dimensional cutting stock problem". European Journal of Operational Research, 84(3): 572-579.

[15] GILMORE, P. C., GOMORY, R. E., (1961) "A linear programming approach to the cutting stock problem". Operations Research, 9: 848-859.

[16] GILMORE, P. C., GOMORY, R. E., (1963) "A linear programming approach to the cutting stock problem - Part II'. Operations Research, 11: 863-888.

[17] GILMORE, P. C., GOMORY, R. E., (1965) "Multi-stage cutting stock problems of two and more dimensions". Operations Research, 13: 94-120.

[18] GRAMANI, M. C. N., (2001) "Otimização do processo de cortagem acoplado ao planejamento da produção". Tese de Doutorado, FEEC - UNICAMP.

[19] GRAMANI, M. C. N., FRANÇA, P., (2006) "The combined cutting stock and lotsizing problem in industrial processes". European Journal of Operational Research, 174(1): 509-521.

[20] HENDRY, L. C., FOK, K. K., SHEK, K. W. (1996) "A cutting stock and scheduling problem in the copper industry". The Journal of the Operational Research Society, 47(1): $38-47$.

[21] HERZ, J., (1972) "Recursive computational procedure for two-dimensional stock cutting”. IBM Journal on Research Development, 16: 462-469.

[22] HAESSLER, R. W., (1975) "Controlling cutting pattern changes in one-dimensional trim loss problems". Operations Research, 23(3): 483-493.

[23] HAESSLER, R. W., (1979) "Solving the two-stage cutting stock problem". Omega: The International Journal of Management Science 7(2): 145-151.

[24] HAESSLER, R. W., (1980) "A note on computational modifications to the GilmoreGomory cutting stock algorithm". Operations Research, 28(4): 1001-1005.

[25] HIFI, M., ZISSIMOPOULOS, V., (1996) “A recursive exact algorithm for weighted two-dimensional cutting”. European Journal of Operational Research, 91: 553-564.

[26] HINXMAN, A. I., (1980) "The trim-loss and assortment problems: a survey". European Journal of Operational Research, 5(1): 8-18.

[27] HOLTHAUS, O. (2002) "Decomposition approaches for solving the integer onedimensional cutting stock problem with different types of standard lengths". European Journal of Operational Research, 141(2): 295-312. 
[28] HOTO, R. S. V., (2001) "O problema da mochila compartimentada aplicado no corte de bobinas de aço". Tese de Doutorado, COPPE - UFRJ.

[29] HOtO R., ARENAles, M., MACUlAn, N., (2006) "The one dimensional compartmentalised knapsack problem: a case study". European Journal of Operational Research, doi:10.1016/j.ejor.2005.07.030.

[30] JOHNSON, L. A., MONTGOMERY, D.C, (1974) "Operations research in production planning, scheduling and inventory control'. New York, John Wiley \& Sons.

[31] LASDON, L., (1970) "Optimization theory for large systems". The Macmillan Company, New York.

[32] LODI, A., MARTELlO, S., MONACI, M., (2002) "Two-dimensional packing problems: a survey". European Journal of Operational Research 141(2): 241-252.

[33] LEFRANÇOIS, P., GASCON, A., (1995) "Solving a one-dimensional cutting stock problem in a small manufacturing firm: a case study". IIE Transactions, 27.

[34] MAES, J., McCLAIN, J. O., VAN WASSENHOVE, L. N., (1991) "Multilevel capacited lotsizing complexity and LP-based heuristics". European Journal of Operational Research 53(2): 131-148.

[35] MARQUES, F. P., (2000) "O problema da mochila compartimentada". Dissertação de Mestrado, ICMC - USP.

[36] MARQUES, F.P., ARENALES, M. N., (2007) "The constrained compartmentalised knapsack problem". Computers \& Operations Research, 34(7):2109-2129.

[37] MENON S., SCHRAGE, L., (2002) "Order allocation for stock cutting in the paper industry". Operations Research 50(2): 324-332.

[38] MORABITO, R., (1989) “Corte de estoque bidimensional'. Dissertação de Mestrado, ICMC - USP.

[39] MORABITO, R., (1992) "Uma abordagem em grafo-e-ou para o problema de empacotamento: aplicação ao carregamento de paletes e contêineres". Tese de Doutorado, EESC - USP.

[40] MORABITO, R., ARENAlES, M. N., ARCARO, V. F., (1992) "An and/or-graph approach for two-dimensional cutting problems". European Journal of Operational Research, 58(2): 263-271.

[41] MORABITO, R., ARENALES, M. N., (1992) "Um exame dos problemas de corte $e$ empacotamento". Pesquisa Operacional, 12(1): 1-20. 
[42] MORABITO, R., ARENALES, M. N., (1995) "Performance of two heuristics for solving large scale two-dimensional guillotine cutting problems". INFOR - Canadian Journal of Operational Research and Information Processing, 33: 145-155.

[43] MORABITO, R., ARENAlES, M. N., (1996) "Staged and constrained twodimensional guillotine cutting problems: an AND/OR-graph approach". European Journal of Operational Research, 94(3): 548-560.

[44] MORABITO, R., GARCIA, V., (1998) "The cutting stock problem in a hardboard industry: a case study". Computers \& Operations Research, 25(6): 469-485.

[45] NONAS, S. L., THORSTENSON, A., (2000) "A combined cutting-stock and lot-sizing problem". European Journal of Operational Research, 120(2): 327-342.

[46] OLIVEIRA, J., FERREIRA, J., (1990) “An improved version of Wang's algorithm for two dimensional cutting problems". European Journal of Operational Research, 44: $256-266$.

[47] PILEGGI, G. C. F., (2002) "Abordagens para otimização integrada dos problemas de geração e sequenciamento de padrões de corte". Tese de Doutorado, ICMC - USP.

[48] PINTO, M. J., (1999) "O problema de corte de estoque inteiro". Dissertação de Mestrado, ICMC - USP.

[49] POLDI, K. C., (2003) "Algumas extensões do problema de corte de estoque". Dissertação de Mestrado, ICMC - USP.

[50] POLDI, K. C., ARENALES, M. N., (2005) "Dealing with small demand in integer cutting stock problems with limited different stock lengths". Notas de Computação no 85 - ICMC - USP.

[51] POLDI, K. C., ARENALES, M. N., (2006) "Heuristicas para o problema de corte de estoque unidimensional inteiro". Pesquisa Operacional, 26(3): 473-492.

[52] Poldi, K. C., Arenales, M. N., Vianna, A. C. G., 2005. Two-dimensional cutting stock problem under low demand: a case study. Operations Research Proceedings 2005 Selected papers of the German Operations Research Society (GOR) 291-296.

[53] POLTRONIERE, S. C., (2006) "Otimização do processo de corte integrado à produção de bobinas - modelo e métodos de solução". Tese de Doutorado, ICMC - USP.

[54] POltroniere, S. C., AREnAles, M. N., TOledo, F. M. B., POldi, K. C., (2005) "Coupling cutting stock problem and lot sizing problems in the paper industry". Notas de Computação no 83 - ICMC - USP.

[55] RESPÍCIO, A., CAPTIVO, M. E., (2002) "Integrating the cutting stock problem in capacity planning". Department of Informatics and Centre of Operational Research. University of Lisbon/Portugal (2002). 
[56] RIEHME, J., SCHEITHAUER, G., TERNO, J., (1996) "The solution of two-stage guillotine cutting stock problems having extremely varying order demands". European Journal of Operational Research, 91(3): 543-552.

[57] SCHEITHAUER, G., TERNO, J., (1995a) "A branch and bound algorithm for solving one-dimensional cutting stock problems exactly'. Applicatione Mathematikae, 23(2): 151-167.

[58] SCHEITHAUER, G., TERNO, J., (1995b) "The modified integer round-up property of the one-dimensional cutting stock problem". European Journal of Operational Research, 84(3): 562-571.

[59] STADTLER, H., (1990) "A one-dimensional cutting stock problem in the aluminium industry and its solution". European Journal of Operational Research, 44(2): 209-223.

[60] TOLEDO F. M. B., (1998) “Dimensionamento de lotes em máquinas paralelas". Tese de Doutorado. DENSIS-UNICAMP .

[61] TRIGIEIRO W. W., THOMAS L. G. McCLAIN J. O., (1989) "Capacited lot sizing with setup times". Management Science 35(3): 353-366.

[62] VIANNA, A. C. G., (2000) "Problemas de corte e empacotamento: uma abordagem em grafo E/OU'. Tese de Doutorado, ICMC - USP.

[63] WAGNER, H. M., WHITIN, T. M., (1958) "Dynamic version of the economic lot size model'. Management Science 5(1): 89-96.

[64] WANG, P. Y., (1983) "Two algorithms for constrained two-dimensional cutting stock problem". Operations Research, 31(3):573-586.

[65] WÄSCHER, G., GAU, T., (1996) "Heuristics for the integer one-dimensional cutting stock problem: a computational study”. OR Spektrum, 18: 131-144.

[66] WÄSCHER, G., HAUßNER, H., SCHUMANN, H., (2006) "An improved typology of cutting and packing problems". European Journal of Operational Research, doi:10.1016/j.ejor.2005.12.1047.

[67] YANASSE, H. H., SOMA, N. Y., (1987) "A new enumeration scheme for the knapsack problem". Discrete Applied Mathematics, 18: 235-245.

[68] ZAK, E. J., (2002) "Row and column generation technique for a multistage cutting stock problem". Computers \& Operations Research, 29:1143-1156. 